Aus der Klinik für Pädiatrische Kardiologie und Intensivmedizin

(Prof. Dr. med. T. Paul)

der Medizinischen Fakultät der Universität Göttingen

\title{
Gewebereaktionen auf nicht-metallische kardiovaskuläre Implantatmaterialien zum Einsatz bei der Therapie angeborener Herzfehler
}

\author{
INAUGURAL-DISSERTATION \\ zur Erlangung des Doktorgrades \\ der Medizinischen Fakultät der \\ Georg-August-Universität zu Göttingen
}

vorgelegt von

Stephanie Carola Hüll

aus

Sigmaringen

Göttingen 2016 
Dekan:

I. Berichterstatter/in: Prof. Dr. M. Sigler

II. Berichterstatter/in: PD Dr. J. Männer

III. Berichterstatter/in: Prof Dr. T. Meyer 


\section{Inhaltsverzeichnis}

$1 \quad$ Einleitung...........................................................................................................................5

1.1 Kardiovaskuläre Implantate zum Einsatz bei Patienten mit angeborenem

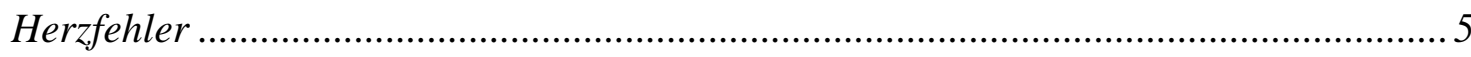

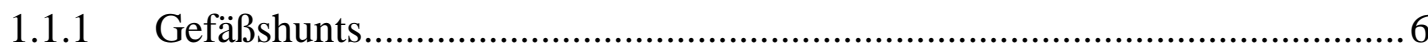

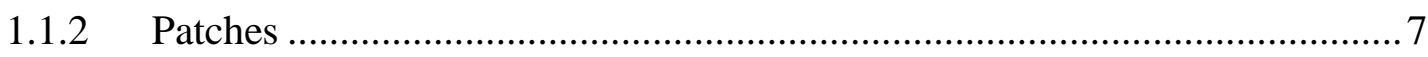

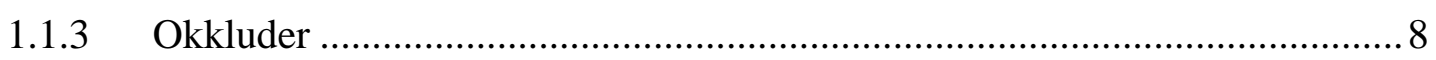

1.2 Biomaterialien in der interventionellen und chirurgischen kardiovaskulären

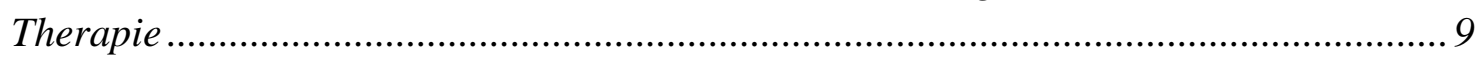

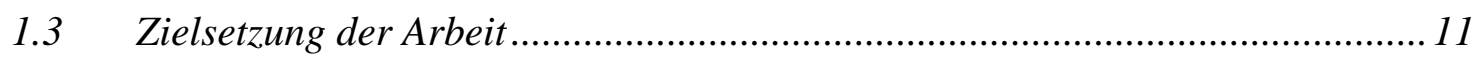

2 Material und Methoden........................................................................................ 12

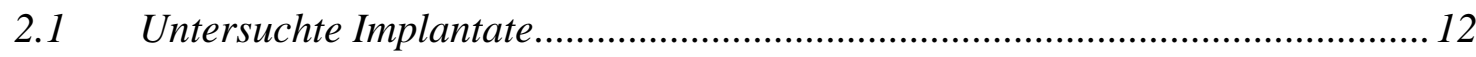

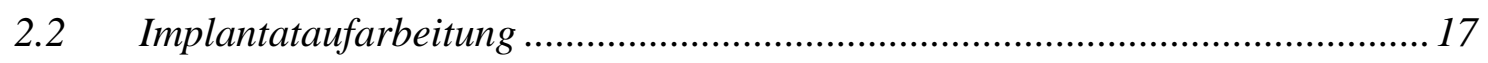

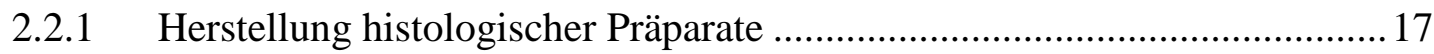

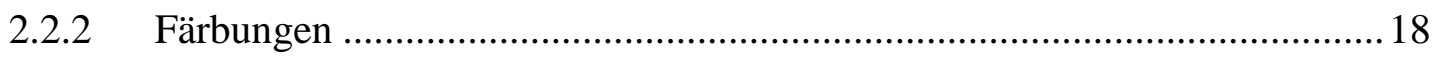

2.3 Technische Ausrüstung zur Auswertung der Präparate .................................. 23

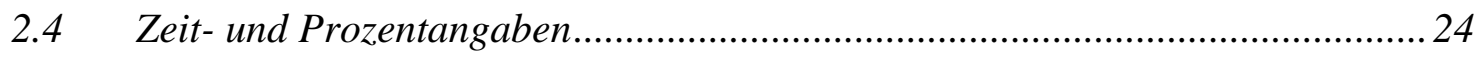

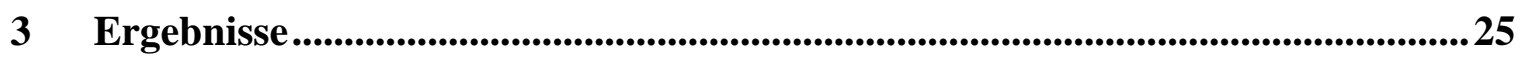

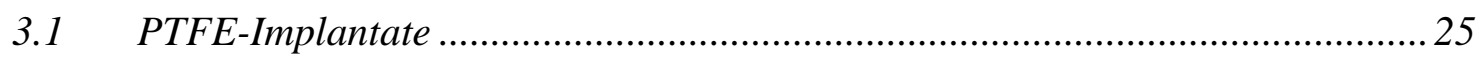

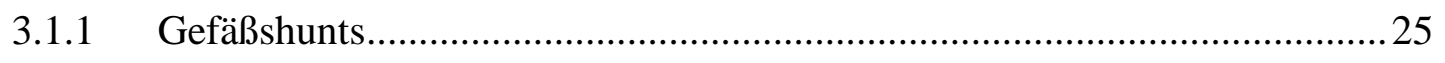

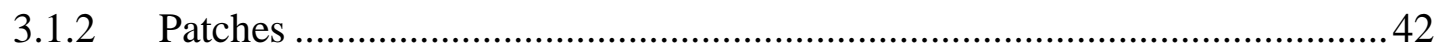

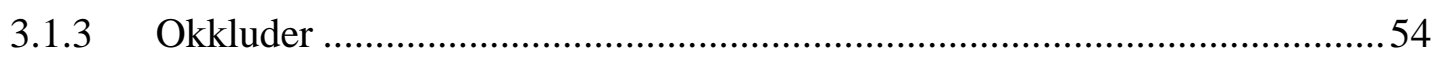

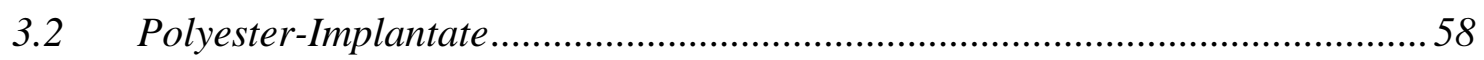

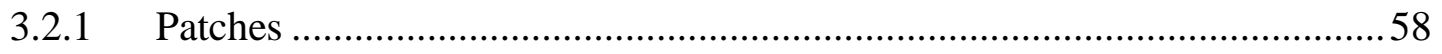

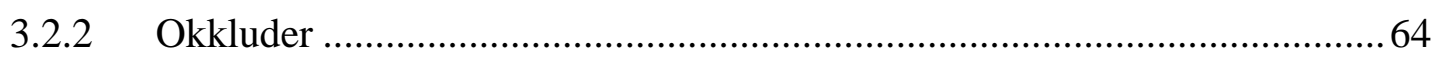

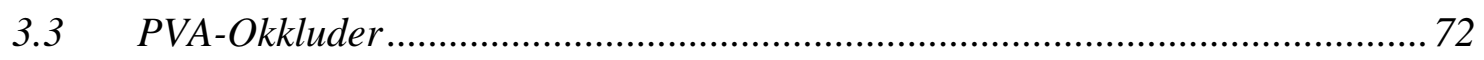

3.4 Übersicht: Verkalkung der verschiedenen Implantatmaterialien in Abhängigkeit

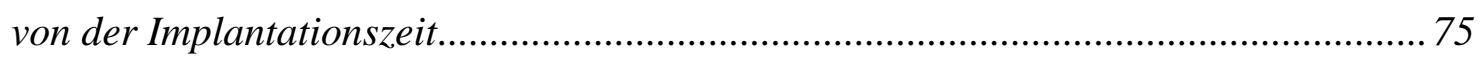

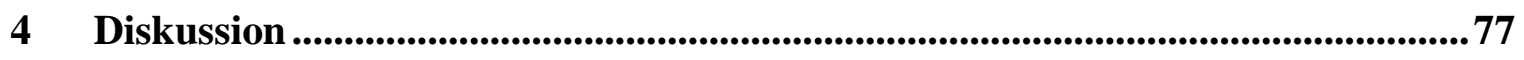

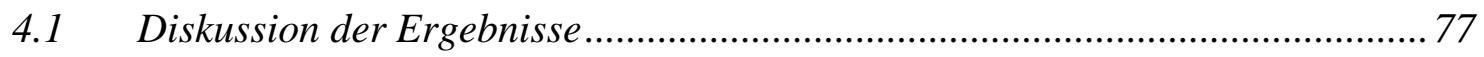

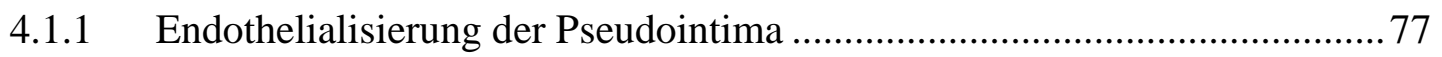

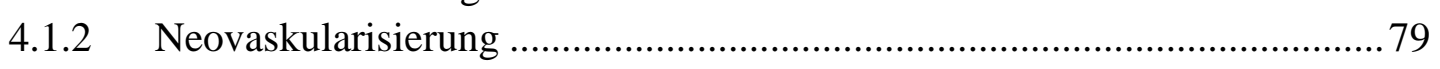

4.1.3 Zellen und EZM des Pseudointima- und Implantatgewebes ...................... 81 


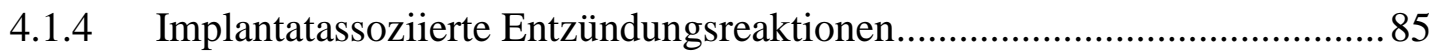

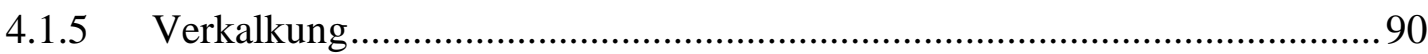

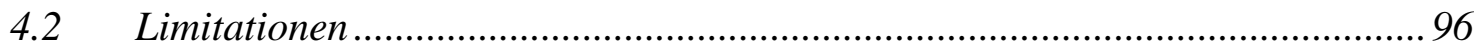

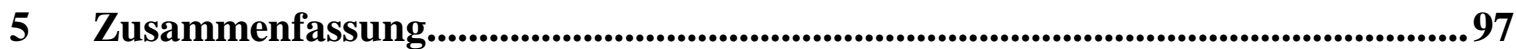

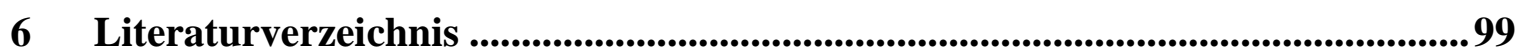

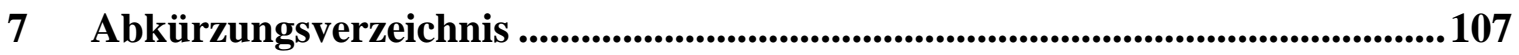




\section{$1 \quad$ Einleitung}

Die folgende Arbeit beschäftigt sich mit biologischen Gewebereaktionen auf nichtmetallische kardiovaskuläre Implantatmaterialien zum Einsatz bei der Therapie angeborener Herzfehler. Hierzu wurden im Rahmen von Korrekturoperationen entnommene kardiovaskuläre Implantate histologisch untersucht, um Aussagen bezüglich der Biokompatibilität verschiedener, nicht-metallischer Implantatmaterialien treffen zu können.

Biokompatibilität beschreibt „die Verträglichkeit zwischen einem technischen und biologischen System“ (Wintermantel et al. 2008, S. 59), also eine „Anpassung der chemischen, physikalischen, biologischen und morphologischen Oberflächeneigenschaften des Implantates an das Empfängergewebe“ (Wintermantel et al. 2008, S. 60).

\subsection{Kardiovaskuläre Implantate zum Einsatz bei Patienten mit angeborenem Herzfehler}

Die Häufigkeit angeborener Herzfehler liegt bei 10 bis 12 pro 1000 Lebendgeborenen und zählt somit zu den häufigsten Organfehlbildungen (Limbach et al. 2012). In ca. 80 bis $90 \%$ der Fälle liegt eine multifaktorielle Genese zugrunde. $10 \%$ der Fälle sind chromosomalen Aberrationen und ca. $5 \%$ monogenen Erbstörungen sowie seltenen teratogenen Faktoren wie Alkoholgenuss während der Schwangerschaft oder einem Diabetes mellitus der Mutter geschuldet (Kececioglu 2009). Die vulnerable Phase für den Einfluss teratogener Substanzen auf die Herzentwicklung liegt zwischen der 3. und 8. Schwangerschaftswoche (Limbach et al. 2012). Die relative Häufigkeitsverteilung angeborener Herzfehler ist der Tabelle 1.1 zu entnehmen. 


\begin{tabular}{|c|c|c|c|}
\hline Herzfehler & $\mathbf{\%}$ & Herzfehler & \% \\
\hline Ventrikelseptumdefekt & 28 & Aortenisthmusstenose & 6 \\
\hline Atriumseptumdefekt & 11 & Transposition der großen Arterien & 5 \\
\hline Pulmonalstenose & 9 & atrioventrikulärer Septumdefekt & 4 \\
\hline persistierender Ductus arteriosus Botalli & 9 & Trikuspidalatresie & 3 \\
\hline Fallot'sche Tetralogie & 8 & Double inlet ventricle & 2 \\
\hline Aortenstenose & 7 & hypoplastisches Linksherzsyndrom & 2 \\
\hline andere & 6 & & \\
\hline
\end{tabular}

Tabelle 1.1: Häufigkeitsverteilung angeborener Herzfehler; aus Kececioglu (2009), S. 515

Bei einigen Herzfehlern kommen kardiovaskuläre Implantate als interventionelle oder chirurgische Therapieoption infrage. Es folgt ein Überblick über kardiovaskuläre Implantate, die im Rahmen dieser Arbeit untersucht wurden.

\subsubsection{Gefäßshunts}

Shunts, also Gefäßprothesen, kommen beispielsweise bei zyanotischen Herzfehlern wie der Fallot'schen Tetralogie (ToF), der Trikuspidalatresie (TA) und der Pulmonalatresie mit Ventrikelseptumdefekt (PA mit VSD) sowie beim hypoplastischen Linksherzsyndrom (HLHS) und dem Double Inlet/Outlet Ventricle im Rahmen der chirurgischen Therapie zum Einsatz. Als systemikopulmonale Shunts in Form von modifizierten BlalockTaussig-Anastomosen (BTA) oder aortopulmonalen (AP) Shunts sollen sie bei diesen Herzfehlern die Lungendurchblutung gewährleisten (Edmunds et al. 1980; Kay et al. 1983). Bei der modifizierten BTA handelt es sich um eine Shuntverbindung zwischen Arteria pulmonalis und Arteria subclavia (Doble et al. 2008). Ein AP-Shunt stellt eine direkte Verbindung zwischen Aorta und Arteria pulmonalis dar (Reddy et al. 1995). Beim HLHS kommt des Weiteren eine Gefäßprothese in Form eines Sano-Shunts als Verbindung zwischen rechtem Ventrikel (RV) und Pulmonalarterie infrage (Sano et al. 2003).

Heutzutage werden meistens Shunts aus Polytetrafluorethylen (PTFE; z. B. von W. L. Gore \& Associates, Newark, Delaware, USA) eingesetzt (Kalra et al. 2010; Starr 2010), die auch im Rahmen dieser Arbeit untersucht wurden. 


\subsubsection{Patches}

Ein Patch kommt zumeist bei einer Abflussbehinderung aus dem RV - wie bei der ToF, der Pulmonalstenose (PS), dem double outlet right ventricle (DORV), der PA mit intaktem Ventrikelseptum (IVS) oder VSD - oder aus dem linken Ventrikel (LV) - wie bei der Aortenstenose (AS) - zum Einsatz Die Engstelle wird im Rahmen der chirurgischen Therapie erweitert und der Defekt mit einem Patch gedeckt. Außerdem wurde früher im Rahmen der Mustard-OP bei der Transposition der großen Arterien (TGA) ein Patch auf Vorhofebene eingebracht, der den Blutfluss auf Vorhofebene umleitete.

Patches können aus körpereigenem (z. B. autologes Perikard) oder Fremdgewebe (z. B. bovines Perikard, PTFE, Polyester) (Izutani 2000; Miyazaki et al. 2011; Oda et al. 2012; Wainwright et al. 2012) bestehen. Die genannten Patch-Materialien werden heutzutage am häufigsten eingesetzt (Pok und Jacot 2011; Witt et al. 2013).

Patches aus PTFE (z. B. von W. L. Gore \& Associates oder C. R. Bard, Murray Hill, New Jersey, USA) und Polyester (z. B. von Meadox Medicals, Oakland, New Jersey, USA) wurden im Rahmen dieser Arbeit untersucht. 


\subsubsection{Okkluder}

Okkluder, also Schirmchen, werden zum interventionellen Verschluss von Atriumseptumdefekten (ASD) und persistierenden Foramina ovalia (PFO) verwandt (Ewert 2008). Folgende heutzutage eingesetzte Okkluder (mit Ausnahme der Produkte des Unternehmens NMT Medical, welches 2011 die Produktion einstellte) wurden im Rahmen dieser Arbeit untersucht:

\begin{tabular}{|c|c|c|c|}
\hline Produktbezeichnung & Material & Hersteller & Indikation \\
\hline Helex Septal Occluder & $\begin{array}{c}\text { PTFE, } \\
\text { Nickel-Titan- } \\
\text { Legierung }\end{array}$ & $\begin{array}{c}\text { W. L. Gore \& Associates, Newark, } \\
\text { Delaware, USA }\end{array}$ & $\begin{array}{l}\text { ASD, } \\
\text { PFO }\end{array}$ \\
\hline Amplatzer Septal Occluder & $\begin{array}{l}\text { Polyester, } \\
\text { Nickel-Titan- } \\
\text { Legierung }\end{array}$ & $\begin{array}{c}\text { St. Jude Medical, Maple Grove, } \\
\text { Minnesota, USA }\end{array}$ & $\begin{array}{l}\text { ASD, } \\
\text { PFO }\end{array}$ \\
\hline $\begin{array}{c}\text { CardioSEAL Septal Occlusion } \\
\text { System }\end{array}$ & $\begin{array}{c}\text { Polyester, } \\
\text { Nickel-Cobalt- } \\
\text { Legierung }\end{array}$ & \multirow{2}{*}{$\begin{array}{l}\text { NMT Medical, Boston, } \\
\text { Massachusetts, USA }\end{array}$} & $\begin{array}{l}\text { ASD, } \\
\text { PFO }\end{array}$ \\
\hline STARFlex System & $\begin{array}{l}\text { Polyester, } \\
\text { Nickel-Titan- } \\
\text { Legierung }\end{array}$ & & $\begin{array}{l}\text { ASD, } \\
\text { PFO }\end{array}$ \\
\hline Atriasept Occluder & $\begin{array}{c}\text { PVA, } \\
\text { Nickel-Titan- } \\
\text { Legierung }\end{array}$ & \multirow{2}{*}{ Cardia, Eagan, Minnesota, USA } & $\begin{array}{l}\text { ASD, } \\
\text { PFO }\end{array}$ \\
\hline Cardia PFO Occluder & $\begin{array}{c}\text { PVA, } \\
\text { Nickel-Titan- } \\
\text { Legierung }\end{array}$ & & $\mathrm{PFO}$ \\
\hline Premere PFO Occlusion System & $\begin{array}{c}\text { Polyester, } \\
\text { Nickel-Titan- } \\
\text { Legierung }\end{array}$ & $\begin{array}{c}\text { St. Jude Medical, Maple Grove, } \\
\text { Minnesota, USA }\end{array}$ & $\mathrm{PFO}$ \\
\hline
\end{tabular}

Tabelle 1.2: Im Rahmen dieser Arbeit untersuchte Okkludersysteme; (ASD Atriumseptumdefekt, PFO persistierendes Foramen ovale, PTFE Polytetrafluorethylen, PVA Polyvinylalkohol) 


\subsection{Biomaterialien in der interventionellen und chirurgischen kardiovaskulären Therapie}

Der Begriff ,Biomaterial' beschreibt jegliche Art von Fremdmaterial, das vorübergehend oder permanent in den menschlichen Körper implantiert wird (Vander Sloten et al. 1998). Man unterscheidet synthetische Biomaterialien wie Polymere (z. B. PTFE, Polyester, Polyvinylalkohol (PVA)), Metalle, Keramik und Karbon von biologischen Biomaterialien. Letztere unterteilt man in Autografts (körpereigenes Material), Allografts (Fremdmaterial derselben Spezies) und Xenografts (Fremdmaterial einer anderen Spezies) (Black 1995; Hench 1998; Witt et al. 2013).

Vorteile synthetischer Biomaterialien bestehen darin, dass sie „vorhersehbare mechanische Eigenschaften“ (Black 1995, S. 151; Übersetzung der Verfasserin aus dem Englischen; bezieht sich auch auf alle folgenden Zitate) besitzen und dadurch immer verfügbar und reproduzierbar sind (Hench 1998).

Nachteilig ist dagegen, dass synthetische Biomaterialien nur bedingt biokompatibel sind. Beispielsweise kann ein kardiovaskuläres Implantat aus PTFE, welches nicht resorbierbar ist, zu „schwerwiegenden Entzündungsreaktionen wie fibrotischem Umbau, Verkalkung und Mediastinitis“ (Pok und Jacot 2011, S. 651) führen. Außerdem fehlt synthetischen Biomaterialien - im Gegensatz zu biologischen Biomaterialien - die „Fähigkeit zur Selbstreparatur“ (Hench 1998, S. 1420) und Anpassung an den Wirtsorganismus (Hench 1998).

Biologische Implantatmaterialien dagegen sind meist besser biokompatibel (de Mol 1996). Beispielsweise ist nach aktuellen Empfehlungen im Anschluss an einen biologischen Herzklappenersatz in Abhängigkeit der Implantatposition eine orale Antikoagulation bzw. Thrombozytenaggregationshemmung mit Acetylsalicylsäure über 3 Monate ausreichend (Vahanian und Alfieri 2012), bis das Implantat vollständig endothelialisiert ist (Geißler et al. 2009). Dagegen wird nach einem mechanischem Herzklappenersatz eine lebenslange, orale Antikoagulation notwendig (Vahanian und Alfieri 2012). Jedoch sind biologische Implantatmaterialien weniger widerstandsfähig als mechanische und degenerieren schneller (de Mol 1996). Außerdem sind sie im Vergleich zu synthetischen oft nur eingeschränkt verfügbar (Hench 1998). 
Eben erwähnte Einschränkungen führten $\mathrm{zu}$ Weiterentwicklungen auf dem Feld der Biomaterialien, dem tissue engineering. Dennoch ist der Einsatz kardiovaskulärer Implantate aus ,herkömmlichen“ Implantatmaterialien wie PTFE, Polyester oder PVA, die in dieser Arbeit untersucht wurden, unabdingbar: Beispielsweise werden in der Klinik für Thorax-, Herz- und Gefäßchirurgie und speziell in der Kinderherzchirurgie der Universitätsmedizin Göttingen kardiovaskuläre Shunts und Patches aus PTFE weiterhin regelhaft eingesetzt. Außerdem finden die in dieser Arbeit untersuchten Implantatmaterialien als Bestandteil von Verbundmaterialien im Rahmen des tissue engineering Anwendung: So untersuchten u. a. Wang et al. die Biokompatibilität eines Verbundmaterials aus PVA, Hydroxyapatit und Gelatine im Rattenmodell (Wang et al. 2008).

Somit leisten die Ergebnisse dieser Arbeit einen Beitrag zur Ausweitung des Verständnisses bezüglich der Biokompatibilität kardiovaskulärer Implantatmaterialien aus PTFE, Polyester und PVA, die trotz Weiterentwicklungen auf dem Feld der Biomaterialien auch in Zukunft zum Einsatz kommen werden. 


\subsection{Zielsetzung der Arbeit}

Im Rahmen der vorliegenden Arbeit wurden nicht-metallische Anteile kardiovaskulärer Implantate nach deren chirurgischer Entfernung untersucht. Diese waren zur Therapie bei Patienten mit angeborenem Herzfehler eingesetzt worden. Biologische Gewebereaktionen auf unterschiedliche Implantatmaterialien wurden im Hinblick auf Endothelialisierung, Entzündungszellreaktion, Verkalkung sowie Neovaskularisierung und Ausbildung von Bindegewebe histologisch untersucht. Besonderes Augenmerk galt sowohl der Art und Intensität von Entzündungsreaktionen als auch dem Vorhandensein und Ausprägungsgrad von Verkalkung neu gebildeten Gewebes am und im Implantat in Abhängigkeit von der Implantationszeit und dem Implantatmaterial.

Es sollten Unterschiede bzw. Gemeinsamkeiten bezüglich der Biokompatibilität verschiedener, nicht-metallischer Implantatmaterialien herausgearbeitet werden. Anhand von Kenntnissen über die Biokompatibilität kann eine gezielte Auswahl des Materials kardiovaskulärer Implantate zur Therapie angeborener Herzfehler, die bei 10 bis 12 pro 1000 Lebendgeborenen auftreten (Limbach et al. 2012), zu besseren Langzeitergebnissen und somit zu einer verbesserten und nachhaltigeren Therapie der Herzfehler beitragen. 


\section{Material und Methoden}

\subsection{Untersuchte Implantate}

Die untersuchten kardiovaskulären Implantate wurden im Forschungslabor der Abteilung für Pädiatrische Kardiologie und Intensivmendizin der Universitätsmedizin Göttingen nach einem standardisierten Protokoll (Sigler et al. 2005) aufgearbeitet und anschließend histologisch untersucht.

Insgesamt wurden 52 Implantate ausgewertet, die im Rahmen von Korrekturoperationen in verschiedenen Kliniken (Deutschland: Ludwig-Maximilians-Universität München, Deutsches Herzzentrum (DHZ) München, Universitätsmedizin Göttingen, Universitätsklinikum Aachen, Herz- und Diabeteszentrum Nordrhein-Westfalen (Bad Oeynhausen), DHZ Berlin, Sana Herzchirurgie Stuttgart, Universitätsklinkum Gießen, Universitätsklinikum Heidelberg; England: John Radcliffe Hospital, Oxford) entfernt und zur Analyse eingeschickt wurden. Es wurden 3 unterschiedliche Implantatgruppen untersucht: Shunts aus dem Material PTFE $(n=21$, durchschnittliche Implantationszeit: 18 Monate), Patches $(\mathrm{n}=17)$ aus den Materialien PTFE $(\mathrm{n}=13$, durchschnittliche Implantationszeit: 247 Monate) und Polyester $(n=4$, durchschnittliche Implantationszeit: 321 Monate) sowie Okkluder $(\mathrm{n}=14)$ aus den Materialien PTFE $(\mathrm{n}=3$, durchschnittliche Implantationszeit: 74 Monate), Polyester $(n=9$, durchschnittliche Implantationszeit: 30 Monate) und PVA ( $\mathrm{n}=2$, durchschnittliche Implantationszeit: 23 Monate). Die Shunts waren zwischen 1999 und 2011 zumeist als modifizierte BTA, in 3 Fällen als AP-Shunt und in einem Fall als Sano-Shunt implantiert und zwischen 2004 und 2012 explantiert worden. Das minimale Patientenalter bei Implantation lag bei 2 Tagen, das maximale bei 19 Jahren und 4 Monaten. Die Patches wurden zwischen 1977 und 1998 implantiert und zwischen 2006 und 2012 explantiert bei einem minimalen Patientenalter bei Implantation von 67 Tagen und einem maximalen von 41 Jahren und 6 Monaten. Die Patches waren meistens im RVOT implantiert sowie in einem Fall auf Aortenklappenniveau und in einem weiteren Fall als Baffle im Rahmen einer Mustard/Baffle-Operation zur Vorhofumkehr eingebracht worden. Die Okkluder waren zwischen 2001 und 2011 implantiert und zwischen 2004 und 2012 explantiert worden. Die Patienten waren hierbei zwischen 1 Jahr und 1 Monat und 65 Jahren und 2 Monaten alt. Die Okkluder waren 
hauptsächlich im interatrialen Septum (IAS) bei ASD oder PFO sowie in einem Fall zum Verschluss einer Waterston-Cooley-Anastomose implantiert worden. In Tabelle 2.1 findet sich eine Zusammenschau der ausgewerteten Präparate.

\begin{tabular}{|c|c|c|c|c|c|}
\hline$\#$ & Material & IZ & $\begin{array}{c}\text { Diagnose(n); } \\
\text { Intervention(en) }\end{array}$ & $\begin{array}{l}\text { Explantations- } \\
\text { grund }\end{array}$ & $\begin{array}{l}\text { Implantat- } \\
\text { bezeichnung; } \\
\text { Entnahme- } \\
\text { lokalisation }\end{array}$ \\
\hline \multicolumn{6}{|c|}{ Shunts } \\
\hline 1 & PTFE & $\begin{array}{l}11 \\
\mathrm{M}\end{array}$ & $\begin{array}{c}\text { funktionelle PA bei hochgradiger PS, } \\
\text { RV- und TV-Hypoplasie; } \\
\text { Z. n. modifizierter BTA }\end{array}$ & TCPA-Komplettierung & modifizierte BTA \\
\hline 2 & PTFE & $4 \mathrm{M}$ & $\begin{array}{l}\text { DILV, ISTA, TGA, restriktives } \\
\text { Foramen bulboventriculare; } \\
\text { Z. n. ISTA-Korrektur, DKS-OP, } \\
\text { modifizierter BTA }\end{array}$ & $\begin{array}{l}\text { Glenn-Anastomosen- } \\
\text { Anlage }\end{array}$ & modifizierte BTA \\
\hline 3 & PTFE & $8 \mathrm{M}$ & $\begin{array}{c}\text { DILV, PA mit VSD; } \\
\text { Z. n. Glenn-Anastomose und AP-Shunt }\end{array}$ & TCPA-Komplettierung & AP-Shunt \\
\hline 4 & PTFE & $\begin{array}{c}5 \mathrm{a} \\
9 \mathrm{M}\end{array}$ & $\begin{array}{l}\text { PA mit VSD, MAPCAs, VSD; } \\
\text { Z. n. BTA, BTA-Verschluss mit } \\
\text { operativer Ausschälung }\end{array}$ & AP-Shunt-Anlage & modifizierte BTA \\
\hline 5 & PTFE & $\begin{array}{c}9 \mathrm{a} \\
5 \mathrm{M}\end{array}$ & $\begin{array}{c}\text { TOF, MAPCAs; } \\
\text { Z. n. modifizierter BTA }\end{array}$ & $\begin{array}{l}\text { Shuntobstruktion mit } \\
\text { multiplen Stenosen und } \\
\text { Verkalkung }\end{array}$ & modifizierte BTA \\
\hline 6 & PTFE & $\begin{array}{c}1 \mathrm{a} \\
1 \mathrm{M}\end{array}$ & $\begin{array}{c}\text { PS, Straddling TV, TGA, VSD; } \\
\text { Z. n. modifizierter BTA }\end{array}$ & $\begin{array}{l}\text { Glenn-Anastomosen- } \\
\text { Anlage }\end{array}$ & modifizierte BTA \\
\hline 7 & PTFE & $9 \mathrm{M}$ & $\begin{array}{l}\text { DORV, ISTA, hypoelastischer } \\
\text { Aortenbogen; } \\
\text { Z. n. ISTA-Resektion, DKS, } \\
\text { modifizierter BTA } \\
\end{array}$ & $\begin{array}{l}\text { Glenn-Anastomosen- } \\
\text { Anlage }\end{array}$ & modifizierte BTA \\
\hline 8 & PTFE & $\begin{array}{c}1 \mathrm{a} \\
2 \mathrm{M}\end{array}$ & $\begin{array}{l}\text { HLHS; } \\
\text { Z. n. Norwood II-OP mit Sano-Shunt, } \\
\text { Aortenbogenrekonstruktion, Glenn- } \\
\text { Anastomose }\end{array}$ & $\begin{array}{l}\text { Stenose Pulmonalarterie } \\
\text { links zwischen Glenn- } \\
\text { Anastomose und Sano- } \\
\text { Shunt }\end{array}$ & Sano-Shunt \\
\hline 9 & PTFE & $\begin{array}{c}1 \mathrm{a} \\
1 \mathrm{M}\end{array}$ & $\begin{array}{c}\text { PA mit VSD, ASD II; } \\
\text { Z. n. Unifokalisation mit } \\
\text { Kollateralenimplantation, AP-Shunt }\end{array}$ & $\begin{array}{l}\text { Korrektur-OP mit RVOT- } \\
\text { Rekonstruktion }\end{array}$ & AP-Shunt \\
\hline 10 & PTFE & $3 \mathrm{M}$ & $\begin{array}{l}\text { RV-Hypoplasie, Malposition der großen } \\
\text { Arterien, PA mit VSD; } \\
\text { Z. n. PAB, PDA-Verschluss, } \\
\text { Atrioseptektomie, DKS-OP mit } \\
\text { modifizierter BTA } \\
\end{array}$ & $\begin{array}{l}\text { Glenn-Anastomosen- } \\
\text { Anlage }\end{array}$ & modifizierte BTA \\
\hline 11 & PTFE & $5 \mathrm{M}$ & $\begin{array}{l}\text { TGA, VSD, ASD II; } \\
\text { Z. n. Atrioseptostomie, PAB, } \\
\text { modifizierter BTA }\end{array}$ & $\begin{array}{l}\text { Switch-OP, De-Banding, } \\
\text { ASD-, VSD-Verschluss }\end{array}$ & modifizierte BTA \\
\hline 12 & PTFE & $8 \mathrm{M}$ & $\begin{array}{c}\text { TA; } \\
\text { Z. n. modifizierter BTA }\end{array}$ & $\begin{array}{l}\text { Glenn-Anastomosen- } \\
\text { Anlage }\end{array}$ & modifizierte BTA \\
\hline 13 & PTFE & $6 \mathrm{~d}$ & $\begin{array}{l}\text { HLHS; } \\
\text { Z. n. Norwood I-OP }\end{array}$ & $\begin{array}{l}\text { Pumpversagen, BTA- } \\
\text { Verkleinerung }\end{array}$ & modifizierte BTA \\
\hline
\end{tabular}




\begin{tabular}{|c|c|c|c|c|c|}
\hline \# & Material & IZ & $\begin{array}{c}\text { Diagnose(n); } \\
\text { Intervention(en) }\end{array}$ & $\begin{array}{l}\text { Explantations- } \\
\text { grund }\end{array}$ & $\begin{array}{l}\text { Implantat- } \\
\text { bezeichnung; } \\
\text { Entnahme- } \\
\text { lokalisation }\end{array}$ \\
\hline 14 & PTFE & $4 \mathrm{M}$ & $\begin{array}{l}\text { TGA, LVOTO, VSD; } \\
\text { Z. n. modifizierter BTA }\end{array}$ & Shuntobstruktion & modifizierte BTA \\
\hline 15 & PTFE & $6 \mathrm{M}$ & $\begin{array}{c}\text { PA mit IVS; } \\
\text { Z. n. modifizierter BTA }\end{array}$ & Shuntobstruktion & modifizierte BTA \\
\hline 16 & PTFE & $2 \mathrm{M}$ & $\begin{array}{c}\text { LV-Hypoplasie; } \\
\text { Z. n. modifizierter BTA }\end{array}$ & Shuntobstruktion & modifizierte BTA \\
\hline 17 & PTFE & $9 \mathrm{M}$ & $\begin{array}{c}\text { DORV, PA; } \\
\text { Z. n. modifizierter BTA }\end{array}$ & elektive Korrektur-OP & modifizierte BTA \\
\hline 18 & PTFE & $3 \mathrm{M}$ & $\begin{array}{l}\text { DORV, LV-Hypoplasie; } \\
\text { Z. n. Norwood I-OP }\end{array}$ & Norwood I-OP & modifizierte BTA \\
\hline 19 & PTFE & $\begin{array}{c}5 \mathrm{a} \\
2 \mathrm{M}\end{array}$ & $\begin{array}{c}\text { TA; } \\
\text { Z. n. modifizierter BTA }\end{array}$ & $\begin{array}{l}\text { Glenn-Anastomosen- } \\
\text { Anlage }\end{array}$ & modifizierte BTA \\
\hline 20 & PTFE & $2 \mathrm{a}$ & $\begin{array}{c}\text { HLHS; } \\
\text { Z. n. modifizierter BTA }\end{array}$ & $\begin{array}{l}\text { Glenn-Anastomosen- } \\
\text { Anlage }\end{array}$ & modifizierte BTA \\
\hline 21 & PTFE & $4 \mathrm{M}$ & $\begin{array}{c}\text { DORV; } \\
\text { Z. n. modifizierter BTA }\end{array}$ & $\begin{array}{l}\text { Glenn-Anastomosen- } \\
\text { Anlage }\end{array}$ & modifizierte BTA \\
\hline 22 & PTFE & $\begin{array}{l}11 \mathrm{a} \\
7 \mathrm{M}\end{array}$ & $\begin{array}{c}\text { TGA, VSD; } \\
\text { Z. n. Mustard-OP }\end{array}$ & $\begin{array}{l}\text { Glenn-Anastomosen- und } \\
\text { modifizierte BTA- Anlage }\end{array}$ & Mustard-Baffle \\
\hline 23 & PTFE & $\begin{array}{c}25 \mathrm{a} \\
11 \\
\mathrm{M}\end{array}$ & $\begin{array}{l}\text { TOF, Atrioventrikularkanaldefekt; } \\
\text { Z. n. TAP-Plastik RVOT }\end{array}$ & RVOT-Rekonstruktion & TAP; RVOT \\
\hline 24 & PTFE & $\begin{array}{l}15 \mathrm{a} \\
8 \mathrm{M}\end{array}$ & $\begin{array}{l}\text { TOF, PV-Insuffizienz; } \\
\text { Z. n. TAP-Plastik RVOT }\end{array}$ & PKE & TAP; RVOT \\
\hline 25 & PTFE & $\begin{array}{l}13 \mathrm{a} \\
8 \mathrm{M}\end{array}$ & $\begin{array}{c}\text { TOF; } \\
\text { Z. n. BTA, TAP-Plastik RVOT }\end{array}$ & PKE & TAP; RVOT \\
\hline 26 & PTFE & $\begin{array}{l}8 \mathrm{a} \\
3 \mathrm{M}\end{array}$ & $\begin{array}{c}\text { PS; } \\
\text { Z. n. TAP-Plastik RVOT }\end{array}$ & PKE & TAP; RVOT \\
\hline 27 & PTFE & $12 \mathrm{a}$ & $\begin{array}{c}\text { TOF; } \\
\text { Z. n. modifizierter BTA, TAP-Plastik } \\
\text { RVOT }\end{array}$ & PKE & TAP; RVOT \\
\hline 28 & PTFE & $\begin{array}{l}20 \mathrm{a} \\
9 \mathrm{M}\end{array}$ & $\begin{array}{c}\text { TOF; } \\
\text { Z. n. TAP-Plastik RVOT }\end{array}$ & PKE & TAP; RVOT \\
\hline 29 & PTFE & $\begin{array}{l}28 \mathrm{a} \\
6 \mathrm{M}\end{array}$ & $\begin{array}{c}\text { TOF; } \\
\text { Z. n. TAP-Plastik RVOT }\end{array}$ & PKE & TAP; RVOT \\
\hline 30 & PTFE & $\begin{array}{l}28 \mathrm{a} \\
1 \mathrm{M}\end{array}$ & $\begin{array}{c}\text { TOF; } \\
\text { Z. n. TAP-Plastik RVOT }\end{array}$ & PKE & TAP; RVOT \\
\hline 31 & PTFE & $\begin{array}{l}30 \mathrm{a} \\
4 \mathrm{M}\end{array}$ & $\begin{array}{c}\text { TOF; } \\
\text { Z. n. TAP-Plastik RVOT }\end{array}$ & PKE & TAP; RVOT \\
\hline 32 & PTFE & $\begin{array}{l}32 \mathrm{a} \\
3 \mathrm{M}\end{array}$ & $\begin{array}{c}\text { TOF; } \\
\text { Z. n. BTA, TAP-Plastik RVOT }\end{array}$ & PKE & TAP; RVOT \\
\hline
\end{tabular}




\begin{tabular}{|c|c|c|c|c|c|}
\hline$\#$ & Material & IZ & $\begin{array}{c}\text { Diagnose(n); } \\
\text { Intervention(en) }\end{array}$ & $\begin{array}{l}\text { Explantations- } \\
\text { grund }\end{array}$ & $\begin{array}{l}\text { Implantat- } \\
\text { bezeichnung; } \\
\text { Entnahme- } \\
\text { lokalisation }\end{array}$ \\
\hline 33 & PTFE & $\begin{array}{l}19 \mathrm{a} \\
4 \mathrm{M}\end{array}$ & $\begin{array}{c}\text { TOF; } \\
\text { Z. n. BTA, TAP-Plastik RVOT }\end{array}$ & PKE & TAP; RVOT \\
\hline 34 & PTFE & $\begin{array}{l}21 \mathrm{a} \\
3 \mathrm{M}\end{array}$ & $\begin{array}{c}\text { TOF; } \\
\text { Z. n. TAP-Plastik RVOT }\end{array}$ & PKE & TAP; RVOT \\
\hline 35 & Polyester & $\begin{array}{l}18 \mathrm{a} \\
1 \mathrm{M}\end{array}$ & $\begin{array}{c}\text { AS, AI, Aneurysma Aorta ascendens; } \\
\text { Z. n. zweimaliger AoV- } \\
\text { Kommisurotomie mit Patch-Plastik, } \\
\text { bakterieller Endokarditis mit } \\
\text { subanulärem AoV-Abszess }\end{array}$ & AKE & Aortenpatch \\
\hline 36 & Polyester & $\begin{array}{l}22 \mathrm{a} \\
5 \mathrm{M}\end{array}$ & $\begin{array}{c}\text { TOF; } \\
\text { Z. n. TAP-Plastik RVOT }\end{array}$ & PKE & TAP; RVOT \\
\hline 37 & Polyester & $\begin{array}{l}31 \mathrm{a} \\
2 \mathrm{M}\end{array}$ & $\begin{array}{l}\text { TGA, TA, rudimentärer RV, VSD, PS; } \\
\text { Z. n. BTA links und rechts, } \\
\text { modifizierter Fontan-OP mit } \\
\text { klappenloser Conduit-Anlage vom RA } \\
\text { zur Pulmonalarterienbifurkation }\end{array}$ & TCPA-Anlage & $\begin{array}{l}\text { klappenloser } \\
\text { Conduit }\end{array}$ \\
\hline 38 & Polyester & $\begin{array}{l}35 \mathrm{a} \\
2 \mathrm{M}\end{array}$ & $\begin{array}{c}\text { TOF; } \\
\text { Z. n. TAP-Plastik RVOT }\end{array}$ & PKE & TAP; RVOT \\
\hline 39 & PTFE & $\begin{array}{l}5 \mathrm{a} \\
10 \\
\mathrm{M}\end{array}$ & ASD II & Restdefekt & $\begin{array}{l}\text { Helex Septal } \\
\text { Occluder; IAS }\end{array}$ \\
\hline 40 & PTFE & $\begin{array}{c}6 \mathrm{a} \\
3 \mathrm{M}\end{array}$ & ASD II & $\begin{array}{l}\text { Okkluderentfernung im } \\
\text { Rahmen eines AKE }\end{array}$ & $\begin{array}{l}\text { Helex Septal } \\
\text { Occluder; IAS }\end{array}$ \\
\hline 41 & PTFE & $\begin{array}{c}6 \mathrm{a} \\
4 \mathrm{M}\end{array}$ & ASD II & Restdefekt, Okkluderbruch & $\begin{array}{l}\text { Helex Septal } \\
\text { Occluder; IAS }\end{array}$ \\
\hline 42 & Polyester & $\begin{array}{c}1 \mathrm{a} \\
8 \mathrm{M}\end{array}$ & ASD II & Restdefekt & $\begin{array}{l}\text { STARFlex System; } \\
\text { IAS }\end{array}$ \\
\hline 43 & Polyester & $\begin{array}{l}3 \mathrm{a} \\
11 \\
\mathrm{M}\end{array}$ & ASD II, Z. n. Apoplex & $\begin{array}{c}\text { Re-Apoplex, V. a. } \\
\text { Thrombusbildung am } \\
\text { Okkluder }\end{array}$ & $\begin{array}{l}\text { STARFlex System; } \\
\text { IAS }\end{array}$ \\
\hline 44 & Polyester & $\begin{array}{c}6 \mathrm{a} \\
9 \mathrm{M}\end{array}$ & PFO, Z. n. Posteriorinfarkt & $\begin{array}{c}\text { Thrombusbildung am } \\
\text { Okkluder }\end{array}$ & $\begin{array}{l}\text { STARFlex System; } \\
\text { IAS }\end{array}$ \\
\hline 45 & Polyester & $\begin{array}{l}2 \mathrm{a} \\
11 \\
\mathrm{M}\end{array}$ & PFO, Z. n. Apoplex, TIA & $\begin{array}{c}\text { Okkluderbruch, } \\
\text { Thrombusbildung am } \\
\text { Okkluder }\end{array}$ & $\begin{array}{c}\text { CardioSEAL Septal } \\
\text { Occlusion System; } \\
\text { IAS }\end{array}$ \\
\hline 46 & Polyester & $\begin{array}{c}2 \mathrm{a} \\
3 \mathrm{M}\end{array}$ & $\begin{array}{c}\text { TOF; } \\
\text { Z. n. Waterston-Cooley-Anastomose, } \\
\text { Korrektur-OP, interventioneller } \\
\text { Verschluss der Waterston-Cooley- } \\
\text { Anastomose }\end{array}$ & PKE & $\begin{array}{c}\text { CardioSEAL Septal } \\
\text { Occlusion System; } \\
\text { Waterston-Cooley- } \\
\text { Anastomose }\end{array}$ \\
\hline 47 & Polyester & $3 \mathrm{M}$ & PFO & Okkluderdislokation & $\begin{array}{c}\text { Premere PFO } \\
\text { Occlusion System; } \\
\text { IAS }\end{array}$ \\
\hline 48 & Polyester & $\begin{array}{c}3 \mathrm{a} \\
4 \mathrm{M}\end{array}$ & $\begin{array}{l}\text { ASD II, Sinus-Venosus-Defekt, } \\
\text { Lungenvenenfehlmündung }\end{array}$ & Korrektur-OP & $\begin{array}{l}\text { Amplatzer Septal } \\
\text { Occluder; IAS }\end{array}$ \\
\hline
\end{tabular}




\begin{tabular}{|c|c|c|c|c|c|}
\hline \# & Material & IZ & $\begin{array}{c}\text { Diagnose(n); } \\
\text { Intervention(en) }\end{array}$ & $\begin{array}{l}\text { Explantations- } \\
\text { grund }\end{array}$ & $\begin{array}{l}\text { Implantat- } \\
\text { bezeichnung; } \\
\text { Entnahme- } \\
\text { lokalisation }\end{array}$ \\
\hline 49 & Polyester & $\begin{array}{c}1 \mathrm{a} \\
3 \mathrm{M}\end{array}$ & $\begin{array}{c}\text { TGA; } \\
\text { Z. n. Vorhofumkehr nach Mustard, } \\
\text { interventionellem Verschluss von } \\
\text { Baffle-Leaks }\end{array}$ & $\begin{array}{c}\text { Baffle-Leaks, operativer } \\
\text { Verschluss }\end{array}$ & $\begin{array}{l}\text { Amplatzer Septal } \\
\text { Occluder im } \\
\text { Mustard-Baffle }\end{array}$ \\
\hline 50 & Polyester & $5 \mathrm{M}$ & ASD II & Okkluderdislokation & $\begin{array}{l}\text { Amplatzer Septal } \\
\text { Occluder; IAS }\end{array}$ \\
\hline 51 & PVA & $\begin{array}{c}3 \mathrm{a} \\
3 \mathrm{M}\end{array}$ & PFO, rezidivierende zerebrale Ischämien & $\begin{array}{l}\text { rezidivierende TIA nach } \\
\text { Implantation, Thrombus } \\
\text { LA }\end{array}$ & $\begin{array}{c}\text { Cardia PFO } \\
\text { Occluder; IAS }\end{array}$ \\
\hline 52 & PVA & $7 \mathrm{M}$ & multiple ASDs & Restdefekt & $\begin{array}{l}\text { Atriasept Occluder; } \\
\text { IAS }\end{array}$ \\
\hline
\end{tabular}

Tabelle 2.1: Präparateübersicht; (\# Präparatnummer, a Jahr(e), AI Aortenklappeninsuffizienz, AKE Aortenklappenersatz, AoV Aortenklappe, AP aortopulmonal, ASD Atriumseptumdefekt, BTA Blalock-Taussig-Anastomose, d Tag(e), DHZ Deutsches Herzzentrum, DILV double inlet left ventricle, DKS Damus-Kaye-Stansel, DORV double outlet right ventricle, HLHS hypoplastisches Linksherzsyndrom, IAS interatriales Septum, ISTA Aortenisthmusstenose, IVS intaktes Ventrikelseptum, IZ Implantationszeit, LA linkes Atrium, LV linker Ventrikel, LVOTO left ventricular outflow tract obstruction, $\mathbf{M}$ Monat(e), MAPCA major aortopulmonary collateral artery, PA Pulmonalatresie, PFO persistierendes Foramen ovale, PKE Pulmonalklappenersatz, PS Pulmonalstenose, PV Pulmonalklappe, RA rechtes Atrium, RV rechter Ventrikel, RVOT rechtsventrikulärer Ausflusstrakt, TA Trikuspidalatresie, TAP transanulärer Patch, TCPA totale cavo-pulmonale Anastomose, TGA Transposition der großen Arterien, TIA transitorisch-ischämische Attacke, TV Trikuspidalklappe, TOF Fallot'sche Tetralogie, Z. n. Zustand nach) 


\subsection{Implantataufarbeitung}

\subsubsection{Herstellung histologischer Präparate}

Nach der chirurgischen Entfernung wurden alle Implantate samt umliegendem Gewebe in Formalin (Phosphat-gepuffert, 4 \%; Carl Roth GmbH \& Co. KG, Karlsruhe, Deutschland) über mindestens 48 Stunden fixiert. Je nachdem, ob Metallanteile oder makroskopisch sichtbare Verkalkungen enthalten waren, wurden die Implantate unterschiedlich weiterbehandelt: Bei den Okkludern, die alle metallische Anteile enthielten, sowie bei den Implantaten mit bereits makroskopisch sichtbarer Verkalkung wurde zunächst das Formalin über 4 bis 6 Stunden unter fließendem, kaltem Leitungswasser ausgewaschen und anschließend eine Entwässerung mithilfe einer aufsteigenden Ethanolreihe (je 2 Tage in $2 \times 70 \%$ igem, $90 \%$ igem, $2 \times 96 \%$ igem, $3 \times 100 \%$ igem Ethanol) und Xylol $(3 \times$ je 2 Tage; Carl Roth GmbH \& Co. KG, Karlsruhe, Deutschland) durchgeführt. Daraufhin wurden sie in Methylmethacrylat-Kunstharz (Technovit 9100, Kulzer \& Co., Wehrheim, Deutschland) eingebettet und härteten aus. Für die von Kossa- und immunhistochemischen Färbungen wurden die Präparatblöcke anschließend mit Silikonkleber (ELASTOSIL E41, Wacker Chemie GmbH, München, Deutschland) auf Glasobjektträgern und für die Richardson-Färbungen mit Präzisionskleber (Technovit 7210 VLC, Kulzer \& Co., Wehrheim, Deutschland) auf Kunststoffobjektträgern befestigt.

Mit einer Diamantsäge (300CP, Exakt GmbH, Norderstedt, Deutschland) wurden Scheiben von 200 bis $300 \mu \mathrm{m}$ Dicke hergestellt, die mit einem Mikro-Schleif-System (400CS, Exakt GmbH, Norderstedt, Deutschland) auf 10 bis $30 \mu \mathrm{m}$ Dicke abgeschliffen wurden. Die Shunts und Patches, die keine Metallanteile oder bereits makroskopisch sichtbare Verkalkungen enthielten, wurden nach Auswaschen des Formalins (s. o.) mit einer aufsteigenden Ethanolreihe (je 1 Stunde in 70 \%igem, 80 \%igem, 96 \%igem, $3 \times$ $100 \%$ igem Ethanol) entwässert, mit Xylol $(2 \times$ je 1,5 Stunden $)$ behandelt und in Paraffin (Paraplast Plus, Leica Biosystems Inc., Richmond, Illinois, USA) eingebettet. Mit einem Rotationsmikrotom (Leica RM2165, Leica Microsystems Nussloch GmbH, Nussloch, Deutschland) wurden Schnitte von circa $5 \mu \mathrm{m}$ Dicke angefertigt und anschließend auf Glasobjektträger aufgebracht. 


\subsubsection{Färbungen}

\section{Konventionelle Färbungen}

Zur histologischen Übersicht wurde standardmäßig bei den Methylmethacrylat-Schliffen eine Färbung nach Richardson durchgeführt, in der sich basophile Strukturen blau und metachromatische Strukturen rotviolett darstellten. Hierzu wurde folgendes Protokoll eingesetzt:

- Ansetzen von Lösung Nr. 1: Erwärmung von $1 \mathrm{~g}$ Methylenblau (Carl Roth GmbH \& Co. KG, Karlsruhe, Deutschland) und $1 \mathrm{~g}$ Natriumborat (Apotheke des Universitätsklinikums Göttingen, Deutschland) in $100 \mathrm{ml}$ destilliertem Wasser

- Ansetzen von Lösung Nr. 2: 1 g Azur II (Waldeck GmbH \& Co. KG, Münster, Deutschland) in $100 \mathrm{ml}$ destilliertem Wasser

- Mischung beider Lösungen im Verhältnis 1:1

- Filtration

- Färbung über 3 bis 5 min auf einer Heizplatte bei $60^{\circ} \mathrm{C}$

- Spülung über 5 min mit Leitungswasser

Bei den Paraffin-Schnitten wurde, ebenfalls zur histologischen Übersicht, eine Hämatoxylin-Eosin (HE)-Standardfärbung angefertigt, die basophile Strukturen blau und azidophile Strukturen rot darstellte. Dies geschah nach folgendem Protokoll:

- Entparaffinierung mit Xylol $(3 \times$ je 8 min $)$ und absteigender Ethanolreihe $(2 \times$ je 5 $\min$ in $100 \%$ igem Ethanol, je $1 \times$ über 5 min in $96 \%$ igem, $70 \%$ igem, $50 \%$ igem, $30 \%$ igem Ethanol)

- Rehydrierung mit entionisiertem Wasser (5 min)

- Hämatoxylin nach Mayer $(3 \times$ je 3 min; Carl Roth GmbH \& Co. KG, Karlsruhe, Deutschland)

- fließendes Leitungswasser (6 min)

- entionisiertes Wasser (2 min) 
- wässriges 0,5 \%iges Eosin $(2 \times$ je 2 min; Eosin G (gelblich), 115935, Merck KGaA, Darmstadt, Deutschland)

- Spülen in entionisiertem Wasser

- $96 \%$ iges Ethanol (1 min)

- $100 \%$ iges Ethanol $(2 \times$ je 2 min $)$

- Xylol $(3 \times$ je 3 min $)$

Zuletzt wurden die Schnitte mit Entellan (107960, Merck KGaA, Darmstadt, Deutschland) eingedeckt.

Bei einigen Schliffen und Schnitten wurde zur Darstellung von Verkalkung eine Färbung nach von Kossa vorgenommen, in der sich Calciumphosphat-Ablagerungen schwarz darstellten. Hierfür wurde folgendes Protokoll eingesetzt:

- Schnitte: Entparaffinieren mit Xylol $(3 \times$ je 8 min) und absteigender Ethanolreihe $(2 \times$ je 5 min in $100 \%$ igem Ethanol, je $1 \times$ über 5 min in $96 \%$ igem, $70 \%$ igem, 50 \%igem, 30 \%igem Ethanol)

Schliffe: Deplastifizieren mit Xylol $(3 \times$ je $20 \mathrm{~min})$, Methoxyethylacetat $(20 \mathrm{~min})$, Aceton $(2 \times$ je $5 \mathrm{~min})$

- Rehydrierung mit entionisiertem Wasser (5 min)

- 5 \%ige Silbernitratlösung (10 bis 60 min bei Tageslicht; Silbernitrat, 101512, Merck KGaA, Darmstadt, Deutschland)

- destilliertes Wasser $(3 \times$ je 3 min $)$

- 1 \%ige Pyrogallussäure (3 min; Pyrogallol, 3963.1, Carl Roth GmbH \& Co. KG, Karlsruhe, Deutschland)

- 5 \%ige Natriumthiosulfatlösung (5 min; Natriumthiosulfat-Pentahydrat, T109.2, Carl Roth GmbH \& Co. KG, Karlsruhe, Deutschland)

- fließendes Leitungswasser (10 min) 
- Kernechtrot-Färbelösung (30 min; Carl Roth GmbH \& Co. KG, Karlsruhe, Deutschland)

- destilliertes Wasser (2 min)

- $70 \%$ iges Ethanol (1 min)

- $100 \%$ iges Ethanol ( 2 x je 2 min)

- Xylol (3 x je 3 min)

Zuletzt wurden die Schnitte mit Entellan eingedeckt.

\section{Immunhistochemische Färbungen}

Die Schnitte wurden entparaffiniert und die Schliffe deplastifiziert (s. o.), um eine Bindung der Primärantikörper an die Antigene zu ermöglichen. Zur Antigendemaskierung wurden die Präparate je nach Primärantikörper mit verschiedenen Pufferlösungen und anschließender Inkubation im Dampfkochtopf bei $90{ }^{\circ} \mathrm{C}$ über 20 beziehungsweise $40 \mathrm{~min}$ mit Proteinase K (Proteinase K, S3004, Dako, Glostrup, Dänemark) und Inkubation auf einer Wärmeplatte bei $37{ }^{\circ} \mathrm{C}$ über 5 Minuten vorbehandelt (s. Tabelle 2.2). Auf einen Waschschritt mit TTBS (tween tris-buffered saline; Carl Roth GmbH \& Co. KG, Karlsruhe, Deutschland) folgte das Blocken der endogenen Peroxidase mittels Wasserstoffperoxid-haltiger Lösung (Peroxidase Blocking Reagent, S2023, Dako, Glostrup, Dänemark) und anschließender Inkubation über 17 Minuten. Nach einer 30minütigen Inkubation mit Antibody Diluent (Antibody Diluent Dako REAL, S2022, Dako, Glostrup, Dänemark) zur Gewährleistung eines angemessen gepufferten Mediums zur Verdünnung der Primärantikörper wurden die Präparate mit den jeweiligen Primärantikörpern über Nacht bei $4{ }^{\circ} \mathrm{C}$ inkubiert. Es kamen 10 Primärantikörper zum Einsatz: Zur Darstellung von Endothelzellen wurden Antikörper gegen von-WillebrandFaktor (vWF) sowie CD 31 eingesetzt. Um kontraktile Zellen hervorzuheben, wurden sowohl Antikörper gegen smooth muscle actin (SMA) als auch smooth muscle myosin (SMM) verwandt. Antikörper gegen Vimentin als Typ 3-Intermediärfilament des Zytoskeletts von Fibroblasten, Endothelzellen und Gefäßmuskelzellen (kontraktiler Zellen) kamen zur Darstellung der genannten Zellen zum Einsatz. Antikörper gegen Kollagen Typ IV als Bestandteil der Lamina densa der Basallamina, die Endothel- und 
Epithelgewebe begrenzt und auch andere Zellen umgibt, die in Kontakt mit Bindegewebe stehen, wie beispielsweise Muskelzellen, wurden zur Darstellung von Endothelien sowie zur Lokalisation glatter Muskelzellen in Pseudointima-, Implantat- und Pseudoadventitiagewebe genutzt. Außerdem kamen Antikörper gegen Oberflächenmerkmale von Entzündungszellen zum Einsatz: gegen CD 68 auf Monozyten, Makrophagen und Fremdkörperriesenzellen (FKR), gegen CD 3 auf T-Lymphozyten, gegen CD $79 \alpha$ auf BLymphozyten und Plasmazellen, gegen CD 15 auf Granulozyten. Die Inkubation der Primärantikörper erfolgte über Nacht bei $4{ }^{\circ} \mathrm{C}$. Anschließend wurden nach einem Waschschritt die jeweiligen Sekundärantikörper aufgebracht und je nach System 30 oder 60 Minuten inkubiert (s. Tabelle 2.2). Auf einen Waschschritt folgte die Visualisierung der Antigen-Antikörper-Komplexe mittels eines Diaminobenzidin-Substrat-ChromogenSystems (DAB Substrate Kit High Contrast, DAB5000plus, Zytomed Systems GmbH, Berlin, Deutschland), welches unter Mikroskopkontrolle 5 bis 30 Minuten inkubierte. Daraufhin wurden die Präparate nach einem weiteren Waschschritt mit Hämalaun gegengefärbt und mittels aufsteigender Ehanolreihe und Xylol entwässert (s. o.). Zum Schluss erfolgte die Eindeckung mit Entellan.

\begin{tabular}{|c|c|c|}
\hline Primärantikörper & Antigendemaskierung & Sekundärantikörper \\
\hline $\begin{array}{l}\text { Polyclonal Rabbit Anti-Human } \\
\text { von-Willebrand-Faktor, A0082, } \\
\text { Dako; Verdünnung: 1:500 }\end{array}$ & $\begin{array}{l}\text { Target Retrieval Solution pH 6,0, S2031, } \\
\text { Dako; INZ im Dampfkochtopf bei } 90^{\circ} \mathrm{C} \text { : } \\
40 \mathrm{~min}\end{array}$ & $\begin{array}{c}\text { Polyclonal Swine Anti-Rabbit } \\
\text { Immunglobulins/HRP, P0217, Dako; } \\
\text { Verdünnung: 1:100; INZ bei RT: } 60 \mathrm{~min}\end{array}$ \\
\hline $\begin{array}{l}\text { Monoclonal Mouse Anti-Human } \\
\text { CD 31, Endothelial Cell Clone } \\
\text { JC70A, M0823, Dako; } \\
\text { Verdünnung: 1:100 }\end{array}$ & $\begin{array}{l}\text { Target Retrieval Solution pH 6,1, S1699, } \\
\text { Dako; INZ im Dampfkochtopf bei } 90^{\circ} \mathrm{C} \text { : } \\
40 \mathrm{~min}\end{array}$ & $\begin{array}{c}\text { Polyclonal Rabbit Anti-Mouse } \\
\text { Immunglobulins/HRP, P0260, Dako; } \\
\text { Verdünnung: 1:100; INZ bei RT: } 60 \text { min }\end{array}$ \\
\hline $\begin{array}{c}\text { Monoclonal Mouse Anti-Human } \\
\text { Smooth Muscle Actin, Clone 1A4, } \\
\text { M 0851, Dako; Verdünnung: } \\
\text { 1:300 }\end{array}$ & $\begin{array}{l}\text { Target Retrieval Solution pH 6,0, S2031, } \\
\text { Dako; INZ im Dampfkochtopf bei } 90^{\circ} \mathrm{C} \text { : } \\
40 \mathrm{~min}\end{array}$ & $\begin{array}{c}\text { Polyclonal Rabbit Anti-Mouse } \\
\text { Immunglobulins/HRP, P0260, Dako; } \\
\text { Verdünnung: 1:100; INZ bei RT: } 60 \mathrm{~min}\end{array}$ \\
\hline $\begin{array}{c}\text { Monoclonal Mouse Anti-Human } \\
\text { Smooth Muscle Myosin Heavy } \\
\text { Chain, Clone SMMS-1, M3558, } \\
\text { Dako; Verdünnung: 1:500 }\end{array}$ & $\begin{array}{l}\text { 1. Proteinase K, S3004, Dako; } \\
\text { Verdünnung: } 1: 500 \text {; INZ auf Wärmeplatte } \\
\text { bei } 37^{\circ} \mathrm{C}: 5 \text { min } \\
\text { 2. Target Retrieval Solution pH 6,0, } \\
\text { S2031, Dako; INZ im Dampfkochtopf bei } \\
90^{\circ} \mathrm{C}: 40 \text { min }\end{array}$ & $\begin{array}{l}\text { EnVision+Dual Link System-HRP, } \\
\text { K4063, Dako; INZ bei RT: } 30 \text { min }\end{array}$ \\
\hline $\begin{array}{c}\text { Monoclonal Mouse Anti-Vimentin } \\
\text { Clone V9 IgG1, M0725, Dako; } \\
\text { Verdünnung 1:300 }\end{array}$ & $\begin{array}{l}\text { Target Retrieval Solution pH 6,0, S2031, } \\
\text { Dako; INZ im Dampfkochtopf bei } 90^{\circ} \mathrm{C} \text { : } \\
\qquad 40 \mathrm{~min}\end{array}$ & $\begin{array}{c}\text { Polyclonal Rabbit Anti-Mouse } \\
\text { Immunglobulins/HRP, P0260, Dako; } \\
\text { Verdünnung: 1:100; INZ bei RT: } 60 \mathrm{~min}\end{array}$ \\
\hline $\begin{array}{l}\text { Monoclonal Mouse Anti-Human } \\
\text { Collagen IV, Clone CIV 22, } \\
\text { M0785, Dako; Verdünnung 1:100 }\end{array}$ & $\begin{array}{l}\text { Target Retrieval Solution pH 6,1, S1699, } \\
\text { Dako; INZ im Dampfkochtopf bei } 90^{\circ} \mathrm{C} \text { : } \\
40 \mathrm{~min}\end{array}$ & $\begin{array}{c}\text { Polyclonal Rabbit Anti-Mouse } \\
\text { Immunglobulins/HRP, P0260, Dako; } \\
\text { Verdünnung: 1:100; INZ bei RT: } 60 \text { min }\end{array}$ \\
\hline
\end{tabular}




\begin{tabular}{|c|c|c|}
\hline $\begin{array}{l}\text { Monoclonal Mouse Anti-Human } \\
\text { CD 68, Clone PG-M1, M0876, } \\
\text { Dako; Verdünnung 1:200 }\end{array}$ & $\begin{array}{l}\text { Target Retrieval Solution High pH, 50x } \\
\text { concentrated Tris/EDTA, pH 9, K8004, } \\
\text { Dako; INZ im Dampfkochtopf bei } 90^{\circ} \mathrm{C} \text { : } \\
20 \text { min, Abkühlungszeit: } 20 \text { min }\end{array}$ & $\begin{array}{l}\text { EnVision+Dual Link System-HRP, } \\
\text { K4063, Dako; INZ bei RT: } 30 \mathrm{~min}\end{array}$ \\
\hline $\begin{array}{c}\text { Polyclonal Rabbit Anti-Human } \\
\text { CD 3, A0452, Dako; Verdünnung } \\
\text { 1: } 500\end{array}$ & $\begin{array}{l}\text { Target Retrieval Solution pH 6,1, S1699, } \\
\text { Dako; INZ im Dampfkochtopf bei } 90^{\circ} \mathrm{C} \text { : } \\
\qquad 40 \mathrm{~min}\end{array}$ & $\begin{array}{l}\text { EnVision+Dual Link System-HRP, } \\
\text { K4063, Dako; INZ bei RT: } 30 \text { min }\end{array}$ \\
\hline $\begin{array}{c}\text { Monoclonal Mouse Anti-Human } \\
\text { CD 79 } \alpha \text {, Clone JCB117, M7050, } \\
\text { Dako; Verdünnung 1:100 }\end{array}$ & $\begin{array}{l}\text { Target Retrieval Solution High pH, 50x } \\
\text { concentrated Tris/EDTA, pH 9, K8004, } \\
\text { Dako; INZ im Dampfkochtopf bei } 90^{\circ} \mathrm{C} \text { : } \\
20 \mathrm{~min} \text {, Abkühlungszeit: } 20 \mathrm{~min}\end{array}$ & $\begin{array}{l}\text { EnVision+Dual Link System-HRP, } \\
\text { K4063, Dako; INZ bei RT: } 30 \text { min }\end{array}$ \\
\hline $\begin{array}{l}\text { Monoclonal Mouse IgMк Anti- } \\
\text { Human CD 15, Clone Carb-3, } \\
\text { MSK005-05, Zytomed; } \\
\text { Verdünnung 1: } 300\end{array}$ & $\begin{array}{l}\text { Target Retrieval Solution pH 6,1, S1699, } \\
\text { Dako; INZ im Dampfkochtopf bei } 90^{\circ} \mathrm{C} \text { : } \\
\qquad 40 \mathrm{~min}\end{array}$ & $\begin{array}{l}\text { ZytoChem-Plus HRP Polymer-System } \\
\text { (Mouse/Rabbit), POLHRP-100, } \\
\text { Zytomed; INZ PostBlock bei RT: } 20 \\
\text { min, INZ HRP-Polymer bei RT: } 30 \text { min }\end{array}$ \\
\hline
\end{tabular}

Tabelle 2.2: Übersicht über Antigendemaskierung, Primärantikörper, Sekundärantikörper; (INZ Inkubationszeit, RT Raumtemperatur) 


\subsection{Technische Ausrüstung zur Auswertung der Präparate}

Die Präparate wurden entweder lichtmikroskopisch (LEICA DMLB, Leica Microsystems

$\mathrm{GmbH}$, Wetzlar, Deutschland) oder auch digitalisiert mithilfe eines Präparatescanners (dotSlide System, Olympus Life Science Europe GmbH, Hamburg, Deutschland) ausgewertet. Fotografien wurden mithilfe der CCD-Farbkamera Color View II angefertigt und mit der Software Analysis 3.2 der Firma Olympus (Olympus Europa Holding GmbH, Hamburg, Deutschland) verarbeitet. 


\subsection{Zeit- und Prozentangaben}

Bei Präparaten, die bis zu 1 Monat implantiert waren, wurde die Implantationszeit in Tagen angegeben, darüber hinaus in Jahren und/oder Monaten. Wurde ein Implantat vor dem 15. eines Monats eingesetzt, zählte dies bezüglich der Implantationszeit als ganzer Implantationsmonat; nach dem 15. wurde dieser Monat nicht berechnet. Wurde ein Implantat vor dem 15. eines Monats entfernt, wurde dieser Monat in die Implantationszeit nicht einberechnet. Eine Entfernung nach dem 15. zählte als ganzer Implantationsmonat. In Prozentangaben ausgedrückte Ergebnisse dieser Arbeit wurden auf die nächste ganze Zahl auf- bzw. abgerundet. 


\section{Ergebnisse}

Dieser Teil der Arbeit ist folgendermaßen gegliedert: Nach Implantatmaterialien (PTFE, Polyester und PVA) gruppiert, werden die histologischen Ergebnisse der verschiedenen Implantattypen (Shunts, Patches und Okkluder) besprochen.

Die neu gebildete Gewebsschicht an der blutzugewandten Seite des Implantats wurde in dieser Arbeit, analog zur Intima echter Blutgefäße, als ,Pseudointima‘ bezeichnet. Das neu gebildete Gewebe innerhalb des textilen Fremdmaterials wurde ,Implantatgewebe، genannt. Als ,Pseudoadventitia“ wurde das neu gebildete Gewebe außerhalb des Implantatgewebes bezeichnet.

Bei der Betrachtung der einzelnen Implantatmaterialien wurden die Reaktionen in Pseudointima-, Pseudoadventitia- und Implantatgewebe getrennt voneinander beschrieben. Auf Gewebereaktionen in der Pseudoadventitia wurde nur eingegangen, wenn Auffälligkeiten zu erkennen waren, da das Augenmerk dieser Arbeit vor allem auf Veränderungen in Pseudointima- und Implantatgewebe gerichtet war.

\subsection{PTFE-Implantate}

\subsubsection{Gefäßshunts}

Es wurden insgesamt 21 PTFE-Shunts untersucht.

\section{Endothelialisierung der Pseudointima}

Bei 13 von 15 untersuchten auswertbaren Präparaten konnte die Endothelialisierung durch immunhistochemische Färbungen mit vWF-, CD 31-, Kollagen IV- (s. Abbildung 3.6 B) oder Vimentin- (s. Abbildung 3.5 A) Antikörpern bestätigt werden: 13 von 14 auswertbaren Präparaten färbten positiv für vWF, 3 von 3 für $\mathrm{CD} 31,3$ von 5 für Kollagen IV und 8 von 8 für Vimentin (s. Tabelle 3.1). Das Endothel zeigte sich als einzellige, oberflächliche Zellschicht mit ovalen bis rundlichen Zellkernen in der vWF(s. Abbildung 3.1 A), CD 31- (s. Abbildungen 3.1 B, C) und Vimentin-Färbung, wohingegen in der Kollagen IV-Färbung das subendotheliale Gewebe dargestellt wurde. Präparat Nr. 16 mit der zweitkürzesten Implantationszeit von 2 Monaten zeigte eine deutliche Endothelialisierung (s. Abbildung 3.1 C). 


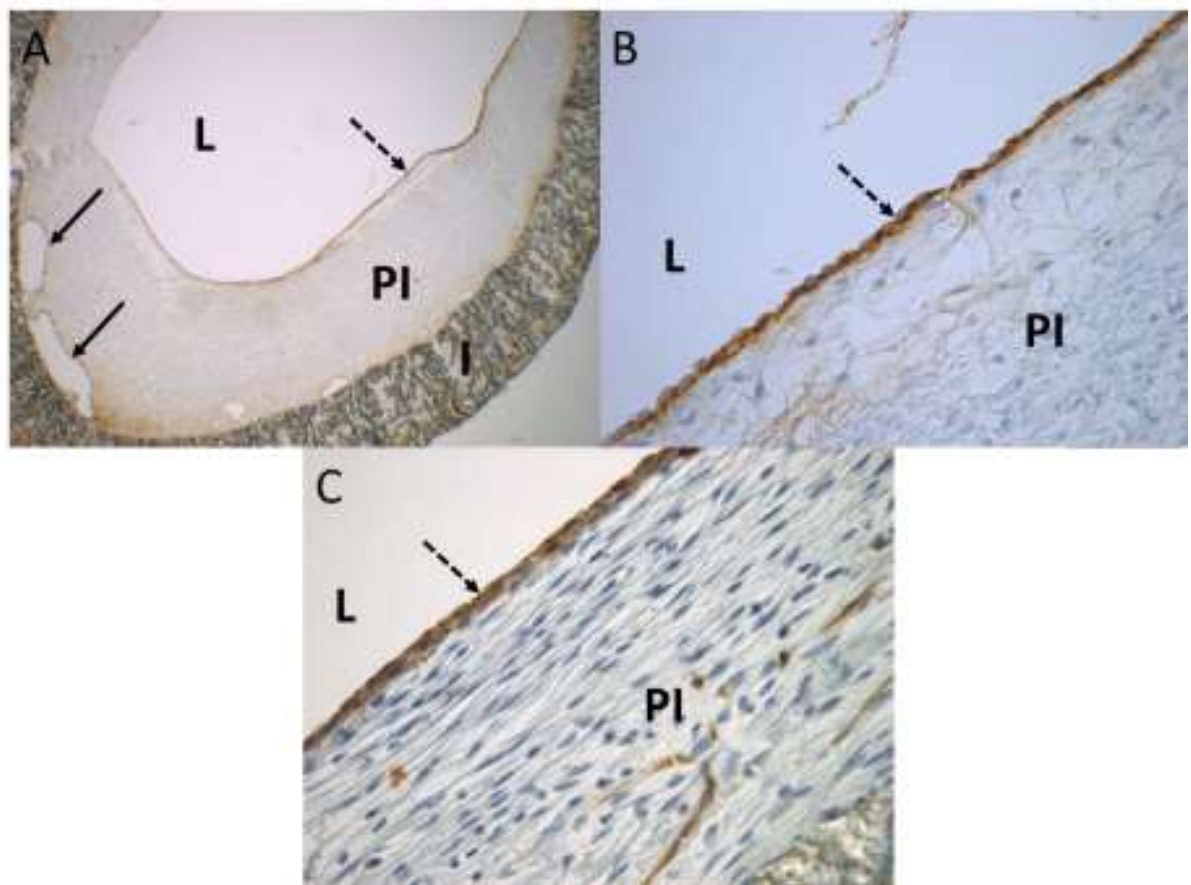

Abbildung 3.1: A VWF-Färbung; Implantatgewebe (I) mit Pseudointima (PI), unterschiedlich geformten Hohlräumen verschiedenen Kalibers (Pfeile) und angefärbtem Endothel (gestrichelter Pfeil), Lumen (L); Vergrößerung 40fach; Präparat Nr. 12; B vWF-Färbung; Ausschnitt aus A; Vergrößerung 400fach; Präparat Nr. 12; C CD 31-Färbung; deutliche Endothelialisierung der Pseudointima nach 2 Monaten Implantationszeit; Vergrößerung 400fach; Präparat Nr. 16

Bei 2 Präparaten war mithilfe der durchgeführten immunhistochemischen Verfahren keine Endothelialisierung zu erkennen. Das Lumen von Präparat Nr. 11 war durch Hyperplasie der Pseudointima komplett verschlossen (s. Abbildung 3.2). Bei Präparat Nr. 13 (Implantationszeit: 6 Tage) lag noch keine ausgebildete Pseudointima vor und daher auch keine Endothelialisierung.

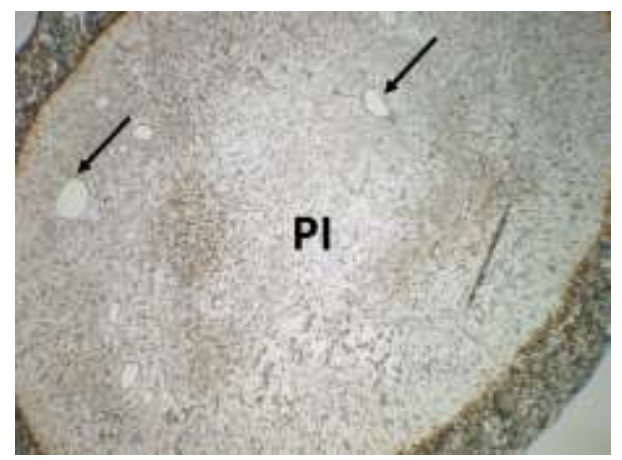

Abbildung 3.2: Vimentin-Färbung; kompletter Shuntverschluss durch Hyperplasie der Pseudointima (PI) mit unterschiedlich geformten Hohlräumen verschiedenen Kalibers (Pfeile); Vergrößerung 40fach; Präparat Nr. 11 


\begin{tabular}{|c|c|c|c|c|c|}
\hline$\#$ & $\mathbf{E}$ & $\mathbf{v W F}$ & CD 31 & Vimentin & Kollagen IV \\
\hline 1 & $\mathrm{~J}$ & + & & + & \\
\hline 2 & $\mathbf{J}$ & + & & + & \\
\hline 3 & $\mathbf{J}$ & + & & + & \\
\hline 4 & $\mathbf{J}$ & + & & + & \\
\hline 5 & $\mathrm{~J}$ & + & & & \\
\hline 6 & $\mathbf{J}$ & + & & + & - \\
\hline 7 & $\mathbf{J}$ & + & & + & \\
\hline 8 & $\mathbf{J}$ & + & & + & \\
\hline 10 & $\mathbf{J}$ & + & & & + \\
\hline 11 & $\begin{array}{c}\mathrm{N} \\
\text { (Shuntverschluss) }\end{array}$ & $\begin{array}{c}- \\
\text { (Shuntverschluss) }\end{array}$ & & $\begin{array}{c}- \\
\text { (Shuntverschluss) }\end{array}$ & $\begin{array}{c}- \\
\text { (Shuntverschluss) }\end{array}$ \\
\hline 12 & $\mathbf{J}$ & + & & + & + \\
\hline 13 & $\begin{array}{c}\mathrm{N} \\
\text { (keine PI } \\
\text { ausgebildet) }\end{array}$ & $\begin{array}{c}- \\
\text { (keine PI } \\
\text { ausgebildet) }\end{array}$ & & & \\
\hline 15 & $\mathbf{J}$ & + & + & & \\
\hline 16 & $\mathrm{~J}$ & + & + & & - \\
\hline 20 & $\mathbf{J}$ & + & + & & + \\
\hline
\end{tabular}

Tabelle 3.1: Endothelialisierung der Pseudointima; (+ positives Färbeergebnis, - negatives Färbeergebnis, \# Präparatnummer, E Endothelialisierung, J ja, N nein, PI Pseudointima)

\section{Neovaskularisierung}

Neben der Darstellung des Endothels und Subendothels der Pseudointima wurde durch die vWF- (s. Abbildung 3.1 A), CD 31-, Kollagen IV- (s. Abbildung 3.3 C), Vimentin- (s. Abbildungen 3.3 C, 3.5), SMA- (s. Abbildung 3.3 A) und SMM- (s. Abbildung 3.3 B) Färbungen auch die Zellauskleidung bzw. umgebende Extrazellulärmatrix (EZM) unterschiedlich geformter Hohlräume verschiedenen Kalibers dargestellt, die in allen Präparaten regelhaft in der Pseudointima - meist implantatnah - und im Implantatgewebe gefunden werden konnten. Das Kaliber dieser Hohlräume war im Pseudointimagewebe deutlich größer als im Implantatgewebe. 


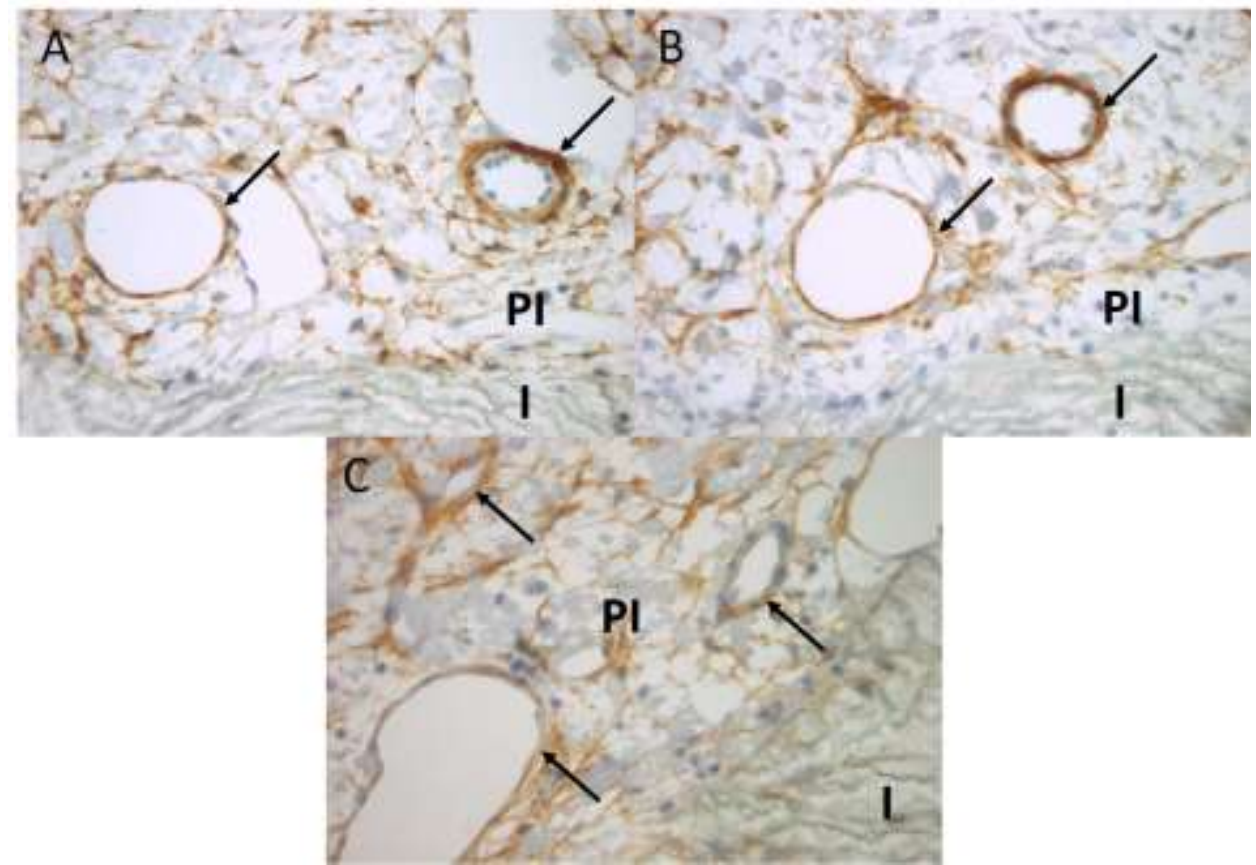

Abbildung 3.3: Kontraktile Zellen (Pfeile) um Hohlräume in unterer Pseudointima (PI), Implantatgewebe (I); Präparat Nr. 20; A SMA-Färbung; Vergrößerung 400fach; B SMM-Färbung; Vergrößerung 400fach; C Kollagen IV-Färbung; Vergrößerung 400fach

\section{Zellen und EZM des Pseudointima- und Implantatgewebes}

Die Ausbildung einer Pseudointima war bei allen auswertbaren Präparaten mit Ausnahme des Präparates Nr. 13 zu erkennen. Hierbei handelt es sich um einen Shunt mit relativ kurzer Implantationszeit von 6 Tagen. In der HE-Färbung erkennt man in diesem Präparat lumenseitig, angrenzend an das PTFE-Gewebe, ein Netz aus Fibrinfäden mit eingestreuten Erythrozyten (s. Abbildungen 3.4 A, B). 


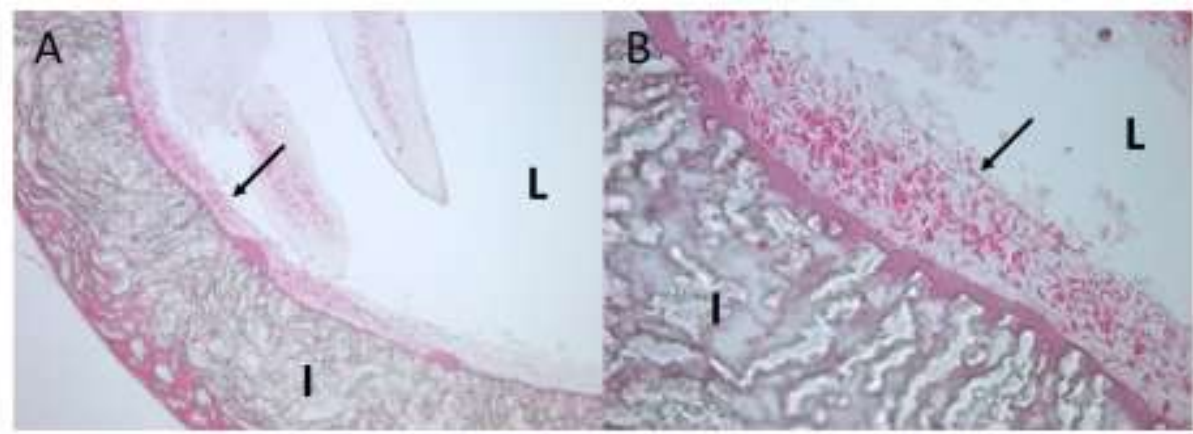

Abbildung 3.4: HE-Färbung; Präparat Nr. 13; A Fibringewebe mit Erythrozyten (Pfeile) am Implantatgewebe (I), Lumen (L); Vergrößerung 100fach; B Ausschnitt aus A; Vergrößerung 400fach

Positiv für Vimentin färbten neben Endothelzellen in allen 11 darauf untersuchten Präparaten - Präparate Nr. 1 bis 8,11, 12 und 18 - auch langgestreckte, spindelförmige Zellen, die in der gesamten Pseudointima zu finden waren (s. Abbildungen 3.5 A, B).

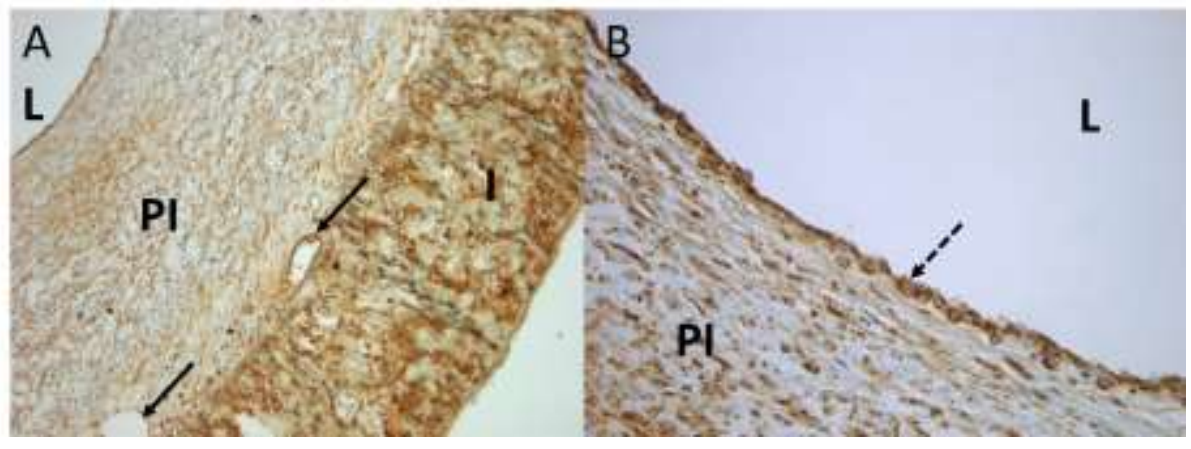

Abbildung 3.5: Vimentin-Färbung; Präparat Nr. 12; A spindelförmige Zellen in der Pseudointima (PI), Auskleidung unterschiedlich geformter Hohlräume verschiedenen Kalibers mit Vimentinpositiven Endothelzellen (Pfeile), Implantatgewebe (I), Lumen (L); Vergrößerung 100fach; B Ausschnitt aus A; spindelförmige Zellen in der Pseudointima (PI), Endothelialisierung der Pseudointima (gestrichelter Pfeil), Vergrößerung 400fach

Positiv für Kollagen IV färbte neben der subendothelialen EZM auch die restliche EZM der Pseudointima in 6 von 8 Präparaten. Sie zeigte eine netzartige Struktur (s. Abbildungen 3.6 A, B). In den Aussparungen dieses Netzes lagen mit Hämalaun gegengefärbte Zellkerne. In Präparat Nr. 4 färbte ein breiter, implantatnaher Abschnitt der Pseudointima nicht für Kollagen IV. In den Präparaten Nr. 10 bis 12 und Nr. 20 färbten Zellen der gesamten Pseudointimabreite. In Präparat Nr. 18 färbte die EZM der PI zwar für Kollagen IV, war aber schlecht erhalten, weswegen sich zum Färbemuster keine Aussage treffen ließ. Negativ fiel die Kollagen IV-Färbung in Präparat Nr. 6 und 16 aus. 


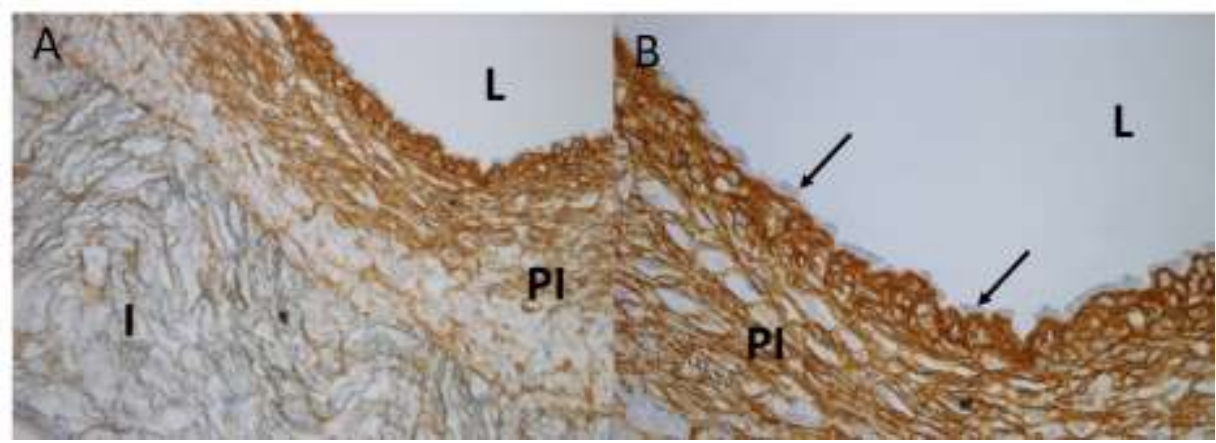

Abbildung 3.6: Kollagen IV-Färbung; Präparat Nr. 12; A Kollagen IV in der Pseudointima (PI), Implantatgewebe (I), Lumen (L); Vergrößerung 200fach; B Ausschnitt aus A, Kollagen IV in der Pseudointima, Färbung der subendothelialen EZM mit aufsitzenden Endothelzellen (Pfeile); Vergrößerung 400fach

In allen 11 auswertbaren Shunts färbten im Implantatgewebe ansässige Zellen positiv für Vimentin (s. Abbildung 3.7 A). In 4 von 8 auswertbaren Präparaten färbte die EZM des Implantatgewebes positiv für Kollagen IV (s. Abbildung 3.7 B und Tabelle 3.2).

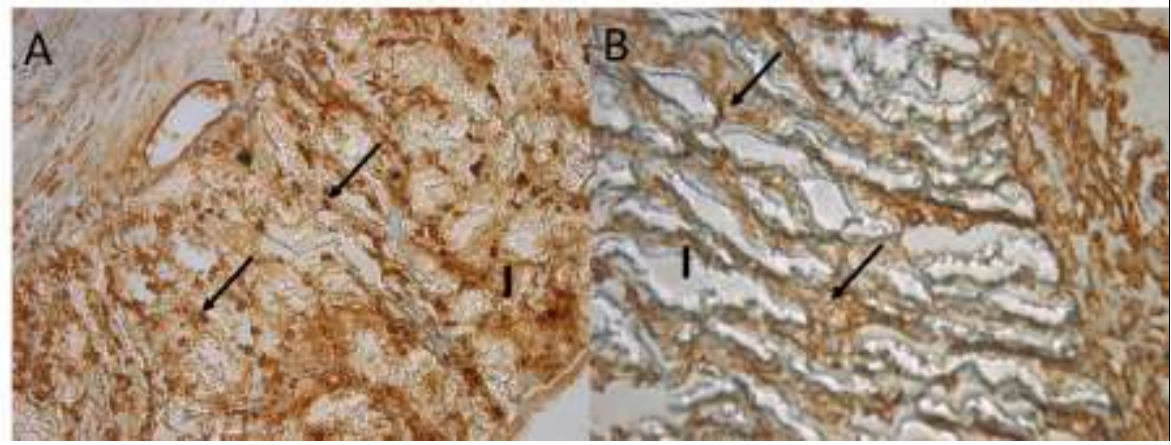

Abbildung 3.7: A Vimentin-Färbung; Bindegewebszellen (Pfeile) im Implantatgewebe (I); Vergrößerung 200fach; Präparat Nr. 12; B Kollagen IV-Färbung; Darstellung der EZM (Pfeile) des Implantatgewebes (I); Vergrößerung 400fach; Präparat Nr. 10 


\begin{tabular}{|c|c|c|}
\hline$\#$ & Vimentin & Kollagen IV \\
\hline 1 & + & \\
\hline 2 & + & \\
\hline 3 & + & - \\
\hline 4 & + & - \\
\hline 5 & + & \\
\hline 6 & + & + \\
\hline 7 & + & + \\
\hline 8 & + & + \\
\hline 10 & + & + \\
\hline 11 & + & + \\
\hline 12 & + & + \\
\hline 15 & + & + \\
\hline 16 & + & + \\
\hline 18 & + & + \\
\hline 20 & + & \\
\hline
\end{tabular}

Tabelle 3.2: Ergebnisse der Vimentin- und Kollagen IV-Färbungen des Implantatgewebes; (+ positives Färbeergebnis, - negatives Färbeergebnis, \# Präparatnummer, NB nicht beurteilbar, P Präparat)

In den SMA- und SMM-Färbungen zeigte die Pseudointima häufig ein komplexes Netz spindelförmiger Zellen, teilweise mit Hämalaun gegengefärbtem, ovalem bis länglichem Zellkern. 18 untersuchte Shunts zeigten ein Vorliegen von intrazellulärem SMA. 12 von 16 Shunts färbten positiv für SMM (s. Tabelle 3.3). Die 4 Präparate, bei denen kein SMM (wohl aber SMA) nachgewiesen werden konnte, waren zwischen 3 Monaten und 1 Jahr und 1 Monat implantiert. Auffällig war, dass unterschiedliche Anordnungsmuster dieser kontraktilen Zellen vorlagen. Einige Präparate zeigten lumenseitig eine deutlich dichtere, organisiertere Anordnung kontraktiler Zellen als implantatnah (s. Abbildungen 3.8 A, B, C). Bei den Präparaten, bei denen dies der Fall war, erschien die Pseudointima insgesamt organisierter: lumenseitig straff organisiertes, implantatnah locker organisiertes Bindegewebe. Sowohl Präparate mit einer kurzen, 3-monatigen Implantationszeit als auch Präparate mit den längsten Implantationszeiten von 2 Jahren und mehr wiesen eine solche Anordnung kontraktiler Zellen auf. 


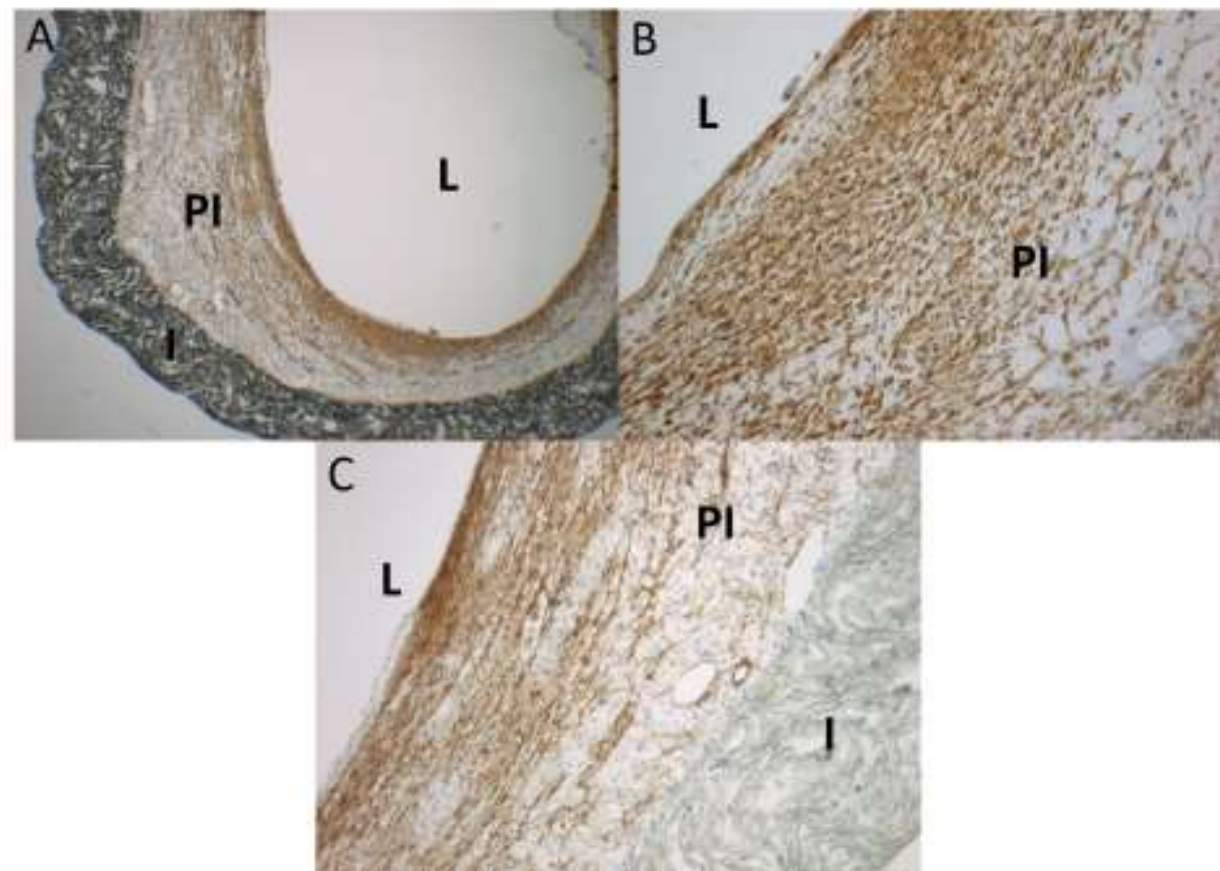

Abbildung 3.8: Lumenseitig dichtere Anordnung kontraktiler Zellen als implantatnah, Lumen (L), Pseudointima (PI), Implantat (I); A SMA-Färbung; Implantationszeit: 2 a; Vergrößerung 40fach; Präparat Nr. 20; B SMA-Färbung; Implantationszeit: 3 Monate, Vergrößerung 200fach; Präparat Nr. 10; C SMM-Färbung; Implantationszeit: 2 a; Vergrößerung 100fach; Präparat Nr. 20

Bei den anderen Präparaten war eine vermehrte Färbung lumenseitig gelegener, kontraktiler Zellen nicht zu erkennen. Wohl befanden sich Stellen mit dichter Anordnung kontraktiler Zellen neben Stellen mit lockerer Anordnung kontraktiler Zellen, aber insgesamt war dieser Zelltyp über die gesamte Pseudointima relativ gleichmäßig verteilt (s. Abbildung 3.9 A). 


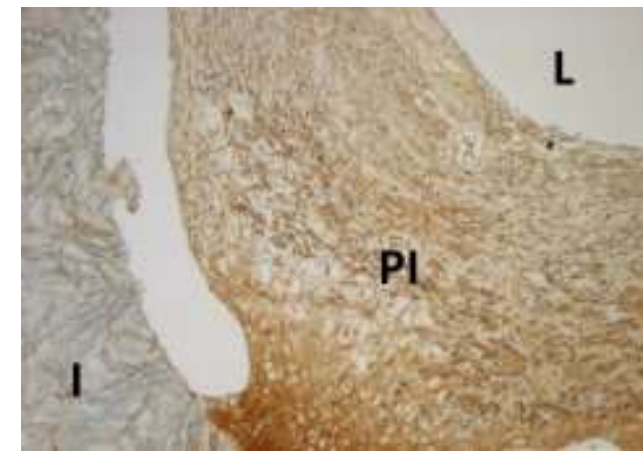

Abbildung 3.9: SMA-Färbung; relativ gleichmäßige Verteilung kontraktiler Zellen in der Pseudointima (PI), Implantatgewebe (I), Lumen (L); Implantationszeit: 8 Monate; Vergrößerung 100fach; Präparat Nr. 12

Neben der Pseudointima konnten auch im Implantatgewebe kontraktile Zellen gefunden werden (s. Abbildungen 3.10 A, B). 11 von 18 Präparate färbten positiv für SMA, 6 von 16 für SMM (s. Tabelle 3.3). 3 Präparate färbten nur positiv für SMA und nicht für SMM. Bei diesen 3 Präparaten lag die Implantationszeit bei 9 Monaten oder weniger. In einigen Präparaten befanden sich die kontraktilen Zellen hauptsächlich im lumenseitigen Abschnitt des Implantatgewebes, oft direkt am Übergang zum Pseudointimagewebe, und weniger im Pseudoadventitia-zugewandten Implantatabschnitt. Zusätzlich fiel auf, dass im Implantatgewebe deutlich weniger kontraktile Zellen zu finden waren als im Pseudointimagewebe.

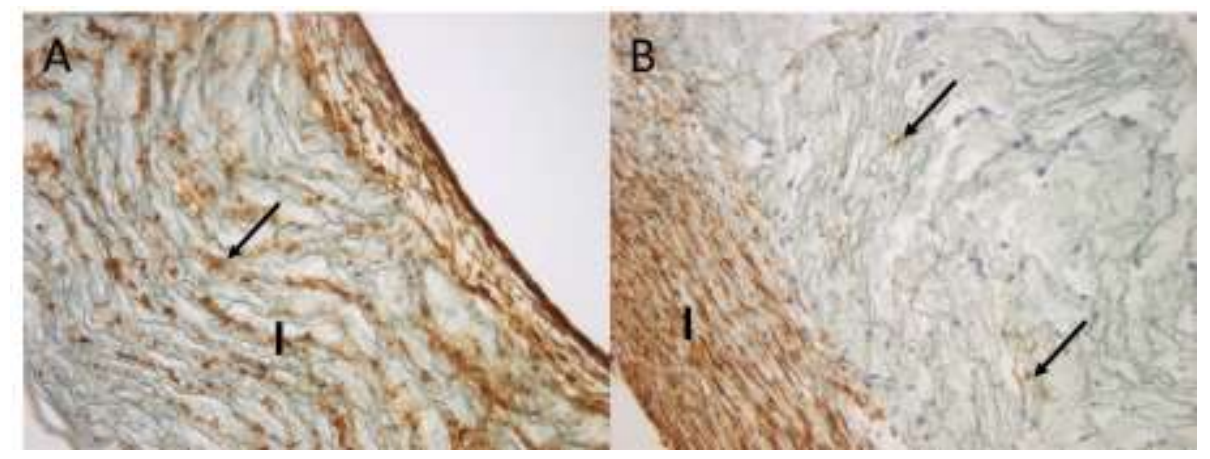

Abbildung 3.10: Kontraktile Zellen (Pfeile) im Implantatgewebe (I); A SMA-Färbung; Vergrößerung 200fach; Präparat Nr. 16; B SMM-Färbung; Vergrößerung 200fach; Präparat Nr. 20 


\begin{tabular}{|c|c|c|c|c|c|c|c|c|}
\hline \multirow{3}{*}{$\begin{array}{l}\# \\
1\end{array}$} & \multicolumn{4}{|c|}{ SMA } & \multicolumn{4}{|c|}{ SMM } \\
\hline & \multicolumn{2}{|c|}{ PI } & \multicolumn{2}{|c|}{ I } & \multicolumn{2}{|c|}{ PI } & \multicolumn{2}{|c|}{ I } \\
\hline & + & $*$ & - & & - & & - & \\
\hline 2 & + & NB & + & $\begin{array}{c}* \\
\text { PI>PA- } \\
\text { Nähe }\end{array}$ & + & NB & + & $\begin{array}{c}* \\
\text { PI>PA- } \\
\text { Nähe }\end{array}$ \\
\hline 3 & + & NB & + & $*$ & - & & + & $*$ \\
\hline 4 & + & $*$ & - & & + & $\mathrm{L}$ & - & \\
\hline 5 & + & $\mathrm{L}$ & $\mathrm{NB}$ & & + & $\mathrm{NB}$ & $\mathrm{NB}$ & \\
\hline 6 & + & NB & + & PI-Nähe & - & & + & PI-Nähe \\
\hline 7 & + & $\mathrm{L}$ & + & PI-Nähe & + & $*$ & - & \\
\hline 8 & + & $*$ & - & & + & $\mathrm{NB}$ & - & \\
\hline 10 & + & $\mathrm{L}$ & + & $\begin{array}{c}* \\
\text { PI>PA- } \\
\text { Nähe }\end{array}$ & + & $*$ & + & $\begin{array}{c}* \\
\text { PI>PA- } \\
\text { Nähe }\end{array}$ \\
\hline 11 & + & $\mathrm{Z}$ & + & PI-Nähe & + & $\mathrm{Z}$ & - & \\
\hline 12 & + & $*$ & + & $*$ & + & $*$ & - & \\
\hline 14 & + & $*$ & + & PI-Nähe & & & & \\
\hline 15 & + & $\mathrm{L}$ & - & & + & $\mathrm{L}$ & - & \\
\hline 16 & + & $*$ & + & $\begin{array}{c}* \\
\text { PI>PA- } \\
\text { Nähe }\end{array}$ & + & $*$ & + & PI-Nähe \\
\hline 17 & + & $*$ & + & PI-Nähe & & & & \\
\hline 18 & + & I-Nähe & - & & - & & - & \\
\hline 19 & + & $\mathrm{L}$ & - & & + & $*$ & - & \\
\hline 20 & + & $\mathrm{L}$ & + & $\begin{array}{c}* \\
\text { PI>PA- } \\
\text { Nähe }\end{array}$ & + & $\mathrm{L}$ & + & $\begin{array}{c}* \\
\text { PI>PA- } \\
\text { Nähe }\end{array}$ \\
\hline 21 & $\mathrm{NB}$ & & - & & NB & & - & \\
\hline
\end{tabular}

Tabelle 3.3: Kontraktile Zellen in Pseudointima- und Implantatgewebe; (+ vorhanden, - nicht vorhanden, * ubiquitär vorhanden, \# Präparatnummer, I Implantat, L lumenseitige Konzentration, NB Lage nicht beurteilbar, PA Pseudoadventitia, PI Pseudointima, PI>PA-Nähe Konzentration kontraktiler Zellen in Pseudointimanähe größer als in Pseudoadventitianähe, $\mathbf{Z}$ zentrale Konzentration) 


\section{Entzündungszellen}

Mit Ausnahme von Präparat Nr. 5 konnten in allen Shuntpräparaten Entzündungszellen im Pseudointima- wie auch Implantatgewebe nachgewiesen werden. In Präparat Nr. 5 waren in den histologischen Standardfärbungen nur vereinzelt Entzündungszellen zu erkennen, sodass nicht von einer relevanten Entzündung ausgegangen werden konnte. Daher wurde entschieden, keine immunhistochemischen Färbungen zur Darstellung von Oberflächenantigenen von Entzündungszellen bei diesem Präparat durchzuführen. Bei den anderen Präparaten wurden u. a. Färbungen zur Hervorhebung von CD 68 durchgeführt. Histiozyten, häufig mit deutlichem Nucleoli, waren in allen 16 Präparaten im Implantatgewebe (s. Abbildungen 3.11 A, B), meist ubiquitär, und allen 14 auswertbaren Präparaten in der Pseudointima zu sehen. Meist färbten viele Zellen in Implantatnähe (s. Abbildung 3.11 A). In 5 auswertbaren Präparaten färbten sehr viele Histiozyten an der Pseudoadventitia-zugewandten Implantatoberfläche positiv für CD 68. In 3 dieser 5 Präparate waren Histiozyten zusätzlich in der gesamten Pseudoadventitia zu sehen (s. Tabelle 3.4).

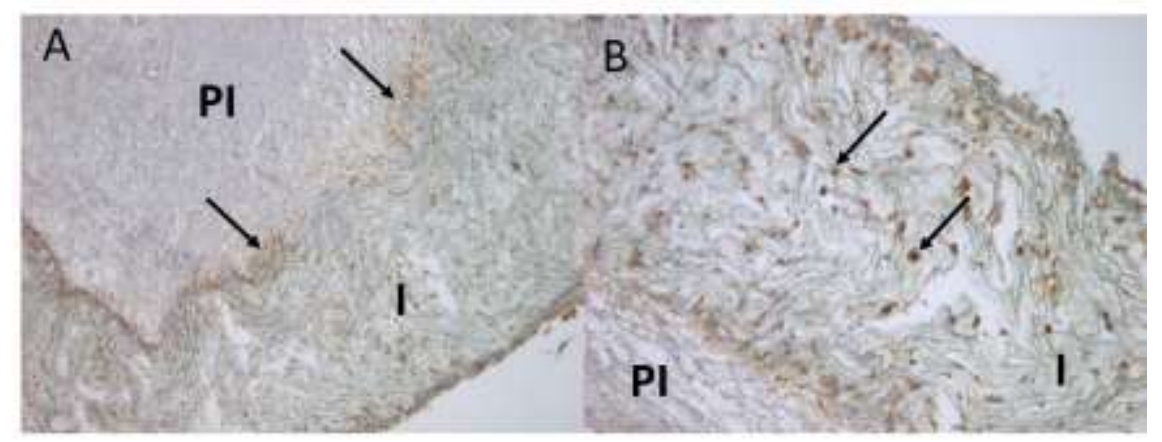

Abbildung 3.11: CD 68-Färbung; Präparat Nr. 4 A Übersicht; Histiozyten (Pfeile) vor allem am Übergang vom Pseudointima (PI)- zum Implantatgewebe (I) sowie im Implantatgewebe; Vergrößerung 100fach; B Ausschnitt aus A; Histiozyten im Implantatgewebe (Pfeile); Vergrößerung 200fach 
Mehrkernige FKR kamen in 9 von 16 Shunts, meist an der Pseudointima- und Pseudoadventitia-zugewandten Implantatoberfläche vor (s. Abbildungen 3.12 A, B, C, D), während an der Pseudoadventitia-zugewandten Implantatoberfläche die meisten FKR zu finden waren. Direkt im Implantatgewebe waren nur wenige Zellen zu sehen, meist in Pseudointima- oder Pseudoadventitianähe (s. Tabelle 3.4). In allen Präparaten hatten die FKR eine direkte örtliche Beziehung zum PTFE-Gewebe.

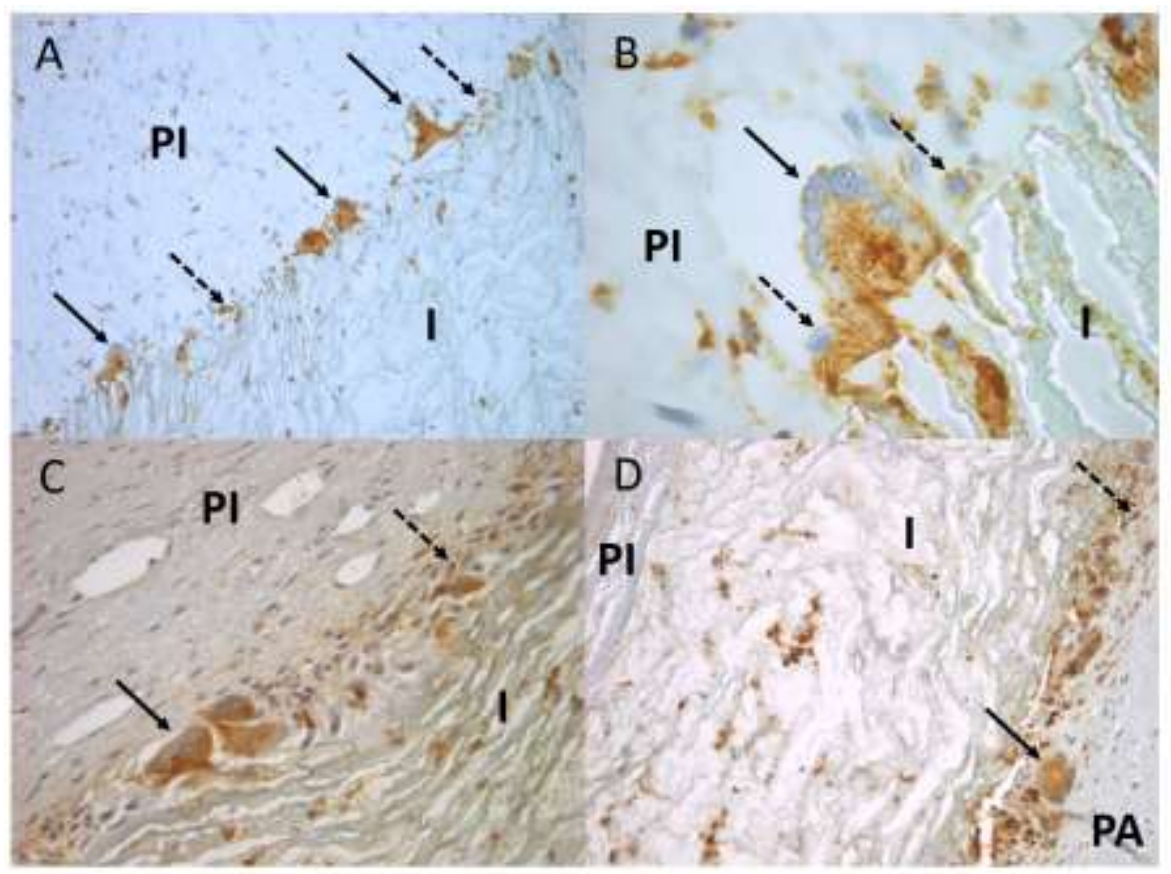

Abbildung 3.12: CD 68-Färbungen; A FKR (Pfeile) und Histiozyten (gestrichelte Pfeile) am Übergang vom Pseudointima (PI)- zum Implantatgewebe (I); Vergrößerung 200fach; Präparat Nr. 11; B Ausschnitt aus A; mehrkernige FKR (Pfeil) mit umliegenden Histiozyten (gestrichelte Pfeile); Vergrößerung 1000fach; Präparat Nr. 11; C FKR (Pfeil) und Histiozyten (gestrichelter Pfeil) am Übergang vom Pseudointima- zum Implantatgewebe; Vergrößerung 400fach; Präparat Nr. 4; D FKR (Pfeil) und Histiozyten (gestrichelter Pfeil) an der Shuntaußenseite am Übergang vom Implantat- zum Pseudoadventitiagewebe (PA); Vergrößerung 200fach; Präparat Nr. 6 


\begin{tabular}{|c|c|c|c|c|c|c|c|c|c|c|c|c|}
\hline \multirow{3}{*}{$\begin{array}{l}\# \\
1 \\
1\end{array}$} & \multicolumn{6}{|c|}{ CD 68 Histiozyten } & \multicolumn{6}{|c|}{ CD 68 FKR } \\
\hline & \multicolumn{2}{|c|}{ PI } & \multicolumn{2}{|c|}{ I } & \multicolumn{2}{|c|}{ PA } & \multicolumn{2}{|c|}{ PI } & \multicolumn{2}{|c|}{$\mathbf{I}$} & \multicolumn{2}{|c|}{ PA } \\
\hline & + & $\begin{array}{c}\text { I- } \\
\text { Nähe, } \\
\text { restl. } \\
\text { PI NB }\end{array}$ & ++ & $\begin{array}{c}* \\
\text { PI- } \\
\text { Nähe }\end{array}$ & NB & & - & & - & & NB & \\
\hline 2 & ++ & $\begin{array}{c}\text { I- } \\
\text { Nähe, } \\
\text { restl. } \\
\text { PI NB }\end{array}$ & ++ & $*$ & +++ & $\begin{array}{c}* \\
\text { I- } \\
\text { Nähe }\end{array}$ & - & & - & & ++ & $\mathrm{I}-\mathrm{OF}$ \\
\hline 3 & + & $\begin{array}{c}\text { I - } \\
\text { Nähe, } \\
\text { restl. } \\
\text { PI NB }\end{array}$ & ++ & * & NB & & - & & - & & NB & \\
\hline 4 & +++ & $\begin{array}{c}* \\
\mathrm{I}-\mathrm{O} \\
\end{array}$ & +++ & $*$ & +++ & $\mathrm{I}-\mathrm{OF}$ & + & $\mathrm{I}-\mathrm{OF}$ & - & & ++ & $\mathrm{I}-\mathrm{OF}$ \\
\hline 6 & ++ & $\begin{array}{c}\text { I- } \\
\text { Nähe, } \\
\text { restl. } \\
\text { PI NB }\end{array}$ & ++ & $*$ & +++ & $\begin{array}{c}* \\
\text { I- } \\
\text { Nähe }\end{array}$ & $(+)$ & $\mathrm{I}-\mathrm{OF}$ & $(+)$ & $\begin{array}{l}\text { PI-, } \\
\text { PA- } \\
\text { Nähe }\end{array}$ & +++ & $\mathrm{I}-\mathrm{OF}$ \\
\hline 7 & + & $*$ & ++ & $*$ & +++ & $\begin{array}{c}* \\
\text { I- } \\
\text { Nähe }\end{array}$ & - & & - & & ++ & $\mathrm{I}-\mathrm{OF}$ \\
\hline 10 & + & $\begin{array}{c}\text { I- } \\
\text { Nähe, } \\
\text { I-OF }\end{array}$ & ++ & $*$ & +++ & $\begin{array}{c}\text { I- } \\
\text { Nähe, } \\
\text { I-OF }\end{array}$ & - & & $(+)$ & $\begin{array}{l}\text { PI- } \\
\text { Nähe }\end{array}$ & +++ & I-OF \\
\hline 11 & +++ & $*$ & ++ & $*$ & NB & & ++ & $\mathrm{I}-\mathrm{OF}$ & $(+)$ & $\begin{array}{c}\text { PI- } \\
\text { Nähe } \\
\end{array}$ & $\mathrm{NB}$ & \\
\hline 12 & + & $\begin{array}{c}\text { I- } \\
\text { Nähe }\end{array}$ & +++ & $*$ & NB & & + & $\mathrm{I}-\mathrm{OF}$ & + & $\begin{array}{l}\text { PI-, } \\
\text { PA- } \\
\text { Nähe } \\
\end{array}$ & NB & \\
\hline 15 & + & $\begin{array}{c}\text { I- } \\
\text { Nähe }\end{array}$ & ++ & $*$ & NB & & - & & + & $*$ & NB & \\
\hline 16 & $(+)$ & $*$ & ++ & * & NB & & -- & & - & & NB & \\
\hline 17 & NB & & ++ & $*$ & NB & & NB & & - & & NB & \\
\hline 18 & +++ & $*$ & ++ & $*$ & NB & & - & & - & & $\mathrm{NB}$ & \\
\hline 19 & ++ & I-OF & + & $*$ & NB & & - & & - & & $\mathrm{NB}$ & \\
\hline 20 & $\begin{array}{l}++- \\
+++\end{array}$ & $\begin{array}{c}* \\
\text { I- } \\
\text { Nähe } \\
\end{array}$ & ++ & $*$ & NB & & + & $\mathrm{I}-\mathrm{OF}$ & $(+)$ & $\begin{array}{l}\text { PI- } \\
\text { Nähe }\end{array}$ & NB & \\
\hline 21 & NB & & + & $\begin{array}{l}\text { PI- } \\
\text { Nähe }\end{array}$ & NB & & NB & & - & & NB & \\
\hline
\end{tabular}

Tabelle 3.4: Ergebnisse der CD 68-Färbungen des Pseudointima-, Implantat-, Pseudoadventitiagewebes; ((+) vereinzelte Zellen, + wenige Zellen, ++ viele Zellen, +++ sehr viele Zellen, - keine Zellen, * ubiquitär vorhanden, \# Präparatnummer, I Implantat, NB nicht beurteilbar, OF Oberfläche, PA Pseudoadventitia, PI Pseudointima) 
CD 15-positive Granulozyten, die einen gelappten Zellkern aufwiesen, waren in 10 von 16 Präparaten vorhanden. 6 Präparate färbten negativ für CD 15, wobei nicht immer alle Präparatanteile auswertbar waren. In 3 Präparaten färbten nur Zellen der Pseudointima, in einem Präparat nur Zellen des Implantatgewebes und in 3 Präparaten nur Zellen der Pseudoadventitia für CD 15. In 2 Präparaten waren Granulozyten in Pseudointima- und Implantatgewebe zu sehen. In einem Präparat färbten in allen 3 Präparatabschnitten Zellen positiv für $\mathrm{CD}$ 15. Insgesamt waren in den positiv färbenden Präparaten nur wenige, vereinzelte Granulozyten zu finden; mit Ausnahme eines Präparates, bei dem gehäuft CD15-positive Zellen in der Pseudointima zu finden waren (s. Abbildung 3.13 und Tabelle 3.5).

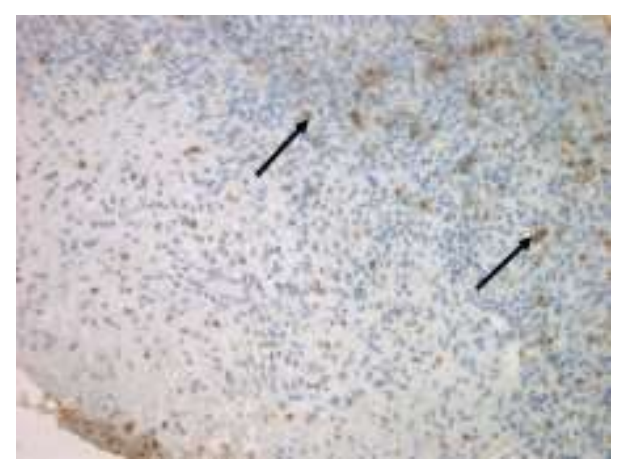

Abbildung 3.13: CD 15-Färbung; Darstellung von Granulozyten (Pfeile) im Pseudointimagewebe; Vergrößerung 200fach; Präparat Nr. 18 


\begin{tabular}{|c|c|c|c|c|c|c|}
\hline \multirow{3}{*}{$\begin{array}{l}\# \\
\# \\
1\end{array}$} & \multicolumn{6}{|c|}{ CD 15} \\
\hline & \multicolumn{2}{|c|}{ PI } & \multicolumn{2}{|c|}{ I } & \multicolumn{2}{|c|}{ PA } \\
\hline & - & & - & & - & $\begin{array}{c}\text { PA } \\
\text { unvollständig } \\
\text { abgebildet }\end{array}$ \\
\hline 2 & NB & & - & & $(+)$ & $*$ \\
\hline 3 & + & $*$ & - & & NB & \\
\hline 4 & - & & - & & - & $\begin{array}{c}\text { PA } \\
\text { unvollständig } \\
\text { abgebildet }\end{array}$ \\
\hline 6 & - & & - & & $(+)$ & * \\
\hline 7 & - & & - & & + & * \\
\hline 8 & NB & & - & & NB & \\
\hline 10 & $(+)$ & $*$ & $(+)$ & * & $(+)$ & * \\
\hline 11 & $(+)$ & $*$ & - & & NB & \\
\hline 12 & $(+)$ & I-Nähe & $(+)$ & $*$ & NB & \\
\hline 15 & - & & - & & NB & \\
\hline 16 & - & & $(+)$ & $*$ & NB & \\
\hline 18 & ++ & $*$ & - & & NB & \\
\hline 19 & - & & - & & NB & \\
\hline 20 & $(+)$ & I-Nähe & $(+)$ & & NB & \\
\hline 21 & NB & & - & & NB & \\
\hline
\end{tabular}

Tabelle 3.5: Ergebnisse der CD 15-Färbungen des Pseudointima-, Implantat-, Pseudoadventitiagewebes; ((+) vereinzelte Zellen, + wenige Zellen, ++ viele Zellen, +++ sehr viele Zellen, - keine Zellen, * ubiquitär vorhanden, \# Präparatnummer, I Implantat, NB nicht beurteilbar, PA Pseudoadventitia, PI Pseudointima) 
Außerdem wurde CD 3 auf T-Lymphozyten dargestellt (s. Abbildungen 3.14 A, B). In 12 von 16 Shunts waren T-Lymphozyten mit großem, rundlichem Zellkern zu sehen. In 4 Präparaten waren keine T-Lymphozyten vorhanden, wobei nicht immer alle Präparatabschnitte auswertbar waren. Die T-Lymphozyten wiesen folgendes Verteilungsmuster auf: in 4 Präparaten nur in der Pseudointima, in einem Präparat nur im Implantatgewebe, in 4 Präparaten nur in der Pseudoadventitia und in 3 Präparaten sowohl im Pseudointima- als auch Implantatgewebe (s. Tabelle 3.6). In Präparat Nr. 6 waren sie teilweise von Erythrozyten umgeben, sodass möglicherweise eine Einblutung vorlag.

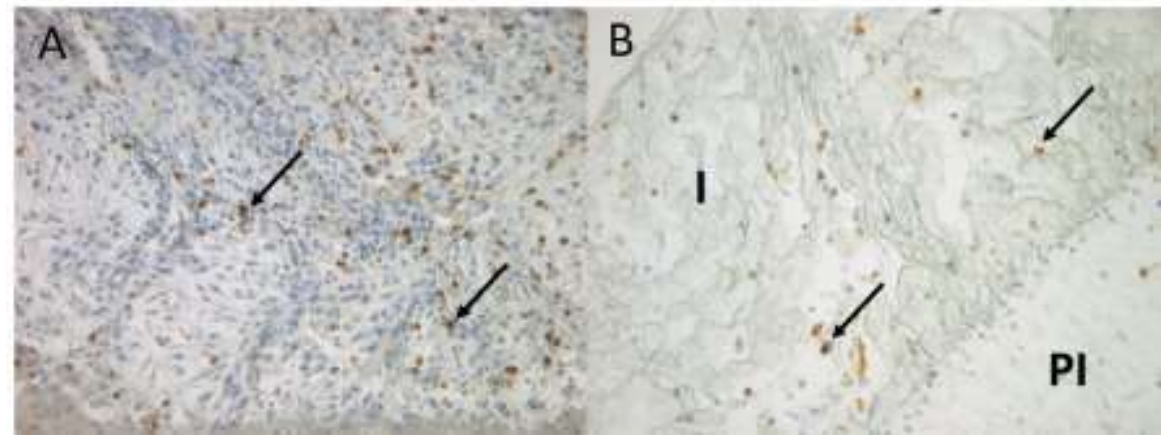

Abbildung 3.14: CD 3-Färbungen; A zahlreiche T-Lymphozyten (Pfeile) in Pseudointima; Vergrößerung 200fach; Präparat Nr. 18; B vereinzelte T-Lymphozyten im Implantatgewebe (I), Pseudointima (PI); Vergrößerung 200fach; Präparat Nr. 11

Ebenso wurde die Shuntgruppe auf das Vorliegen von CD 79 a-positiven Zellen untersucht. In 5 von 15 Präparaten waren diese Zellen mit großem, rundlich-ovalem Zellkern zu finden. In 10 Präparaten färbten keine Zellen für CD $79 \alpha$, allerdings waren nicht immer alle Präparatabschnitte auswertbar. In 3 der 5 Präparate, in denen BLymphozyten vorhanden waren, kamen diese nur in der Pseudointima und in 2 Präparaten nur in der Pseudoadventitia, jeweils in geringer Anzahl, vor. In Präparat Nr. 6 waren sie teilweise von Erythrozyten umgeben, sodass möglicherweise eine Einblutung vorlag. In keinem Shuntpräparat färbten Zellen im Implantatgewebe positiv für CD $79 \alpha$ (s. Tabelle 3.6). 


\begin{tabular}{|c|c|c|c|c|c|c|c|c|c|c|c|}
\hline \multirow{3}{*}{$\begin{array}{l}\# \\
1\end{array}$} & \multicolumn{6}{|c|}{ CD 3} & \multicolumn{5}{|c|}{ CD $79 \alpha$} \\
\hline & \multicolumn{2}{|c|}{ PI } & \multicolumn{2}{|c|}{ I } & \multicolumn{2}{|c|}{ PA } & \multicolumn{2}{|c|}{ PI } & $\mathbf{I}$ & \multicolumn{2}{|c|}{ PA } \\
\hline & - & & - & & ++ & $(\mathrm{NB})$ & - & & - & NB & \\
\hline 2 & NB & & - & & + & $\begin{array}{c}\text { I- } \\
\text { Nähe }\end{array}$ & NB & & - & - & \\
\hline 3 & - & & + & $*$ & NB & & - & & - & NB & \\
\hline 4 & $(+)$ & $\begin{array}{c}\text { I- } \\
\text { Nähe }\end{array}$ & - & & - & & & & & & \\
\hline 6 & - & & - & & $(+)$ & $\begin{array}{c}* * \\
\text { ERY }\end{array}$ & - & & - & $(+)$ & $\begin{array}{c}* \\
\text { ERY }\end{array}$ \\
\hline 7 & - & & - & & $(+)$ & $*$ & - & & - & $(+)$ & $*$ \\
\hline 8 & NB & & - & & NB & & NB & & - & NB & \\
\hline 10 & $(+)$ & $*$ & - & & - & & - & & - & - & \\
\hline 11 & + & * & ++ & $*$ & $\mathrm{NB}$ & & $(+)$ & $*$ & - & $\mathrm{NB}$ & \\
\hline 12 & + & $\begin{array}{c}\text { I- } \\
\text { Nähe }\end{array}$ & $(+)$ & $*$ & NB & & $(+)$ & $\begin{array}{c}\text { I- } \\
\text { Nähe }\end{array}$ & - & NB & \\
\hline 15 & - & & - & & NB & & - & & - & $\mathrm{NB}$ & \\
\hline 16 & - & & - & & $\mathrm{NB}$ & & - & & - & $\mathrm{NB}$ & \\
\hline 18 & +++ & $*$ & NB & & $\mathrm{NB}$ & & + & $*$ & - & $\mathrm{NB}$ & \\
\hline 19 & $(+)$ & $\begin{array}{c}\text { I- } \\
\text { Nähe }\end{array}$ & - & & NB & & - & & - & NB & \\
\hline 20 & + & $\begin{array}{c}\text { I- } \\
\text { Nähe }\end{array}$ & + & $*$ & NB & & - & & - & NB & \\
\hline 21 & NB & & - & & NB & & NB & & - & NB & \\
\hline
\end{tabular}

Tabelle 3.6: Ergebnisse der CD 3- und CD $79 \alpha$-Färbungen des Pseudointima-, Implantat-, Pseudoadventitiagewebes; $((+)$ vereinzelte Zellen, + wenige Zellen, ++ viele Zellen, +++ sehr viele Zellen, - keine Zellen, * ubiquitär vorhanden, \# Präparatnummer, ERY teilweise von Erythrozyten umgeben, I Implantat, PA Pseudoadventitia, NB nicht beurteilbar, (NB) Lage nicht beurteilbar, PI Pseudointima)

\section{Verkalkung}

Von 21 Präparaten färbte nur eines positiv für von Kossa: Präparat Nr. 5 mit der längsten Implantationszeit von 9 Jahren und 5 Monaten (s. Abbildungen 3.15 A, B, C, D). In den Präparaten Nr. 4, 19 und 20, je mit verhältnismäßig langen Implantationszeiten, kam kein Kalk zur Darstellung. Die durch die von Kossa-Färbung versilberten Kalkareale in Pseudointima- und Implantatgewebe stellten sich mikroskopisch als brüchige, schwarze Flächen unterschiedlichen Größenausmaßes mit unscharfer Begrenzung im Übergang zum umliegenden Gewebe dar. Im Implantatgewebe wurde ein großes $(\geq$ halbe Implan- 
tatmaterialbreite; Stelle 1) und ein größeres ( $\leq$ halbe Implantatmaterialbreite; Stelle 2$)$ Kalkaggregat gefunden. In der Pseudointima färbte ein weiteres großes, konfluierendes Kalkareal ( $\geq$ halbe Pseudointimabreite; Stelle 3) für von Kossa.

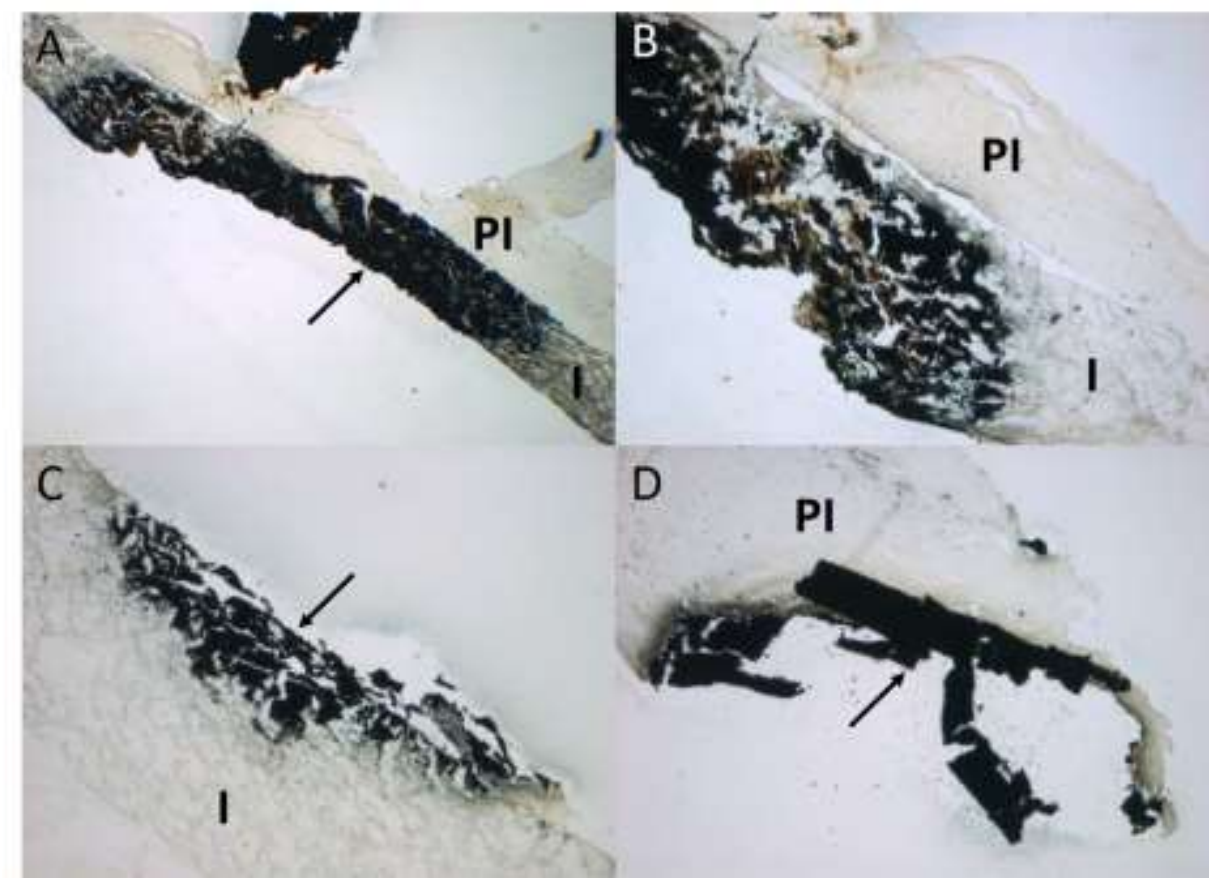

Abbildung 3.15: Von Kossa-Färbung; Kalkherde; Präparat Nr. 5; A Übersicht Stelle 1; Verkalkung (Pfeil) des Implantatgewebes (I), angrenzend Pseudointimagewebe (PI); Vergößerung 40fach; B Ausschnitt aus A; Vergrößerung 100fach; C Stelle 2; Verkalkung des Implantatgewebes (Pfeil); Vergrößerung 100fach; D Stelle 3; durch Präparation ausgebrochener Verkalkungsherd der Pseudointima (Pfeil); Vergrößerung 100fach

\subsubsection{Patches}

Es wurden insgesamt 13 PTFE-Patches untersucht.

\section{Endothelialisierung der Pseudointima}

Durch CD 31-Färbungen konnte in 12 von 13 Präparaten, durch vWF-Färbungen in 2 von

2 Präparaten eine Endothelialisierung dargestellt werden (s. Tabelle 3.7). Die Endothelzellen stellten sich als oberflächliche, blutzugewandte, einzellige Schicht der Pseudointima dar. Die ovalen bis rundlichen Zellkerne nahmen durch die HämalaunGegenfärbung eine bläuliche Farbe an (s. Abbildungen 3.16 A, B, C). 


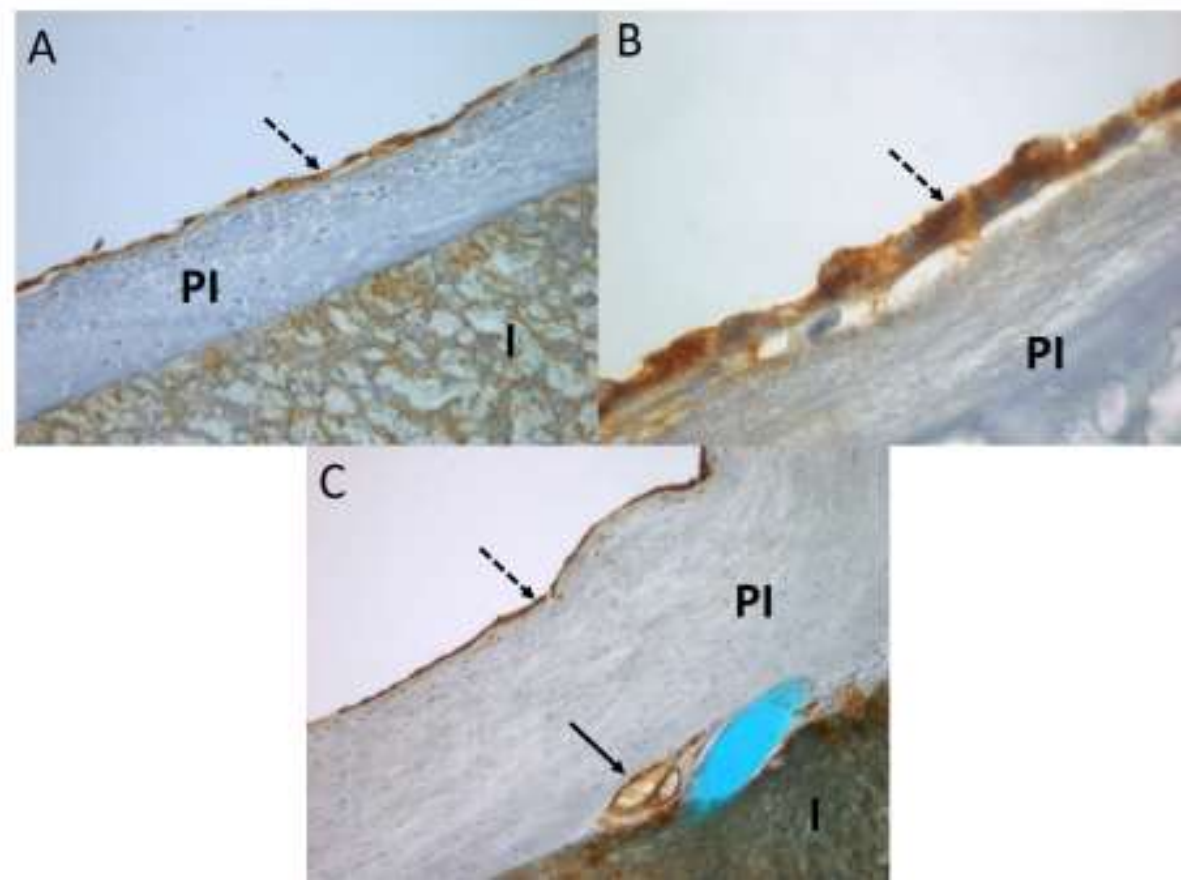

Abbildung 3.16: Endothelialisierung (gestrichelte Pfeile) der Pseudointima (PI) als blutzugewandte Zellschicht, Implantat (I); Präparat Nr. 28; A vWF-Färbung; Vergrößerung 200fach; B Ausschnitt aus A; perlschnurartige Aufreihung der Endothelzellen; Vergrößerung 1000fach; C CD 31-Färbung; Endothel-ausgekleideter Hohlraum in unterer Pseudointima (Pfeil) neben sich neonblau darstellendem Nahtmaterial; Vergrößerung 100fach

Die Endothelzellen färbten in 2 von 2 Präparaten auch positiv für Vimentin (s. Abbildung 3.17) und die subendotheliale EZM in 9 von 9 Präparaten für Kollagen IV (s. Abbildung 3.18 und Tabelle 3.7).

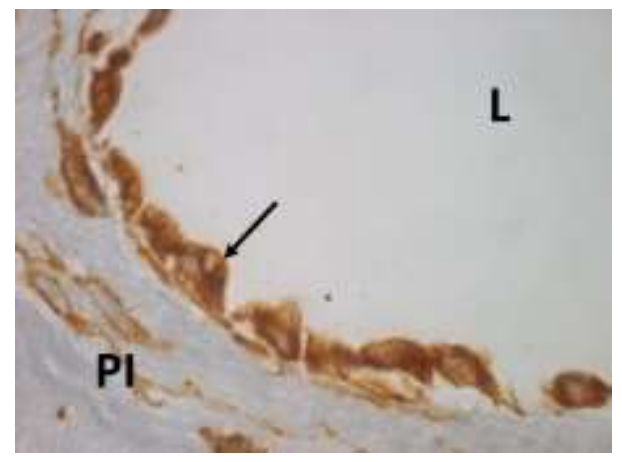

Abbildung 3.17: Vimentin-Färbung; Aufreihung von Endothelzellen (Pfeil), Pseudointima (PI), Lumen (L); Vergrößerung 1000fach; Präparat Nr. 28 


\begin{tabular}{|c|c|c|c|c|c|}
\hline$\#$ & $\mathbf{E}$ & vWF & CD 31 & Vimentin & Kollagen IV \\
\hline 22 & $\mathbf{J}$ & & + & & + \\
\hline 23 & $\mathbf{J}$ & & + & & \\
\hline 24 & $\mathbf{J}$ & & + & & \\
\hline 25 & $\mathbf{J}$ & & + & & + \\
\hline 26 & $\mathbf{J}$ & + & - & & \\
\hline 27 & $\mathbf{J}$ & & + & & + \\
\hline 28 & $\mathbf{J}$ & + & + & + & + \\
\hline 29 & $\mathbf{J}$ & & + & & + \\
\hline 30 & $\mathbf{J}$ & & + & & + \\
\hline 31 & $\mathbf{J}$ & & + & & + \\
\hline 32 & $\mathbf{J}$ & & + & & + \\
\hline 33 & $\mathbf{J}$ & & + & & \\
\hline 34 & $\mathbf{J}$ & & + & + & + \\
\hline
\end{tabular}

Tabelle 3.7: Endothelialisierung der Pseudointima; (+ positives Färbeergebnis, - negatives Färbeergebnis, \# Präparatnummer, J ja, E Endothelialisierung)

\section{Neovaskularisierung}

In der vWF-, CD 31- (s. Abbildung 3.16 C), Vimentin-, Kollagen IV-, SMA- (s. Abbildung 3.20 A) und SMM-Färbung stellte sich zudem die Zellauskleidung bzw. die EZM unterschiedlich geformter Hohlräume verschiedenen Kalibers, die meistens in der unteren, implantatnahen Pseudointima und im Implantatgewebe zu finden waren, dar. Das Kaliber dieser Hohlräume war im Pseudointimagewebe deutlich größer als im Implantatgewebe.

\section{Zellen und EZM des Pseudointima- und Implantatgewebes}

Unabhängig vom Implantationszeitraum war in allen 13 ausgewerteten Implantaten die Ausbildung einer endothelialisierten Pseudointima zu erkennen. Vimentin ließ sich nicht nur in Endothelzellen der Pseudointima, sondern auch in langgezogenen, spindelförmigen Zellen, die im gesamten Pseudointimagewebe in 3 von 3 Präparaten - Nr. 28, 29 und 34 zu finden waren, darstellen. Des Weiteren färbten in 9 von 9 Präparaten - Nr. 22, 25, 27 bis 32 und 34 - feine, langgezogene Fasern in der gesamten EZM der Pseudointima für Kollagen IV. Auffällig war, dass bei den Präparaten Nr. 27 bis 32 ein Kollagen IV-freier 
Abschnitt der Pseudointima in direkter Implantatnähe zu erkennen war (s. Abbildung $3.18)$.

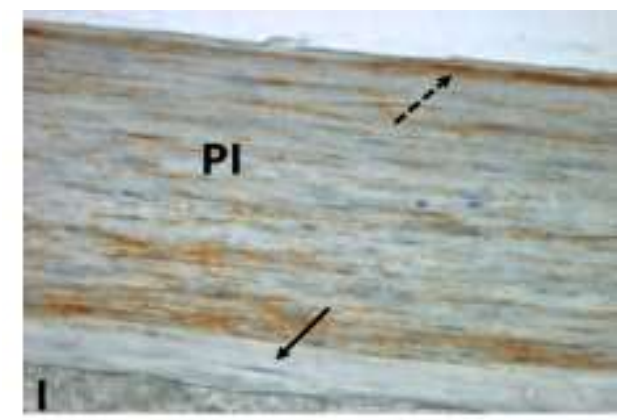

Abbildung 3.18: Kollagen IV-Färbung; Kollagen IV-Fasern im subendothelialen Gewebe (gestrichelter Pfeil) und in der EZM der Pseudointima (PI), Kollagen IV-freier Streifen (Pfeil) in Implantatnähe (I); Vergrößerung 100fach; Präparat Nr. 30

In allen 3 auswertbaren Präparaten färbten Zellen im Implantatgewebe positiv für Vimentin (s. Abbildung 3.19 A). Die EZM des Implantatgewebes färbte in 6 von 9 Präparaten stellenweise positiv für Kollagen IV (s. Abbildung 3.19 B und Tabelle 3.8).

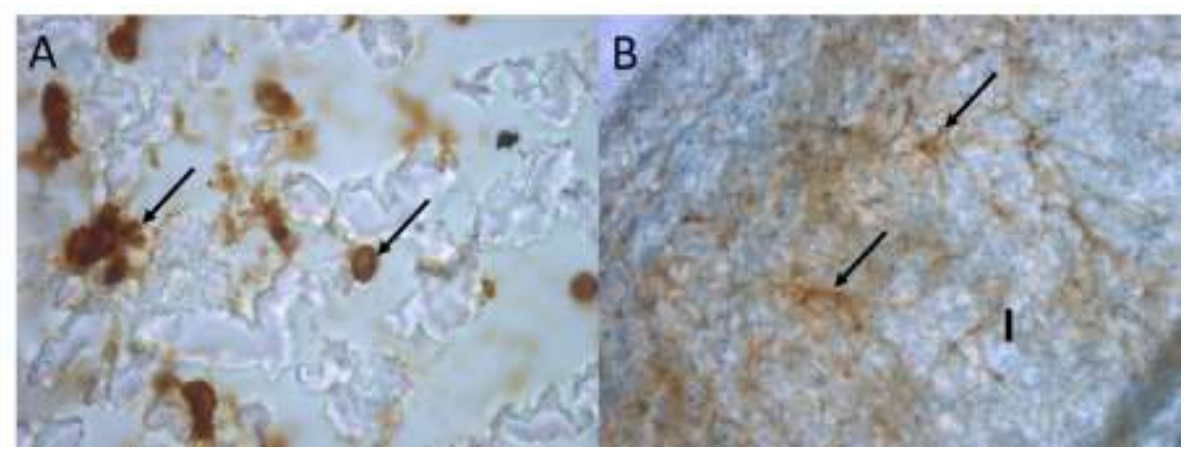

Abbildung 3.19: Präparat Nr. 28; A Vimentin-Färbung; Vimentin-positive Zellen im Implantatgewebe (Pfeile); Vergrößerung 1000fach; B Kollagen IV-Färbung; Kollagen-Fasern (Pfeile) in der EZM des Implantatgewebes (I); Vergrößerung 200fach 


\begin{tabular}{|c|c|c|c|c|}
\hline \# & \multicolumn{2}{|c|}{ Vimentin } & \multicolumn{2}{|c|}{ Kollagen IV } \\
\hline 22 & & & + & $*$ \\
\hline 25 & & & + & $*$ \\
\hline 27 & & & - & \\
\hline 28 & + & $\begin{array}{c}* \\
\text { PA-Nähe }\end{array}$ & + & $\begin{array}{c}* \\
\text { PA-Nähe }\end{array}$ \\
\hline 29 & + & $*$ & - & \\
\hline 30 & & & + & PA-Nähe \\
\hline 31 & & & + & $*$ \\
\hline 32 & & & + & $*$ \\
\hline 34 & + & $*$ & - & \\
\hline
\end{tabular}

Tabelle 3.8: Ergebnisse der Vimentin- und Kollagen IV-Färbungen des Implantatgewebes; (+ positives Färbeergebnis, - negatives Färbeergebnis, * ubiquitär vorhanden, \# Präparatnummer, I Implantat, P Präparat, PA Pseudoadventitia)

SMA kontraktiler Zellen konnten in allen 13 untersuchten Präparaten nachgewiesen werden (s. Tabelle 3.9). Die morphologische Untersuchung der Zellen und ihrer Anordnung zueinander ergab ein ähnliches Bild wie in der Shuntgruppe (s. Kapitel 3.1.1). Die SMA-positiven Zellen lagen in 12 Präparaten im lumenseitigen Teil der Pseudointima. Somit war in allen ausgewerteten Präparaten ein Abschnitt der Pseudointima zu sehen, der, wenn überhaupt, nur sehr wenige SMA-positive Zellen enthielt (s. Abbildung 3.20 A). Dieser Abschnitt befand sich immer in Implantatnähe und war von Präparat zu Präparat und auch innerhalb eines Präparates unterschiedlich breit. In Präparat Nr. 32 färbten stellenweise Zellen der gesamten Pseudointimabreite positiv für SMA, an anderen Stellen war eine lumenseitige Konzentration zu erkennen. SMM konnte in allen 9 untersuchten Präparaten nachgewiesen werden (s. Tabelle 3.9). Bei 7 war es ähnlich wie für die SMA-positiven Zellen beschrieben: Konzentration der Zellen eher im lumenseitigen Abschnitt der Pseudointima. In einem weiteren Präparat befanden sich SMM-positive Zellen in der kompletten Pseudointima (s. Abbildung 3.20 B). 


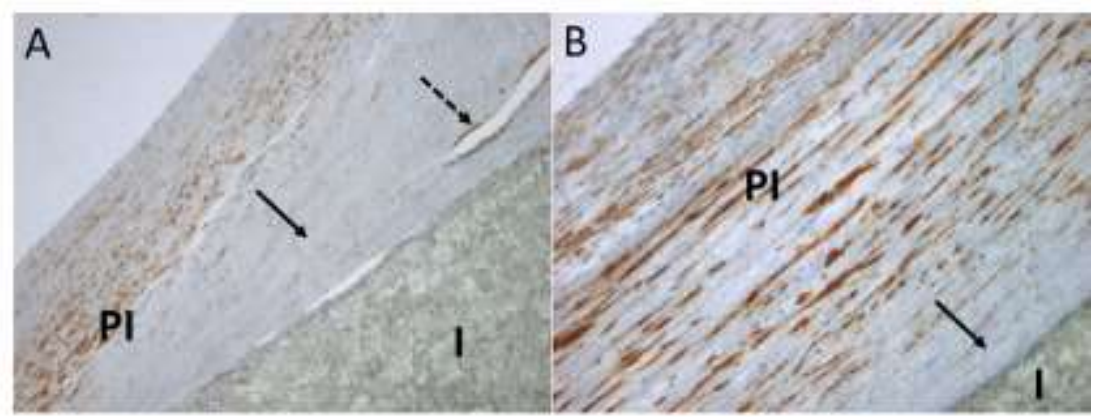

Abbildung 3.20: Kontraktile Zellen in der Pseudointima; A SMA-Färbung; Konzentration SMA-positiver Zellen im lumenseitigen Abschnitt der Pseudointima, freier, implantatnaher Streifen (Pfeil), kontraktile Zellen um Hohlraum (gestrichelter Pfeil), Pseudointima (PI), Implantat (I), Lumen (L); Vergrößerung 100fach; Präparat Nr. 24; B SMM-Färbung; freier Streifen ohne kontraktile Zellen in Implantatnähe (Pfeil); Vergrößerung 200fach; Präparat Nr. 30

\begin{tabular}{|c|c|c|c|c|}
\hline$\#$ & \multicolumn{2}{|c|}{ SMA } & \multicolumn{2}{c|}{ SMM } \\
\hline $\mathbf{2 2}$ & + & $\mathrm{L}$ & + & $\mathrm{L}$ \\
\hline $\mathbf{2 3}$ & + & $\mathrm{L}$ & & \\
\hline $\mathbf{2 4}$ & + & $\mathrm{L}$ & + & \\
\hline $\mathbf{2 5}$ & + & $\mathrm{L}$ & + & $\mathrm{L}$ \\
\hline $\mathbf{2 6}$ & + & $\mathrm{L}$ & + & $\mathrm{NB}$ \\
\hline $\mathbf{2 7}$ & + & $\mathrm{L}$ & + & $\mathrm{L}$ \\
\hline $\mathbf{2 8}$ & + & $\mathrm{L}$ & + & $\mathrm{L}$ \\
\hline $\mathbf{2 9}$ & + & $\mathrm{L}$ & + & $\mathrm{L}$ \\
\hline $\mathbf{3 0}$ & + & $\mathrm{L}$ & + & $*$ \\
\hline $\mathbf{3 1}$ & + & $\mathrm{L}$ & + & $\mathrm{L}$ \\
\hline $\mathbf{3 2}$ & + & $*$ & + & $\mathrm{L}$ \\
\hline $\mathbf{3 3}$ & + & $\mathrm{L}$ & & \\
\hline $\mathbf{3 4}$ & + & $\mathrm{L}$ & & + \\
\hline
\end{tabular}

Tabelle 3.9: Kontraktile Zellen in der Pseudointima; (+ vorhanden, * ubiquitär vorhanden, \# Präparatnummer, L lumenseitige Konzentration, NB Lage nicht beurteilbar)

Im Implantatgewebe von 4 aus 13 PTFE-Patches kamen kontraktile Zellen spärlich vor. Ein besonderer örtlicher Bezug zur angrenzenden Pseudointima oder Pseudoadventitia ließ sich nicht feststellen. In den Präparaten Nr. 26 und 31 wurden nur SMA-positive Zellen gefunden (s. Abbildung 3.21), SMM ließ sich hier nicht nachweisen. In den Präparaten Nr. 23 und 24 wurde nur eine - positive - SMA-Färbung durchgeführt. 
Sowohl in den SMA- als auch in den SMM-Färbungen stellten sich die kontraktilen Zellen mit im PTFE-Gewebe verzweigten Zellausläufern dar. In den Präparaten Nr. 22, 25, 27 bis 30 und Nr. 32 bis 34 ließen sich weder SMA- noch SMM-positive Zellen nachweisen.

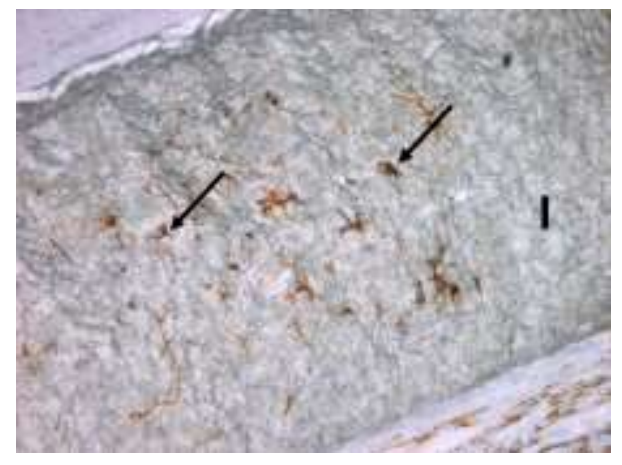

Abbildung 3.21: SMA-Färbung; kontraktile Zellen (Pfeile) im Implantatgewebe (I); Vergrößerung 100fach; Präparat Nr. 31

\section{Entzündungszellen}

Es wurden 11 PTFE-Patches auf Entzündungszellen untersucht. Alle wiesen in unterschiedlichem Ausmaß CD 68-positive Histiozyten in Pseudointima- und Implantatgewebe auf (s. Abbildung 3.22 A und Tabelle 3.10). Meistens befanden sich die Histiozyten über das gesamte Pseudointima- und Implantatgewebe verteilt. In manchen Präparaten war im Implantatgewebe zusätzlich ein größeres Aufkommen in Pseudointima- und/oder Pseudoadventitianähe zu sehen. In 4 Präparaten waren Histiozyten zusätzlich in unterschiedlichem Ausmaß an der Pseudoadventitiazugewandten Implantatoberfläche zu erkennen. In Präparat Nr. 31 war ein Defekt des Implantatgewebes, ausgekleidet mit 68-positiven Zellen, zu erkennen (s. Abbildung 3.22 B). In 3 der 11 Patches kamen jeweils wenige CD 68-positive, mehrkernige FKR auf der Pseudointima-zugewandten, in 4 anderen auf der Pseudoadventitia-zugewandten Implantatoberfläche vor (s. Tabelle 3.10). Lediglich Präparat Nr. 31 wies auf seiner Pseudoadventitia-zugewandten Implantataußenseite ein hohes Aufkommen an FKR auf (s. Abbildung 3.22 B). 


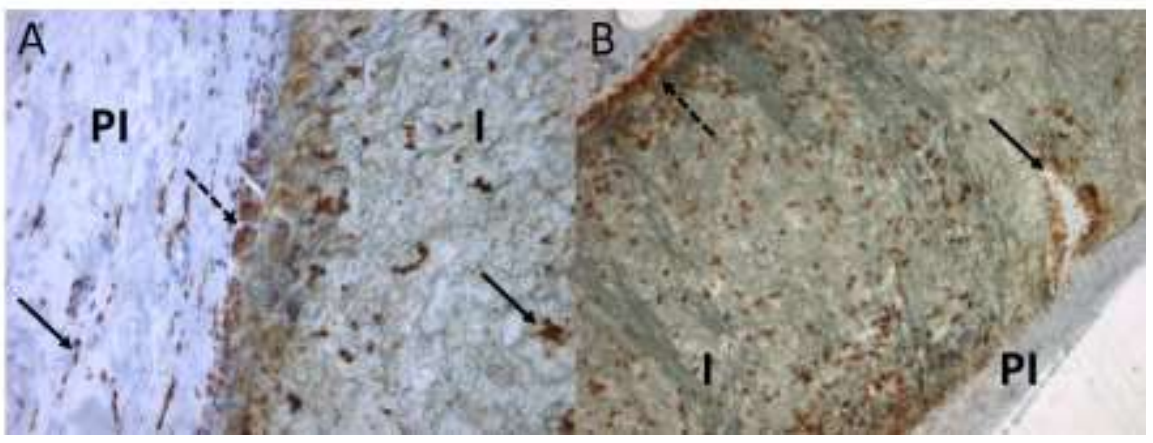

Abbildung 3.22: CD 68-Färbungen; A Histiozyten (Pfeile) in Pseudointima (PI) und Implantat (I), FKR (gestrichelter Pfeil) an der Implantatoberfläche; Vergrößerung 200fach; Präparat Nr. 29; B hohes Aufkommen von Histiozyten und FKR an Pseudoadventitia-zugewandter Implantataußenseite (gestrichelter Pfeil), Defekt des Implantatgewebes ausgekleidet mit 68pos. Zellen (Pfeil); Vergrößerung 100fach; Präparat Nr. 31

\begin{tabular}{|c|c|c|c|c|c|c|c|c|c|c|c|}
\hline \multirow{3}{*}{$\begin{array}{c}\# \\
22\end{array}$} & \multicolumn{6}{|c|}{ CD 68 Histiozyten } & \multicolumn{5}{|c|}{ CD 68 FKR } \\
\hline & \multicolumn{2}{|c|}{ PI } & \multicolumn{2}{|c|}{$\mathbf{I}$} & \multicolumn{2}{|c|}{ PA } & \multicolumn{2}{|c|}{ PI } & $\mathbf{I}$ & \multicolumn{2}{|c|}{ PA } \\
\hline & +++ & $*$ & + & $\begin{array}{c}* \text { PI- } \\
\text { PA- } \\
\text { Nähe }\end{array}$ & - & & + & $\mathrm{I}-\mathrm{OF}$ & - & - & \\
\hline 25 & $(+)$ & $*$ & + & $*$ & - & & - & & - & - & \\
\hline 26 & $(+)$ & $*$ & + & $*$ & + & $\mathrm{I}-\mathrm{OF}$ & - & & - & $(+)$ & $\mathrm{I}-\mathrm{OF}$ \\
\hline 27 & + & $*$ & ++ & $\begin{array}{l}\text { * PA- } \\
\text { Nähe }\end{array}$ & - & & - & & - & - & \\
\hline 28 & ++ & $*$ & $\begin{array}{l}++- \\
+++\end{array}$ & $*$ & - & & - & & - & - & \\
\hline 29 & ++ & $\begin{array}{c}\text { I- } \\
\text { Nähe }\end{array}$ & ++ & $\begin{array}{l}\text { PI-, } \\
\text { PA- } \\
\text { Nähe }\end{array}$ & - & & + & $\mathrm{I}-\mathrm{OF}$ & - & - & \\
\hline 30 & + & $*$ & + & * & ++ & $\mathrm{I}-\mathrm{OF}$ & - & & - & $(+)$ & $\mathrm{I}-\mathrm{OF}$ \\
\hline 31 & $\begin{array}{l}++- \\
+++\end{array}$ & $*$ & +-+++ & $\begin{array}{c}\text { * PI-, } \\
\text { PA- } \\
\text { Nähe }\end{array}$ & +++ & $\mathrm{I}-\mathrm{OF}$ & - & & - & +++ & $\mathrm{I}-\mathrm{OF}$ \\
\hline 32 & + & $*$ & ++ & $\begin{array}{l}\text { PA- } \\
\text { Nähe }\end{array}$ & ++ & $\mathrm{I}-\mathrm{OF}$ & - & & - & $(+)$ & $\mathrm{I}-\mathrm{OF}$ \\
\hline 33 & ++ & $*$ & + & $*$ & - & & - & & - & - & \\
\hline 34 & ++ & $*$ & ++ & * & - & & $(+)$ & $\mathrm{I}-\mathrm{OF}$ & - & - & \\
\hline
\end{tabular}

Tabelle 3.10: Ergebnisse der CD 68-Färbungen des Pseudointima-, Implantat-, Pseudoadventitiagewebes; ((+) vereinzelte Zellen, + wenige Zellen, ++ viele Zellen, +++ sehr viele Zellen, - keine Zellen, * ubiquitär vorhanden, \# Präparatnummer, I Implantat, OF Oberfläche, PA Pseudoadventitia, PI Pseudointima)

9 Patches wurden auf CD 15-positive Granulozyten untersucht. In 3 Präparaten konnten diese in kleiner Anzahl im Pseudointimagewebe nachgewiesen werden (s. Abbildung 3.23 A): In 2 Präparaten waren wenige, kleine Infiltrate, in dem anderen, über die 
Pseudointima verteilt, sehr vereinzelt Granulozyten $\mathrm{zu}$ sehen. In dem letztgenannten Präparat lagen sehr vereinzelt auch im Implantatgewebe sowie einige vereinzelt oder gruppiert liegende Granulozyten an der Pseudoadventitia-zugewandten Implantatseite vor. In einem weiteren Patch, in dem sonst in Pseudointima- oder Implantatgewebe keine CD 15-positiven Zellen gefunden wurden, färbten ebenfalls an der Pseudoadventitiazugewandten Implantatseite mehrere kleine Infiltrate positiv für CD 15. Ein anderer Patch wies ein größeres Granulozyteninfiltrat in der Pseudoadventitia auf, jedoch ohne direkten örtlichen Bezug zum Implantatgewebe (s. Abbildung 3.23 B und Tabelle 3.11).

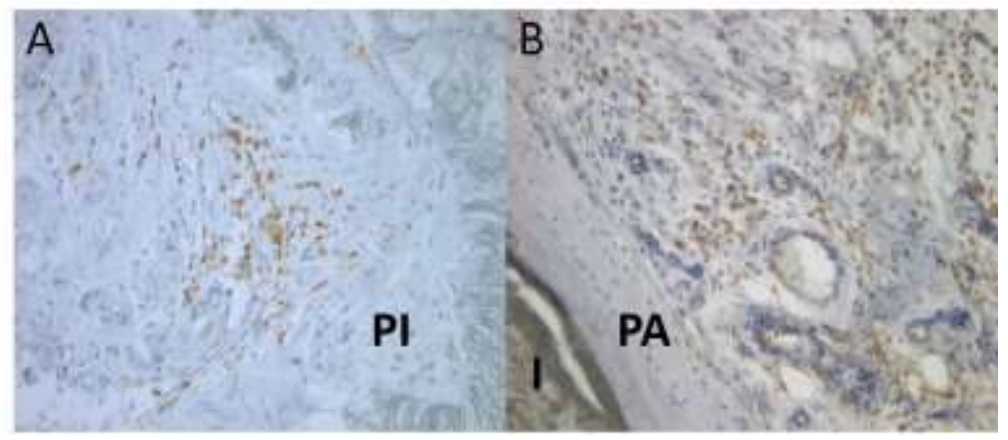

Abbildung 3.23: CD 15-Färbungen; A Granulozyteninfiltrat in Pseudointima (PI); Vergrößerung 200fach; Präparat Nr. 29; B Granulozyteninfiltrat in Pseudoadventitia (PA) gelegen, Implantat (I); Vergrößerung 200fach; Präparat Nr. 30

\begin{tabular}{|c|c|c|c|c|c|c|}
\hline \multirow{3}{*}{$\begin{array}{c}\# \\
26\end{array}$} & \multicolumn{6}{|c|}{ CD 15} \\
\hline & \multicolumn{2}{|c|}{ PI } & \multicolumn{2}{|c|}{ I } & \multicolumn{2}{|c|}{ PA } \\
\hline & - & & - & & ++ & $\mathrm{I}-\mathrm{OF}$ \\
\hline 27 & $(+)$ & I-Nähe & - & & - & \\
\hline 28 & $(+)$ & $*$ & $(+)$ & $*$ & + & $\mathrm{I}-\mathrm{OF}$ \\
\hline 29 & + & I-Nähe & - & & - & \\
\hline 30 & - & & - & & +++ & $*$ \\
\hline 31 & - & & - & & - & \\
\hline 32 & - & & - & & - & \\
\hline 33 & - & & - & & - & \\
\hline 34 & - & & - & & - & \\
\hline
\end{tabular}

Tabelle 3.11: Ergebnisse der CD 15-Färbungen des Pseudointima-, Implantat-, Pseudoadventitiagewebes; ((+) vereinzelte Zellen, + wenige Zellen, ++ viele Zellen, +++ sehr viele Zellen, - keine Zellen, * ubiquitär vorhanden, \# Präparatnummer, I Implantat, OF Oberfläche, PA Pseudoadventitia, PI Pseudointima)

Für CD 3 färbten T-Lymphozyten in 10 von 11 Präparaten (s. Tabelle 3.12). In einem 
Präparat waren sie mit ihrem im Verhältnis zum Plasma großen, rundlichen Zellkern im Pseudointima- und Implantatgewebe $\mathrm{zu}$ finden, in 2 anderen im Implantat- und Pseudoadventitiagewebe. In 7 Präparaten färbten sie in allen 3 Präparatabschnitten. Im Implantat- und Pseudoadventitiagewebe waren sie zahlreicher und häufiger zu finden als im Pseudointimagewebe. In der Mehrzahl der Fälle lagen sie im gesamten Implantatgewebe vor, wobei sie sich in manchen Präparaten zusätzlich oder lediglich im Pseudointima- oder Pseudoadventitia-zugewandten Implantatabschnitt befanden. Ebenso färbten T-Lymphozyten meistens im gesamten Pseudoadventitiagewebe positiv für CD 3, mit zusätzlicher Konzentration in Implantatnähe beziehungsweise an dessen Oberfläche. In den restlichen Präparaten wurden sie in der Pseudoadventitia ohne direkten örtlichen Bezug zum Implantatgewebe gefunden. Im Pseudointimagewebe war die Verteilung unterschiedlich (s. Tabelle 3.12). In den Präparaten Nr. 30 und Nr. 31 waren auch große Ansammlungen von Erythrozyten in der Pseudoadventitia zu sehen, sodass hier möglicherweise eine Einblutung vorlag.

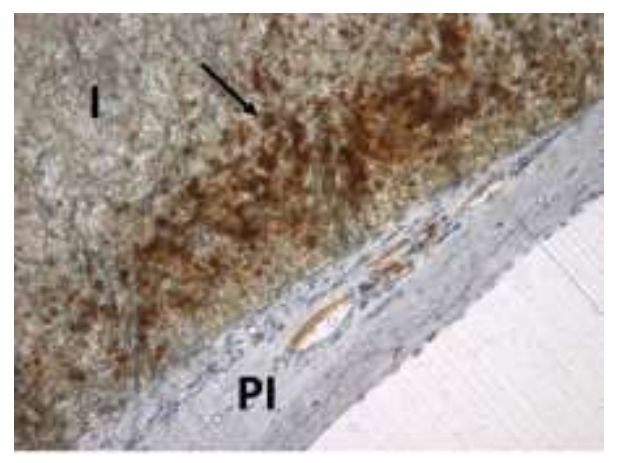

Abbildung 3.24: CD 3-Färbung; T-Lymphozyteninfiltrat (Pfeil) im Implantatgewebe (I), angrenzend Pseudointimagewebe (PI); Vergrößerung 200fach; Präparat Nr. 31

In 4 der 9 ausgewerteten Patches färbten B-Lymphozyten positiv für CD $79 \alpha$ : in einem Präparat nur in der Pseudointima in Implantatnähe, in einem weiteren Präparat nur im Implantatgewebe in Pseudointimanähe, in einem anderen nur im Pseudointimagewebe, ebenfalls in Implantatnähe, sowie zusätzlich im Pseudoadventitiagewebe. In einem Präparat färbten B-Lymphozyten, die von Erythrozyten umgeben waren, nur im Pseudoadventitiagewebe. Hierbei könnte es sich um eine Einblutung handeln. Insgesamt waren nur wenige B-Lymphozyten in den jeweiligen Präparatabschnitten zu sehen (s. Tabelle 3.12 und Abbildungen 3.25 A, B). 


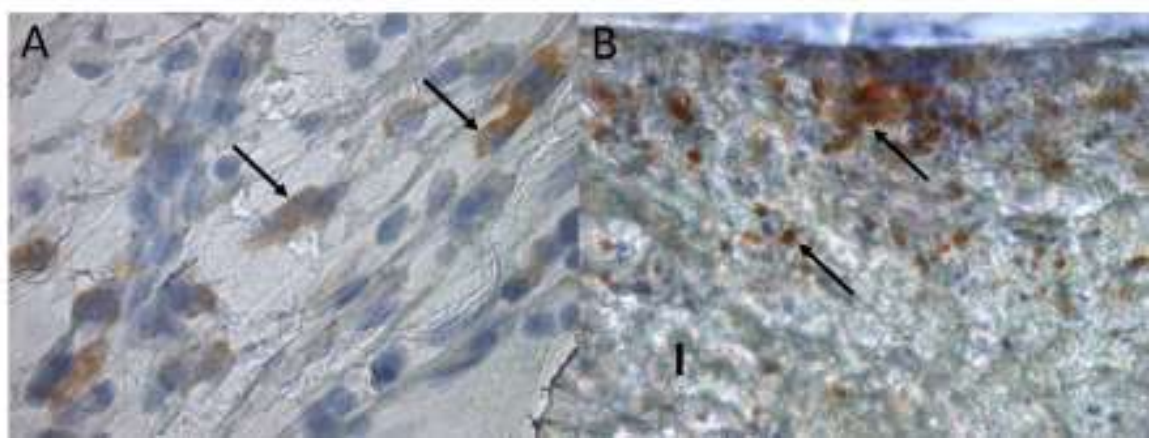

Abbildung 3.25: CD $79 \alpha$-Färbungen; A kleines Infiltrat von B-Lymphozyten (Pfeile) in der Pseudointima; Vergrößerung 1000fach; Präparat Nr. 22; B Infiltrat von B-Lymphozyten (Pfeile) im Implantatgewebe (I); Vergrößerung 400fach; Präparat Nr. 34

\begin{tabular}{|c|c|c|c|c|c|c|c|c|c|c|c|c|}
\hline \multirow{3}{*}{$\begin{array}{c}\# \\
22\end{array}$} & \multicolumn{6}{|c|}{ CD 3} & \multicolumn{6}{|c|}{$\operatorname{CD} 79 \alpha$} \\
\hline & \multicolumn{2}{|c|}{ PI } & \multicolumn{2}{|c|}{ I } & \multicolumn{2}{|c|}{ PA } & \multicolumn{2}{|c|}{ PI } & \multicolumn{2}{|c|}{ I } & \multicolumn{2}{|c|}{ PA } \\
\hline & + & $*$ & $(+)^{*}$ & $*$ & + & $\begin{array}{c}\text { I- } \\
\text { Nähe }\end{array}$ & $(+)$ & $\begin{array}{c}\text { I- } \\
\text { Nähe }\end{array}$ & - & & - & \\
\hline 25 & - & & + & $\begin{array}{l}\text { PI-, } \\
\text { PA- } \\
\text { Nähe }\end{array}$ & + & $*$ & - & & - & & - & \\
\hline 26 & - & & ++ & $*$ & ++ & $\begin{array}{c}* \\
\mathrm{I}-\mathrm{OF}\end{array}$ & - & & - & & - & \\
\hline 27 & + & $\begin{array}{c}\text { I- } \\
\text { Nähe }\end{array}$ & ++ & $*$ & + & $*$ & & & & & & \\
\hline 28 & + & $*$ & + & $*$ & $(+)$ & $*$ & - & & - & & NB & \\
\hline 29 & + & $(\mathrm{NB})$ & $(+)$ & $(\mathrm{NB})$ & NB & & - & & - & & - & \\
\hline 30 & $(+)$ & $\mathrm{L}$ & + & $*$ & ++ & $\begin{array}{c}* \\
\text { ERY }\end{array}$ & - & & - & & + & ERY \\
\hline 31 & $(+)$ & $\begin{array}{c}\text { I- } \\
\text { Nähe }\end{array}$ & ++ & $\begin{array}{c}* \\
\text { PI- } \\
\text { Nähe }\end{array}$ & ++ & $\begin{array}{c}* \\
\text { I-OF } \\
\text { ERY }\end{array}$ & - & & - & & - & \\
\hline 32 & $(+)$ & $\mathrm{L}$ & + & $\begin{array}{l}\text { PA- } \\
\text { Nähe }\end{array}$ & $(+)$ & $*$ & $(+)$ & $\begin{array}{c}\text { I- } \\
\text { Nähe }\end{array}$ & - & & $(+)$ & $*$ \\
\hline 33 & - & & - & & - & & & & & & & \\
\hline 34 & + & $*$ & + & $*$ & $(+)$ & $*$ & - & & + & $\begin{array}{c}\text { PI- } \\
\text { Nähe }\end{array}$ & - & \\
\hline
\end{tabular}

Tabelle 3.12: Ergebnisse der CD 3- und CD $79 \alpha$-Färbungen des Pseudointima-, Implantat-, Pseudoadventitiagewebes; ((+) vereinzelte Zellen, + wenige Zellen, ++ viele Zellen, +++ sehr viele Zellen, - keine Zellen, * ubiquitär vorhanden, \# Präparatnummer, ERY von Erythrozyten umgeben, I Implantat, L lumenseitig, NB nicht beurteilbar, (NB) Lage nicht beurteilbar, OF Oberfläche, P Präparat, PA Pseudoadventitia, PI Pseudointima) 


\section{Verkalkung}

In allen 12 Präparaten färbten Kalkareale für von Kossa (s. Abbildungen 3.26 A, B, C, D und Tabelle 3.13). In fast allen Patches waren im Pseudointima-, Implantat- und Pseudoadventitiagewebe punktförmige Kalkeinschlüsse oder kleine Kalkaggregate vorhanden. In einigen Patches färbten zusätzlich größere Kalkaggregate im Pseudointima-, Implantat- oder Pseudoadventitiagewebe für von Kossa. In 7 Präparaten wurden große, konfluierende Kalkherde sowohl im Pseudointima- als auch Implantatgewebe gefunden, die häufig ineinander übergingen. In 2 dieser 7 Patches wies auch die Pseudoadventitia große, konfluierende Kalkherde auf. In einem anderen Präparat färbte nur in der Pseudointima ein großer, konfluierender Kalkherd.

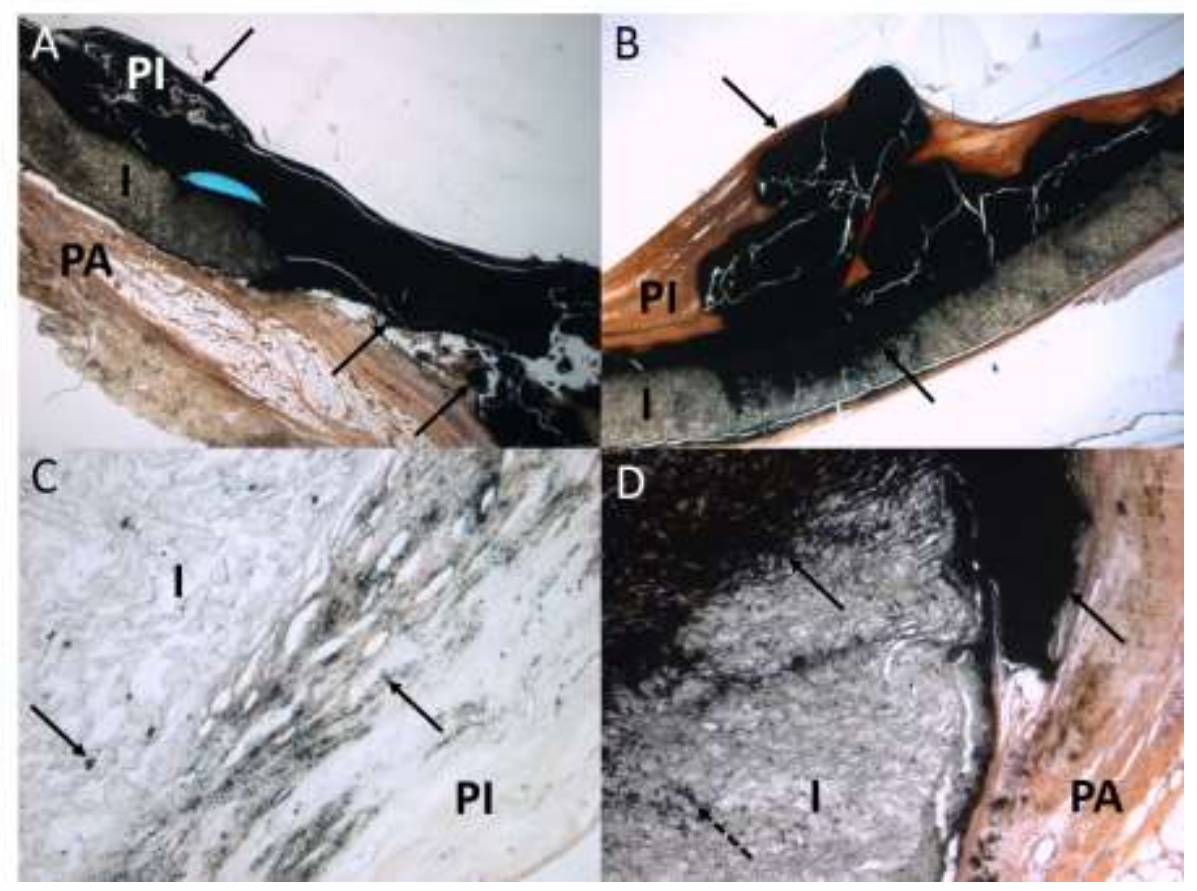

Abbildung 3.26: Von Kossa-Färbungen; A konfluierende Kalkherde (Pfeile) in Pseudointima (PI), Implantat (I) und Pseudoadventitia (PA); Vergrößerung 16fach; Präparat Nr. 25; B konfluierende Kalkherde (Pfeile) in Pseudointima und Implantat; Vergrößerung 16fach; Präparat Nr. 29; C punktförmige Kalkeinschlüsse in Pseudointima und Implantat; Vergrößerung 200fach; Präparat Nr. 28; D punktförmige Kalkeinschlüsse (gestrichelter Pfeil) und konfluierende Kalkherde (Pfeile) in Implantat und Pseudoadventitia; Vergrößerung 100fach; Präparat Nr. 25 


\begin{tabular}{|c|c|c|c|}
\hline \multirow{2}{*}{$\#$} & \multicolumn{3}{|c|}{ von Kossa-Färbung } \\
\cline { 2 - 4 } & PI & I & PA \\
\hline 22 & $+/++$ & $+/++/+++$ & +++++ \\
\hline 23 & $+/+++$ & $+/+++$ & $+/++/++$ \\
\hline 25 & $+/+++$ & $+/+++$ & + \\
\hline 26 & + & + & + \\
\hline 27 & + & ++ & + \\
\hline 28 & + & + & $+/++$ \\
\hline 29 & $+/+/+++$ & $+/+++$ & + \\
\hline 30 & + & $+/++$ & + \\
\hline 31 & $+/+++$ & + & + \\
\hline 32 & $+/+++$ & $+/+++$ & + \\
\hline 33 & $+/+++$ & $+/+++$ & + \\
\hline 34 & +++ & $+++/+++$ & \\
\hline
\end{tabular}

Tabelle 3.13: Verkalkung des Pseudointima-, Implantat-, Pseudoadventitiagewebes; (+ punktförmige Kalkeinschlüsse/kleine Kalkaggregate, ++ größere Kalkaggregate $(\leq$ halbe Pseudointimabzw. Implantatbreite des jeweiligen Präparates), +++ große, konfluierende Kalkherde $(\geq$ Pseudointima- bzw. Implantatbreite des jeweiligen Präparates), Beurteilung der Pseudoadventitia anhand jeweiliger Implantatbreite, da unvollständig abgebildet, \# Präparatnummer, I Implantat, PA Pseudoadventitia, PI Pseudointima)

\subsubsection{Okkluder}

Es wurden insgesamt 3 PTFE-Okkluder untersucht.

\section{Endothelialisierung der Pseudointima}

Bei allen Präparaten der Gruppe lag die Ausbildung einer endothelialisierten Pseudointima vor. In Präparat Nr. 39 färbten die obersten Zellschichten beider Lumenund Septum-zugewandter Pseudointimae positiv für CD 31 (s. Abbildung 3.27 B). In Präparat Nr. 40 färbten die obersten Zellschichten beider Lumen-zugewandter Pseudointimae und einer Septum-zugewandten Pseudointima für vWF (s. Abbildung 3.27 A) und CD 31. Bei Präparat Nr. 41 war nur der Okkluderteil einer Vorhofseite abgebildet, dessen oberste, lumenseitige Zellschicht positiv für CD 31 färbte. Die Septumzugewandte Pseudointima war nicht auswertbar. 


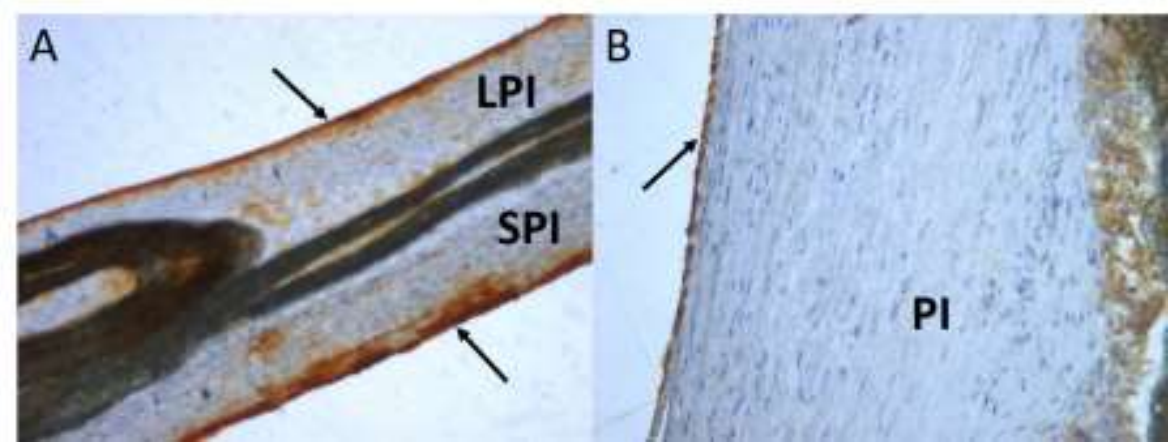

Abbildung 3.27: A VWF-Färbung; Endothelialisierung (Pfeile) der Septum (SPI)- und Lumen (LPI)zugewandten Pseudointima; Vergrößerung 100fach; Präparat Nr. 40; B CD 31-Färbung; Endothelialisierung (Pfeil) der lumenseitigen Pseudointima (PI); Vergrößerung 200fach; Präparat Nr. 39

\section{Neovaskularisierung}

In Präparat Nr. 39 färbte die Zellauskleidung von Hohlräumen, die vor allem im Okkluder-Steg auftraten, positiv für CD 31. In Präparat Nr. 40 färbte die Zellauskleidung von Hohlräumen in der Pseudointima, im lumenseitigen Implantatgewebe und im Okkluder-Steg zwischen links- und rechtsatrialem Okkluderteil für vWF und CD 31. Präparat Nr. 41 stellte nur den Okkluderteil einer Vorhofseite dar. Die Zellauskleidung von Hohlräumen in der Pseudointima färbte hier positiv für CD 31.

\section{Entzündungszellen}

In beiden untersuchten Okkludern waren Histiozyten und FKR vorhanden. In Präparat Nr. 39 färbten sehr viele Histiozyten und viele FKR an der gesamten Implantatoberfläche positiv für CD 68. Über die Lumen-zugewandte Pseudointima verteilt waren einige und in der Septum-zugewandten Pseudointima vermehrt Histiozyten zu erkennen. Besonders im Okkluder-Steg waren sie sehr zahlreich. Dagegen färbten direkt im Implantatgewebe sowohl in Präparat Nr. 39 als auch Nr. 40 nur sehr vereinzelt Histiozyten und keine FKR positiv für $\mathrm{CD}$ 68. In Präparat Nr. 40 lagen an der Lumen-zugewandten Implantatoberfläche nur vereinzelt Histiozyten und FKR vor, während an der Septumzugewandten ein etwas größeres Aufkommen zu erkennen war. Viele Histiozyten befanden sich über das gesamte Lumen- und Septum-zugewandte Pseudointimagewebe verteilt (s. Abbildung 3.28) sowie sehr viele im Bindegewebe des Okkluder-Stegs. Zwischen den verschiedenen Anteilen des PTFE-Gewebes war in beiden Okkludern vereinzelt lockeres Bindegewebe $\mathrm{zu}$ erkennen mit einigen darin oder an der Implantatoberfläche liegenden Histiozyten und wenigen FKR. 


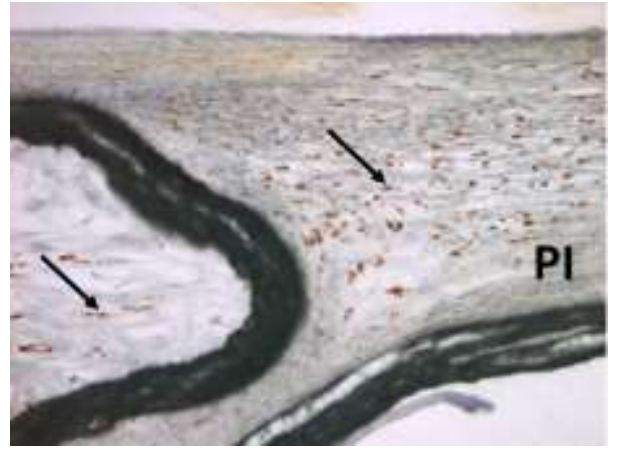

Abbildung 3.28: CD 68-Färbung; Histiozyten (Pfeile) in Pseudointima (PI) und lockerem Bindegewebe zwischen verschiedenen Anteilen des Implantatgewebes; Vergrößerung 100fach; Präparat Nr. 40

In Präparat Nr. 39 färbten nur vereinzelt Granulozyten der Septum-zugewandten Pseudointima positiv für CD 15. In Präparat Nr. 40 waren einige Granulozyten über das Pseudointimagewebe verteilt, aber vorwiegend in Lumennähe, zu erkennen. Zusätzlich färbten ein kleines Infiltrat zwischen den PTFE-Strängen und 2 kleine Infiltrate in der Septum-zugewandten Pseudointima in Implantatnähe für CD 15. Im Implantatgewebe waren keine Granulozyten zu sehen.

Wenige T-Lymphozyten färbten positiv für CD 3: in Präparat Nr. 39 in der Lumenzugewandten Pseudointima (die Septum-zugewandte Pseudointima war nicht darstellbar) in Lumen- und Implantatnähe und in Nr. 40 in der Lumen- und Septum-zugewandten Pseudointima in Implantatnähe. Direkt im Implantatgewebe waren keine T-Lymphozyten zu erkennen, während im Okkluder-Steg in Präparat Nr. 40 einige und in Präparat Nr. 39 sehr viele vorhanden waren. In Präparat Nr. 39 färbten vereinzelt T-Lymphozyten im wenigen, lockeren Bindegewebe zwischen den verschiedenen PTFE-Strängen.

In Präparat Nr. 39 färbten B-Lymphozyten sehr vereinzelt in der Lumen- und vermehrt in der Septum-zugewandten Pseudointima in Implantatnähe. Ein sehr großes Infiltrat war im Okkluder-Steg zu erkennen (s. Abbildung 3.29). Im Implantatgewebe sowie im wenigen, lockeren Bindegewebe zwischen den verschiedenen Anteilen des PTFE-Gewebes waren keine B-Lymphozyten vorhanden. In Präparat Nr. 40 färbten wenige Zellen der Septumzugewandten Pseudointima sowie dem lockeren Bindegewebe zwischen den verschiedenen Anteilen des PTFE-Gewebes positiv für CD 79. 


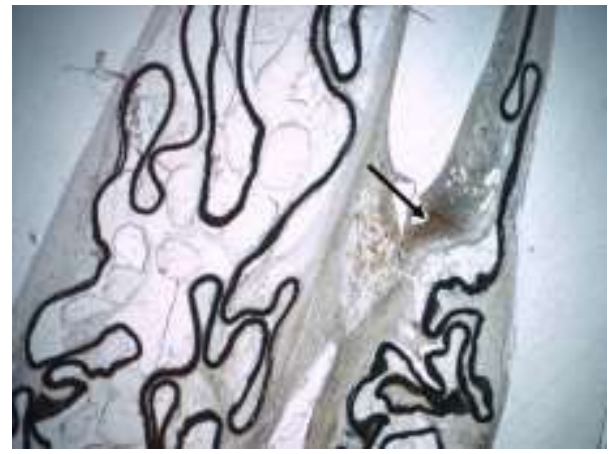

Abbildung 3.29: CD 79 $\alpha$-Färbung; großes B-Lymphozyteninfiltrat im Okkluder-Steg (Pfeil); Vergrößerung 16fach; Präparat Nr. 39

\section{Verkalkung}

Es färbten feine, punktförmige Kalkeinschlüsse sowohl in der Lumen- als auch Septumzugewandten Pseudointima von Präparat Nr. 39 für von Kossa. Über das gesamte Implantatgewebe verteilt waren kleine und größere Kalkaggregate festzustellen (s. Abbildung 3.30 A). In Präparat Nr. 40 war ein größeres Kalkaggregat in der Lumenzugewandten Pseudointima zu sehen, umgeben von feinen, punktförmigen Kalkeinschlüssen (s. Abbildung 3.30 B).

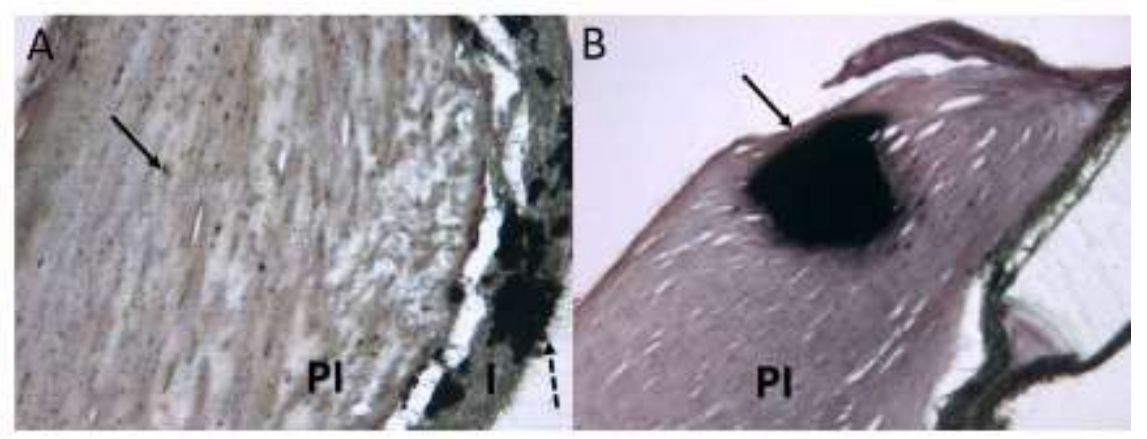

Abbildung 3.30: Von Kossa-Färbungen; A punktförmige Kalkeinschlüsse (Pfeil) in Pseudointima (PI) sowie kleine und größere Kalkaggregate (gestrichelter Pfeil) im Implantatgewebe (I); Vergrößerung 200fach; Präparat Nr. 39; B Kalkaggregat in Pseudointima (Pfeil) mit umliegenden, punktförmigen Kalkeinschlüssen; Vergrößerung 100fach; Präparat Nr. 40 


\subsection{Polyester-Implantate}

\subsubsection{Patches}

Es wurden insgesamt 4 Polyester-Patches untersucht.

\section{Endothelialisierung der Pseudointima}

In Präparat Nr. 38 färbte die oberste, lumenseitige Zellschicht der Pseudointima positiv für vWF (s. Abbildung 3.31), jedoch nicht für CD 31. In Präparat Nr. 37 färbte nur die Zellauskleidung von Hohlräumen in der Pseudointima positiv für CD 31, nicht aber die lumenseitige Zellschicht der Pseudointima.

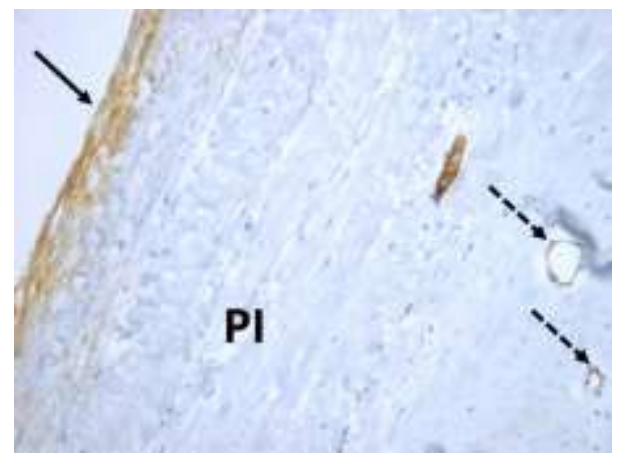

Abbildung 3.31: VWF-Färbung; Endothelialisierung (Pfeil) der Pseudointima (PI) und von Hohlräumen verschiedenen Kalibers (gestrichelte Pfeile); Vergrößerung 200fach; Präparat Nr. 38

In Präparat Nr. 37 färbte aber das direkt unterhalb der lumenseitigen Zellschicht der Pseudointima gelegene Gewebe positiv für Kollagen IV (s. Abbildung 3.32).

\section{Neovaskularisierung}

In Präparat Nr. 37 färbte die Zellauskleidung bzw. die EZM von zumeist im implantatnahen Abschnitt der Pseudointima gelegenen Hohlräumen verschiedenen Kalibers positiv für CD 31, SMA, SMM und Kollagen IV. Die Kollagenfasern stellten sich als feine, langgezogene Fasern, gelegen um eben genannte Hohlräume, dar, wobei die Zellkerne der den Hohlraum auskleidenden Zellen ausgespart blieben (s. Abbildung 3.32). In Präparat Nr. 38 färbte die Zellauskleidung unterschiedlich geformter Hohlräume, die meist im mittleren sowie Implantat-zugewandten Abschnitt der Pseudointima zu finden waren, positiv für vWF (s. Abbildung 3.31), SMA (s. Abbildungen 3.34 B, D) und SMM (s. Abbildung 3.34 C), jedoch nicht für CD 31. In diesem Präparat war das Lumen der Hohlräume größer als in Präparat Nr. 37 und auch verstärkt von für SMA und SMM positiv färbenden Zellen umgeben. 
In Präparat Nr. 38 befanden sich auch im Implantatgewebe kleine Hohlräume, die ebenfalls von für SMA (s. Abbildung 3.35 B) und SMM positiv färbenden Zellen umgeben waren. In Präparat Nr. 36 färbten kleinlumige Hohlräume umgebende Zellen des Implantatgewebes positiv für SMA.

\section{Zellen und EZM des Pseudointima- und Implantatgewebes}

In allen Präparaten der Gruppe war eine Pseudointima ausgebildet. In der Kollagen IVFärbung kamen in Präparat Nr. 37 feine, langgezogene Fasern in der Pseudointima zur Darstellung (s. Abbildung 3.32).

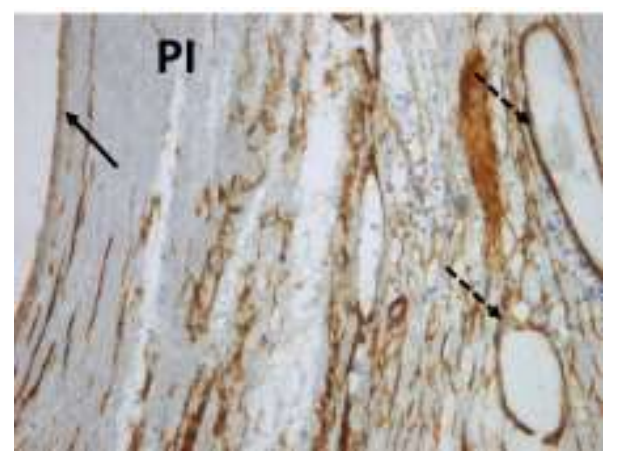

Abbildung 3.32: Kollagen IV-Färbung; Darstellung von Kollagenfasern in der Pseudointima (PI), im Gewebe um Hohlräume (gestrichelte Pfeile) und unterhalb der lumenseitigen Zellschicht der Pseudointima (Pfeil); Vergrößerung 200fach; Präparat Nr. 37

Auf der Pseudointima- und Pseudoadventitia-zugewandten Implantatoberfläche von Präparat Nr. 37 färbten dicht beieinander liegende, feine Fasern stellenweise positiv für Kollagen IV (s. Abbildung 3.33). Sehr vereinzelt färbten auch feine Fasern zwischen den Polyesterfäden.

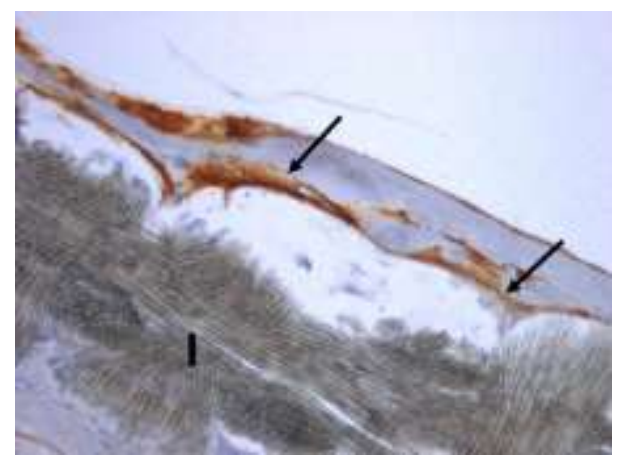

Abbildung 3.33: Kollagen IV-Färbung; Kollagenfasern an Implantatoberfläche (Pfeile), Implantat (I); Vergrößerung 100fach; Präparat Nr. 37

In den beiden untersuchten Präparaten Nr. 37 und 38 färbten Zellen in der Pseudointima positiv für SMA und SMM. Die morphologische Untersuchung dieser Zellen und ihrer 
Anordnung zueinander ergab ein ähnliches Bild wie das der PTFE-Shuntgruppe (s. Kapitel 3.1.1). Die Verteilung kontraktiler Zellen war in beiden Präparaten ähnlich: Es färbten vor allem Zellen im lumenseitigen und implantatnahen Abschnitt der Pseudointima (s. Abbildungen 3.34 A, B, C). Allerdings waren in Implantatnähe mehr SMA- als SMM-positive Zellen zu sehen. Im mittleren Pseudointima-Abschnitt kamen kontraktile Zellen sehr vereinzelt vor.

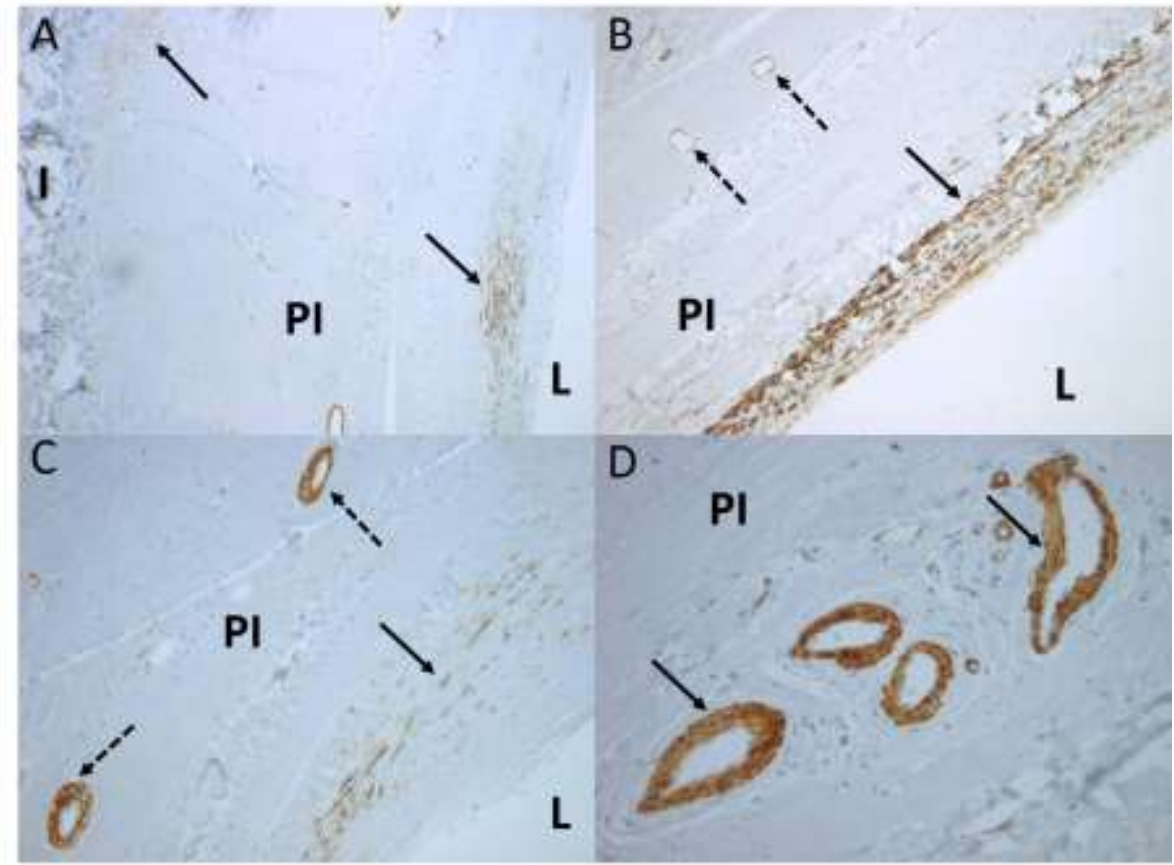

Abbildung 3.34: Präparat Nr. 38; A SMA-Färbung; Übersicht, kontraktile Zellen (Pfeile) im lumenseitigen und implantatnahen Pseudointima (PI)-Abschnitt, Implantat (I), Lumen (L);Vergrößerung 40fach; B SMA-Färbung; kontraktile Zellen lumennah (Pfeil) und um Hohlräume in der Pseudointima (gestrichelte Pfeile); Vergrößerung 100fach; C SMM-Färbung; kontraktile Zellen lumennah (Pfeil) und um Hohlräume in der Pseudointima (gestrichelte Pfeile); Vergrößerung 100fach; D SMA-positive Zellen (Pfeile) um Hohlräume im mittleren Pseudointimadrittel; Vergrößerung 200fach

Bei 3 Präparaten wurde das Implantatgewebe auf das Vorkommen kontraktiler Zellen untersucht. In Präparat Nr. 37 und 38 färbten Zellen auf der Pseudointima- und Pseudoadventitia-zugewandten Implantatoberfläche positiv für SMA und SMM. Jedoch befanden sich dort mehr für SMA als für SMM färbende Zellen. In Präparat Nr. 37 färbten im Implantatgewebe entlang der Polyesterfäden Zellen positiv für SMA (s. Abbildung 3.35 A), nicht aber für SMM. In Präparat Nr. 38 waren hier sowohl für SMA als auch SMM positiv färbende Zellen zu sehen. In Präparat Nr. 36 färbten einzelne Zellen des Implantatgewebes positiv für SMA. 


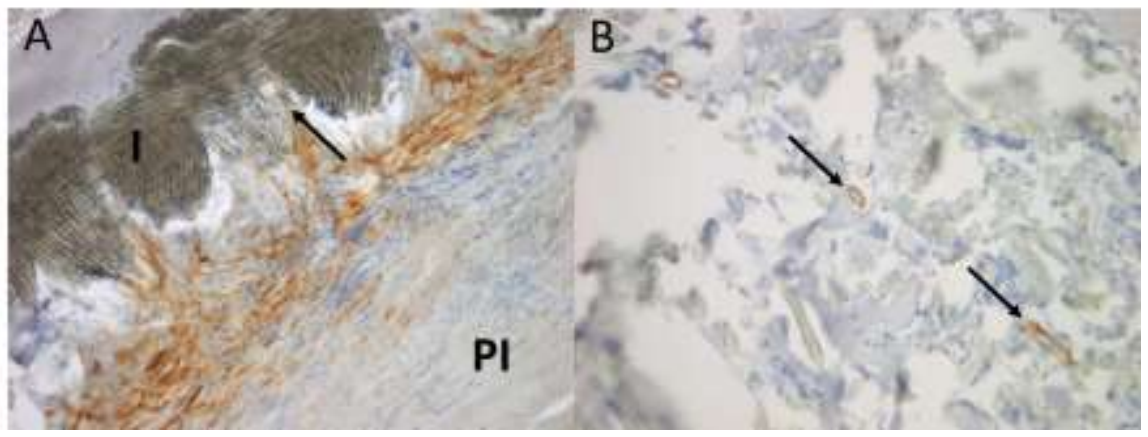

Abbildung 3.35: SMA-Färbungen; A kontraktile Zellen entlang der Polyesterfäden (Pfeil) und an der Implantatoberfläche, Pseudointima (PI), Implantat (I); Vergrößerung 100fach; Präparat Nr. 37; B kontraktile Zellen um kleine Hohlräume (Pfeile) im Implantatgewebe um Polyesterfäden; Vergrößerung 200fach; Präparat Nr. 38

\section{Entzündungszellen}

In allen untersuchten Patches konnten im Pseudointima-, Implantat- und Pseudoadventitiagewebe Entzündungszellen gefunden werden. Allerdings konnten die Pseudointima und Pseudoadventitia von Präparat Nr. 36 nicht ausgewertet werden. CD 68-positive Histiozyten wurden vereinzelt in den Präparaten Nr. 35, 37 und 38 in der gesamten Pseudointima und in allen Präparaten der Gruppe in großer Anzahl in Implantatnähe (s. Abbildung 3.36 A) und im Implantatgewebe um die Polyesterfäden gefunden. Außerdem färbten im Pseudoadventitiagewebe der Präparate Nr. 35, 37 und 38 viele Histiozyten positiv für CD 68. Mehrkernige FKR färbten in allen Patches in großer Anzahl im Implantgewebe um die Polyesterfäden und auf der Pseudointima- und Pseudoadventitia-zugewandten Implantoberfläche positiv für CD 68 (s. Abbildung 3.36 B). In Präparat Nr. 37 waren FKR auch im Pseudoadventitiagewebe vorhanden. 


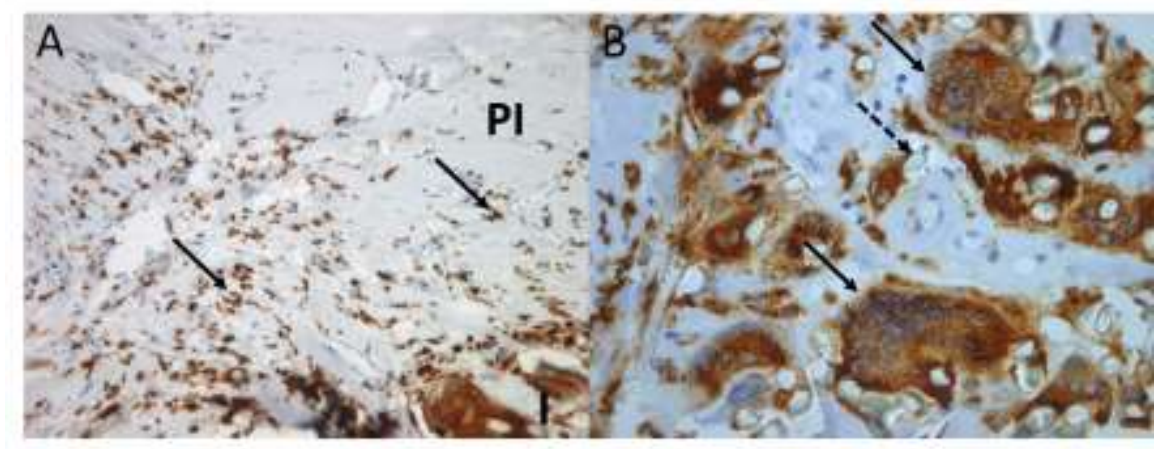

Abbildung 3.36: CD 68-Färbung; Präparat Nr. 38; A große Anzahl von Histiozyten (Pfeile) in Implantatnähe, Implantat (I), Pseudointima (PI); Vergrößerung 200fach; B mehrkernige FKR (Pfeile) um Polyesterfäden (gestrichelter Pfeil); Vergrößerung 400fach

In 1 von 4 untersuchten Präparaten färbten Zellen positiv für CD 15: In Präparat Nr. 38 waren im Implantatgewebe vereinzelt Granulozyten zu sehen, im Pseudointimagewebe noch spärlicher. Im Pseudoadventitiagewebe färbten mehrere Infiltrate für CD 15 (s. Abbildung 3.37), neben denen teilweise große Ansammlungen von Erythrozyten möglicherweise eine Einblutung - zu erkennen waren. Im Implantatgewebe von Präparat Nr. 36 färbten keine Zellen für CD 15. In Präparat Nr. 35 und 37 färbten weder im Pseudointima- noch im Implantat- oder Pseudoadventitiagewebe Granulozyten für CD 15.

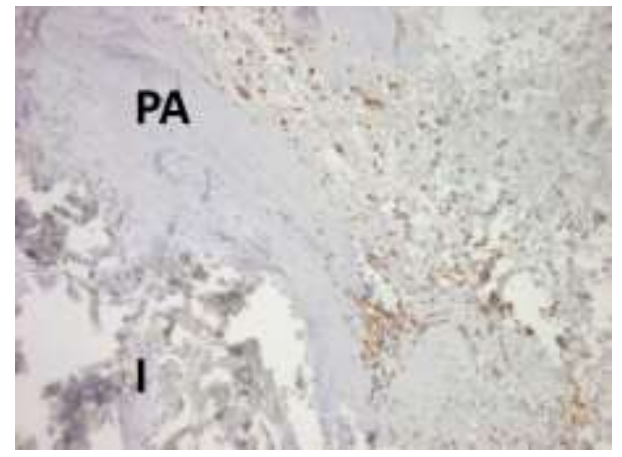

Abbildung 3.37: CD 15-Färbung; Granulozyteninfiltrat in der Pseudoadventitia (PA), angrenzend Implantatgewebe (I); Vergrößerung 100fach; Präparat Nr. 38

In den Präparaten Nr. 37 und 38 (s. Abbildung 3.38 A) färbten viele T-Lymphozyten im Pseudointimagewebe positiv für CD 3. Die Zellen lagen vorwiegend in Implantatnähe und in Präparat Nr. 37 in großer Anzahl auch um Hohlräume im mittleren Pseudointimadrittel (s. Abbildung 3.38 B). In Präparat Nr. 35 färbten keine Zellen der Pseudointima positiv für CD 3. Im Implantatgewebe waren in den Präparaten Nr. 35, 37 und 38 vereinzelt, in Präparat Nr. 36 viele T-Lymphozyten vorhanden. Die Präparate Nr. 
35, 37 und 38 wiesen auch in der Pseudoadventitia, vor allem in Implantatnähe, TLymphozyten auf.

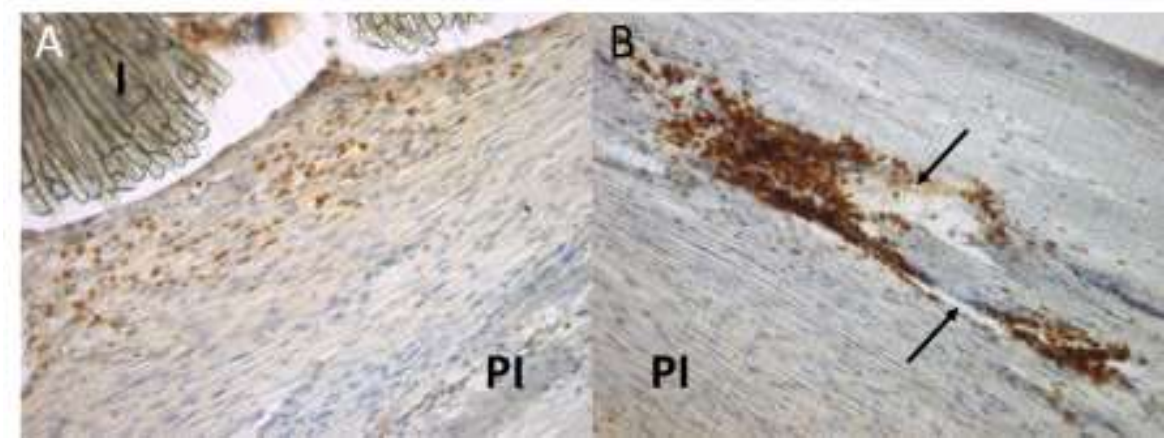

Abbildung 3.38: CD 3-Färbungen; A T-Lymphozyten-Infiltrat in der Pseudointima (PI) in Implantatnähe (I); Vergrößerung 200fach; Präparat Nr. 38; B T-Lymphozyten-Infiltrat um Hohlräume (Pfeile) im mittleren Pseudointimadrittel; Vergrößerung 200fach; Präparat Nr. 37

In allen 4 untersuchten Präparaten färbten jeweils wenige B-Lymphozyten positiv für CD $79 \alpha$ : in Präparat Nr. 35 im Implantatgewebe in Pseudoadventitianähe sowie in der Pseudoadventitia ohne örtlichen Bezug zum Implantatgewebe, in Präparat Nr. 36 im Implantatgewebe. In Präparat Nr. 37 waren sowohl im Pseudoadventitiagewebe in Implantatnähe als auch im Pseudointimagewebe B-Lymphozyten vorhanden, die über die gesamte Pseudointima verteilt waren. In Implantatnähe war zusätzlich ein großes Infiltrat zu sehen. In Präparat Nr. 38 färbten in allen 3 Präparatabschnitten ubiquitär Zellen positiv für CD $79 \alpha$.

\section{Verkalkung}

In allen Patches färbten punktförmige Kalkeinschlüsse in Pseudointima- (s. Abbildung 3.39 A) und Implantatgewebe (s. Abbildung 3.39 B) für von Kossa, in den Präparaten Nr. 35 und 37 zusätzlich im Pseudoadventitiagewebe. 3 der Präparate wiesen zusätzlich flächige Verkalkungsareale auf: In Präparat Nr. 35 färbte ein größeres Kalkaggregat in der Pseudointima und ein großer, konfluierender Kalkherd in der Pseudoadventitia für von Kossa. In Präparat Nr. 36 war ein großer, konfluierender Kalkherd in der Pseudointima zu sehen. Präparat Nr. 38 zeigte im Pseudoadventitiagewebe ein größeres Kalkaggregat und einen großen, konfluierenden Kalkherd (s. Abbildung 3.39 A). 


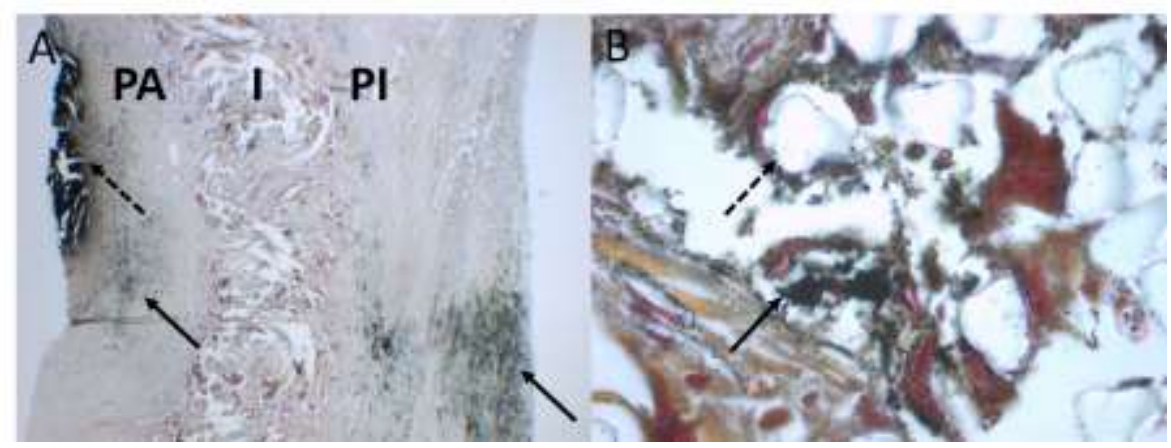

Abbildung 3.39: Von Kossa-Färbungen; A punktförmige Kalkeinschlüsse (Pfeile) in Pseudointima (PI) und Pseudoadventitia (PA), konfluierender Kalkherd in Pseudoadventitia (gestrichelter Pfeil), dazwischen Implantatgewebe (I); Vergrößerung 40fach; Präparat Nr. 38; B punktförmige Kalkeinschlüsse im Implantatgewebe (Pfeil), Polyesterfaden (gestrichelter Pfeil); Vergrößerung 1000fach; Präparat Nr. 36

\subsubsection{Okkluder}

Es wurden insgesamt 9 Polyester-Okkluder untersucht.

\section{Endothelialisierung der Pseudointima}

In den Präparaten Nr. 46 bis 48 und Nr. 50 färbte die oberste, lumenseitige Zellschicht der Pseudointima positiv für CD 31.

\section{Neovaskularisierung}

In den Präparaten Nr. 46 bis 48 und Nr. 50 färbt die Zellauskleidung von Hohlräumen, die über die gesamten Präparate verteilt zu sehen waren, positiv für CD 31. Die zahlreichsten und großkalibrigsten Hohlräume befanden sich im Okkluder-Steg (s. Abbildung 3.40).

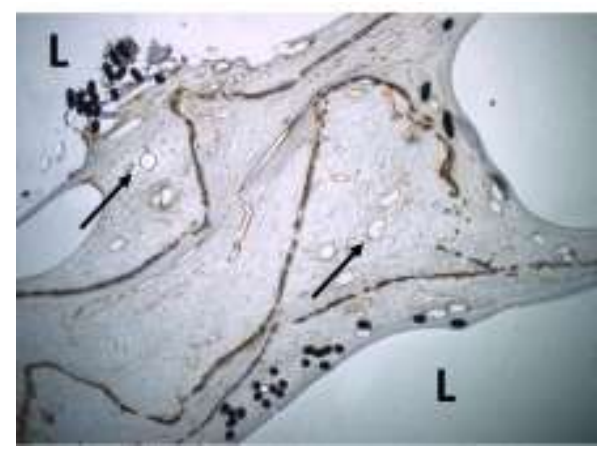

Abbildung 3.40: CD 31-Färbung; Übersicht; Endothelialisierung von Hohlräumen (Pfeile) im OkkluderSteg, Lumen (L); Vergrößerung 16fach; Präparat Nr. 50

In den Präparaten Nr. 43 und 44, bei denen eine Vimentin-Färbung vorgenommen wurde, färbte die Zellauskleidung von Hohlräumen unterschiedlichen Kalibers zwischen den Polyesterfäden. 


\section{Zellen und EZM des Pseudointima- und Implantatgewebes}

In allen Okkludern der Gruppe war eine Pseudointima ausgebildet. Bei den Präparaten Nr. 43 und 44 wurden Vimentin-Färbungen durchgeführt. Es färbten viele spindelförmige Zellen um das Implantatgewebe und um die Polyesterfäden für Vimentin (s. Abbildung 3.41). In beiden Fällen war die Pseudointima nicht auswertbar.

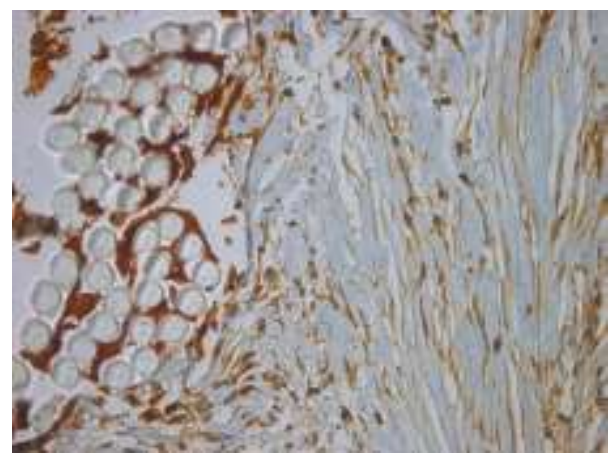

Abbildung 3.41: Vimentin-Färbung; Vimentin-positive Zellen um das Implantatgewebe (rechts im Bild) und um die Polyesterfäden (links im Bild); Vergrößerung 400fach: Präparat Nr. 43

\section{Entzündungszellen}

Bei 7 Präparaten wurde eine CD 68-Färbung durchgeführt. Im Pseudointimagewebe färbten in allen auswertbaren Okkludern meistens sehr viele Histiozyten in Implantatnähe und an der Implantatoberfläche (s. Abbildung 3.42 A). In der restlichen Pseudointima waren in manchen Präparaten etwas weniger Histiozyten $\mathrm{zu}$ sehen. Direkt im Implantatgewebe waren meistens sehr viele Histiozyten vorhanden. In den auswertbaren Okkluder-Stegen färbten ebenfalls sehr viele Histiozyten positiv für CD 68 (s. Tabelle 3.14). FKR färbten in allen auswertbaren Präparaten sehr zahlreich um die Polyesterfäden (s. Abbildung 3.42 B) und an der Implantatoberfläche. In den Okkluder-Stegen färbten keine FKR positiv für CD 68 (s. Tabelle 3.15). 


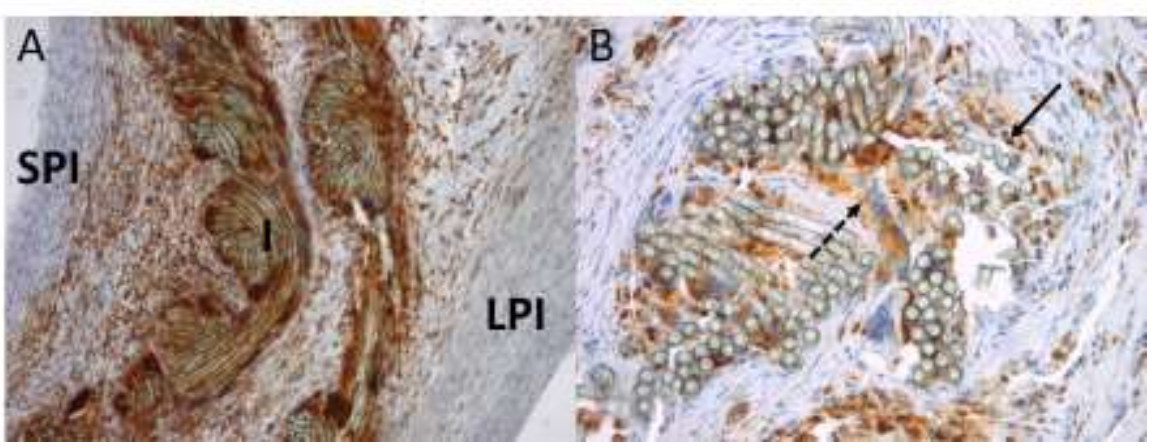

Abbildung 3.42: CD 68-Färbungen; A Histiozyten in der Lumen- (LPI) und Septum-zugewandten Pseudointima (SPI) sowie um die Polyesterfäden, Implantat (I); Vergrößerung 100fach; Präparat Nr. 47; B Histiozyten (Pfeil) und FKR (gestrichelter Pfeil) um Polyesterfäden; Vergrößerung 200fach; Präparat Nr. 46

\begin{tabular}{|c|c|c|c|c|c|c|c|c|}
\hline \multirow{4}{*}{$\begin{array}{c}\# \\
\\
43\end{array}$} & \multicolumn{8}{|c|}{ CD 68 Histiozyten } \\
\hline & \multicolumn{4}{|c|}{ PI } & \multirow{2}{*}{\multicolumn{2}{|c|}{$\mathbf{I}$}} & \multirow{2}{*}{\multicolumn{2}{|c|}{ OS }} \\
\hline & \multicolumn{2}{|c|}{ LPI } & \multicolumn{2}{|c|}{ SPI } & & & & \\
\hline & NB & & NB & & +++ & $*$ & NB & \\
\hline 44 & NB & & NB & & +++ & $*$ & NB & \\
\hline 45 & NB & & NB & & +++ & $*$ & NB & \\
\hline 46 & $\begin{array}{c}+++/ \\
+\end{array}$ & $\begin{array}{c}\mathrm{I}-\mathrm{OF} / \\
\text { restl. PI }\end{array}$ & $\begin{array}{c}+++/ \\
+\end{array}$ & $\begin{array}{c}\text { I-OF/ } \\
\text { restl. PI }\end{array}$ & +++ & $*$ & ++ & $*$ \\
\hline 47 & $\begin{array}{c}+++/ \\
+\end{array}$ & $\begin{array}{c}\mathrm{I}-\mathrm{OF} / \\
\text { restl. PI }\end{array}$ & +++ & $*$ & +++ & $*$ & NB & \\
\hline 48 & ++-+++ & $*$ & +++ & $*$ & ++-+++ & $*$ & +++ & * \\
\hline 50 & $\begin{array}{c}+++/ \\
+\end{array}$ & $\begin{array}{c}\text { I-OF/ } \\
\text { restl. PI }\end{array}$ & ++-+++ & $*$ & ++-+++ & $*$ & +++ & $*$ \\
\hline
\end{tabular}

Tabelle 3.14: Ergebnisse der CD 68-Färbungen; Histiozyten in Pseudointima, Implantat, Okkluder-Steg; (+ wenige Zellen, ++ viele Zellen, +++ sehr viele Zellen, - keine Zellen, * ubiquitär vorhanden, \# Präparatnummer, I Implantat, LPI Lumen-zugewandte Pseudointima, NB nicht beurteilbar, OF Oberfläche, OS Okkluder-Steg, PI Pseudointima, SPI Septum-zugewandte Pseudointima) 


\begin{tabular}{|c|c|c|c|c|c|c|c|c|}
\hline \multirow{4}{*}{$\begin{array}{c}\text { \# } \\
43\end{array}$} & \multicolumn{8}{|c|}{ CD 68 FKR } \\
\hline & \multicolumn{4}{|c|}{ PI } & \multirow{2}{*}{\multicolumn{2}{|c|}{ I }} & \multirow{2}{*}{\multicolumn{2}{|c|}{ OS }} \\
\hline & \multicolumn{2}{|c|}{ LPI } & \multicolumn{2}{|c|}{ SPI } & & & & \\
\hline & NB & & NB & & +++ & $*$ & NB & \\
\hline 44 & NB & & NB & & +++ & $*$ & NB & \\
\hline 45 & NB & & NB & & +++ & $*$ & NB & \\
\hline 46 & +++ & I-OF & +++ & $\mathrm{I}-\mathrm{OF}$ & +++ & $*$ & - & \\
\hline 47 & +++ & I-OF & +++ & $\mathrm{I}-\mathrm{OF}$ & +++ & $*$ & NB & \\
\hline 48 & ++-+++ & I-OF & ++-+++ & $\mathrm{I}-\mathrm{OF}$ & ++-+++ & $*$ & - & \\
\hline 50 & ++-+++ & I-OF & ++-+++ & $\mathrm{I}-\mathrm{OF}$ & ++-+++ & $*$ & - & \\
\hline
\end{tabular}

Tabelle 3.15: Ergebnisse der CD 68-Färbungen; FKR in Pseudointima, Implantat, Okkluder-Steg; (+ wenige Zellen, ++ viele Zellen, +++ sehr viele Zellen, - keine Zellen, * ubiquitär vorhanden, \# Präparatnummer, I Implantat, LPI Lumen-zugewandte Pseudointima, NB nicht beurteilbar, OF Oberfläche, OS Okkluder-Steg, PI Pseudointima, SPI Septum-zugewandte Pseudointima)

In 7 untersuchten Okkludern färbten Granulozyten für CD 15. Dabei war in der Nähe des Implantatgewebes und um die Polyesterfäden häufig ein größeres Aufkommen festzustellen als in der Pseudointima (s. Abbildung 3.43 und Tabelle 3.16).

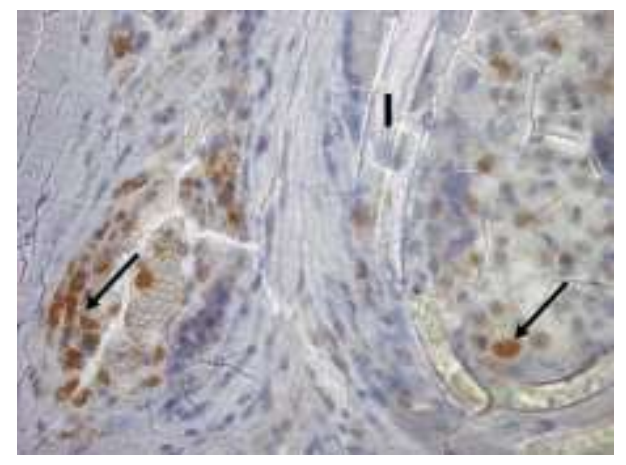

Abbildung 3.43: CD 15 Färbung; Granulozyten (Pfeile) in der Nähe des Implantatgewebes (I) und um die Polyesterfäden; Vergößerung 400fach; Präparat Nr. 46 


\begin{tabular}{|c|c|c|c|c|c|c|c|c|}
\hline \multirow{4}{*}{$\begin{array}{c}\# \\
\\
43\end{array}$} & \multicolumn{8}{|c|}{ CD 15} \\
\hline & \multicolumn{4}{|c|}{ PI } & \multirow{2}{*}{\multicolumn{2}{|c|}{ I }} & \multirow{2}{*}{\multicolumn{2}{|c|}{ OS }} \\
\hline & \multicolumn{2}{|c|}{ LPI } & \multicolumn{2}{|c|}{ SPI } & & & & \\
\hline & $(+)$ & $*$ & NB & & +-++ & $\begin{array}{c}* \\
\mathrm{I}-\mathrm{OF}\end{array}$ & +-++ & $*$ \\
\hline 44 & + & I-Nähe & $(+)-+$ & $\begin{array}{c}* \\
\text { I-Nähe }\end{array}$ & +-++ & $\mathrm{I}-\mathrm{OF}$ & - & \\
\hline 45 & NB & & NB & & $(+)$ & $\mathrm{I}-\mathrm{OF}$ & NB & \\
\hline 46 & NB & & NB & & ++ & $\mathrm{I}-\mathrm{OF}$ & NB & \\
\hline 47 & NB & & NB & & ++ & $\mathrm{I}-\mathrm{OF}$ & NB & \\
\hline 48 & $(+)$ & $*$ & NB & & +-++ & $\mathrm{I}-\mathrm{OF}$ & NB & \\
\hline 50 & - & & - & & $(+)$ & $\mathrm{I}-\mathrm{OF}$ & NB & \\
\hline
\end{tabular}

Tabelle 3.16: Ergebnisse der CD 15-Färbungen in Pseudointima, Implantat, Okkluder-Steg; ((+) vereinzelte Zellen, + wenige Zellen, ++ viele Zellen, +++ sehr viele Zellen, - keine Zellen, * ubiquitär vorhanden, \# Präparatnummer, I Implantat, LPI Lumen-zugewandte Pseudointima, NB nicht beurteilbar, OF Oberfläche, OS Okkluder-Steg, PI Pseudointima, SPI Septum-zugewandte Pseudointima)

In allen 7 untersuchten Okkludern färbten T-Lymphozyten positiv für CD 3 (s. Abbildung 3.44 und Tabelle 3.17). Es fiel auf, dass eine größere Dichte in der Pseudointima an der Implantatoberfläche und in Implantatnähe als direkt im Implantatgewebe um die Polyesterfäden vorhanden war. Auch über den Okkluder-Steg waren in den beiden Amplatzer-Okkludern (Präparat Nr. 48 und 50) viele T-Lymphozyten zu sehen.

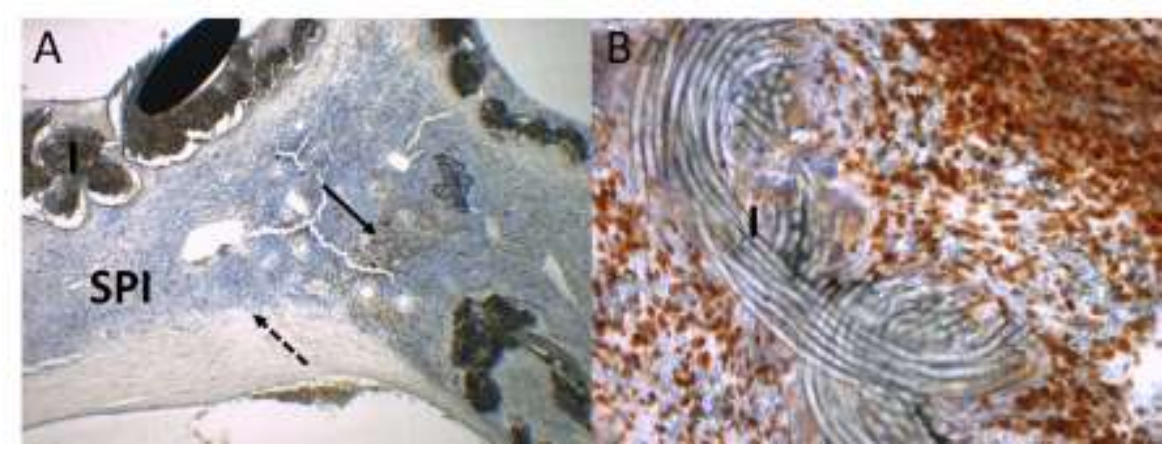

Abbildung 3.44: CD 3-Färbungen; A große Anzahl von Entzündungszellen (gestrichelter Pfeil) in Septumzugewandter Pseudointima (SPI) mit großem T-Lymphozyten-Infiltrat (Pfeil), Implantat (I); Vergrößerung 40fach; Präparat Nr. 46; B großes T-Lymphozyteninfiltrat um das und im Implantatgewebe; Vergößerung 200fach; Präparat Nr. 47 


\begin{tabular}{|c|c|c|c|c|c|c|c|c|}
\hline \multirow{4}{*}{$\begin{array}{c}\# \\
43\end{array}$} & \multicolumn{8}{|c|}{ CD 3} \\
\hline & \multicolumn{4}{|c|}{ PI } & \multirow{2}{*}{\multicolumn{2}{|c|}{ I }} & \multirow{2}{*}{\multicolumn{2}{|c|}{ OS }} \\
\hline & \multicolumn{2}{|c|}{ LPI } & \multicolumn{2}{|c|}{ SPI } & & & & \\
\hline & NB & & NB & & ++ & * & NB & \\
\hline 44 & NB & & NB & & +-++ & $*$ & NB & \\
\hline 45 & NB & & NB & & $(+)-++$ & $*$ & NB & \\
\hline 46 & $+/+++$ & $\begin{array}{c}* \\
\text { I-OF, I- } \\
\text { Nähe, L }\end{array}$ & ++-+++ & $\begin{array}{c}* \\
\text { I-OF, I- } \\
\text { Nähe }\end{array}$ & +-++ & $*$ & NB & \\
\hline 47 & NB & & NB & & ++-+++ & $*$ & NB & \\
\hline 48 & ++-+++ & $\begin{array}{c}* \\
\text { I-OF, I- } \\
\text { Nähe }\end{array}$ & ++-+++ & $\begin{array}{c}* \\
\text { I-OF, I- } \\
\text { Nähe }\end{array}$ & ++ & $*$ & ++-+++ & $\begin{array}{c}* \\
\text { I-Nähe }\end{array}$ \\
\hline 50 & $+/+++$ & $\begin{array}{c}* \\
\text { I-Nähe }\end{array}$ & +-++ & $\begin{array}{c}* \\
\text { I-Nähe, } \\
\text { OS-Nähe }\end{array}$ & $(+)-++$ & $*$ & ++-+++ & $\begin{array}{c}* \\
\text { I-Nähe }\end{array}$ \\
\hline
\end{tabular}

Tabelle 3.17: Ergebnisse der CD 3-Färbungen in Pseudointima, Implantat, Okkluder-Steg; ((+) vereinzelte Zellen, + wenige Zellen, ++ viele Zellen, +++ sehr viele Zellen, * ubiquitär vorhanden, \# Präparatnummer, I Implantat, LPI Lumen-zugewandte Pseudointima, NB nicht beurteilbar, OF Oberfläche, OS Okkluder-Steg, PI Pseudointima, SPI Septum-zugewandte Pseudointima)

In 6 untersuchten, auswertbaren Präparaten färbten B-Lymphozyten positiv für CD $79 \alpha$. Waren Pseudointima und Okkluder-Steg auswertbar, so lagen die B-Lymphozyten häufig an der Implantatoberfläche und/oder in Implantatnähe (s. Abbildung 3.45), wo die Dichte größer war als direkt im Implantatgewebe, in dem nur vereinzelt (um die Polyesterfäden) oder gar keine B-Lymphozyten zu erkennen waren (s. Tabelle 3.18). 


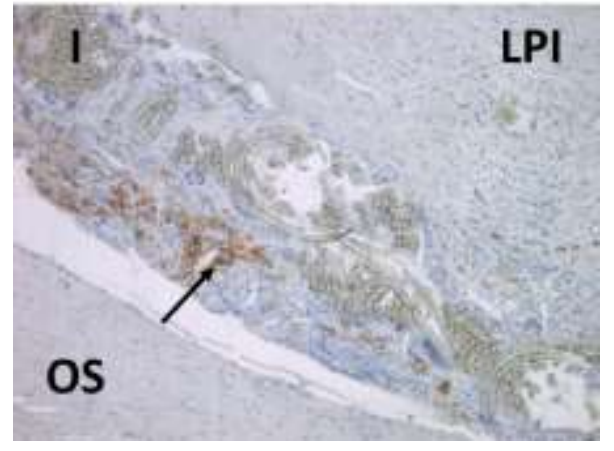

Abbildung 3.45: CD 79 $\alpha$-Färbung; B-Lymphozyten-Infiltrat (Pfeil) in Implantatnähe, Implantat (I), lumenseitige Pseudointima (LPI), Okkluder-Steg (OS); Vergrößerung 100fach; Präparat Nr. 46

\begin{tabular}{|c|c|c|c|c|c|c|c|c|}
\hline \multirow{4}{*}{$\begin{array}{c}\# \\
\\
43\end{array}$} & \multicolumn{8}{|c|}{ CD 79a } \\
\hline & \multicolumn{4}{|c|}{ PI } & \multirow{2}{*}{\multicolumn{2}{|c|}{ I }} & \multirow{2}{*}{\multicolumn{2}{|c|}{ OS }} \\
\hline & \multicolumn{2}{|c|}{ LPI } & \multicolumn{2}{|c|}{ SPI } & & & & \\
\hline & NB & & NB & & $(+)-++$ & $\begin{array}{l}\text { I-OF, I- } \\
\text { Nähe }\end{array}$ & NB & \\
\hline 45 & NB & & NB & & $-1+$ & $\begin{array}{c}\text { I-OF, I- } \\
\text { Nähe }\end{array}$ & NB & \\
\hline 46 & + & $\begin{array}{l}\text { I-OF, I- } \\
\text { Nähe }\end{array}$ & NB & & $(+)$ & $*$ & + & I-Nähe \\
\hline 47 & NB & & NB & & $-1+$ & $\begin{array}{l}\text { I-OF, I- } \\
\text { Nähe }\end{array}$ & NB & \\
\hline 48 & + & $\begin{array}{c}* \\
\text { I-Nähe }\end{array}$ & +-++ & $\begin{array}{c}* \\
\text { I-Nähe }\end{array}$ & - & & ++ & $\begin{array}{c}* \\
\text { I-Nähe }\end{array}$ \\
\hline 50 & $-1+$ & $*$ & $-1+$ & $*$ & $-/(+)$ & $\mathrm{I}-\mathrm{OF}$ & - & $\begin{array}{l}\text { unvoll- } \\
\text { ständig } \\
\text { abgebil- } \\
\text { det }\end{array}$ \\
\hline
\end{tabular}

Tabelle 3.18: Ergebnisse der CD $79 \alpha$-Färbungen in Pseudointima, Implantat, Okkluder-Steg; $((+)$ vereinzelte Zellen, + wenige Zellen, ++ viele Zellen, +++ sehr viele Zellen, - keine Zellen, * ubiquitär vorhanden, \# Präparatnummer, I Implantat, LPI Lumen-zugewandte Pseudointima, NB nicht beurteilbar, OF Oberfläche, OS Okkluder-Steg, PI Pseudointima, SPI Septumzugewandte Pseudointima)

\section{Verkalkung}

8 Präparate (Nr. 42 und Nr. 44 bis 50) wurden auf Verkalkung untersucht. In Präparat Nr.

48 waren punktförmige Kalkeinschlüsse im Pseudointimagewebe und an der Implantatoberfläche zu sehen. Präparat Nr. 44 wies punktförmige Kalkeinschlüsse in Lumen- und Septum-zugewandter Pseudointima sowie stellenweise an der Oberfläche der Polyesterfäden auf. Ein Okkluderteil wies zusätzlich ein großes, konfluierendes Kalkareal 
in der Pseudointima auf. Dieser Okkluderteil war insgesamt verkalkter als der andere (s. Abbildungen 3.46 A, B). In den Präparaten Nr. 42, 46, 47, 49 und 50 färbten keine Kalkareale für von Kossa. In Präparat Nr. 45 war dies im Pseudointimagewebe ebenso der Fall. Das Implantatgewebe dieses Präparats war nicht auswertbar.

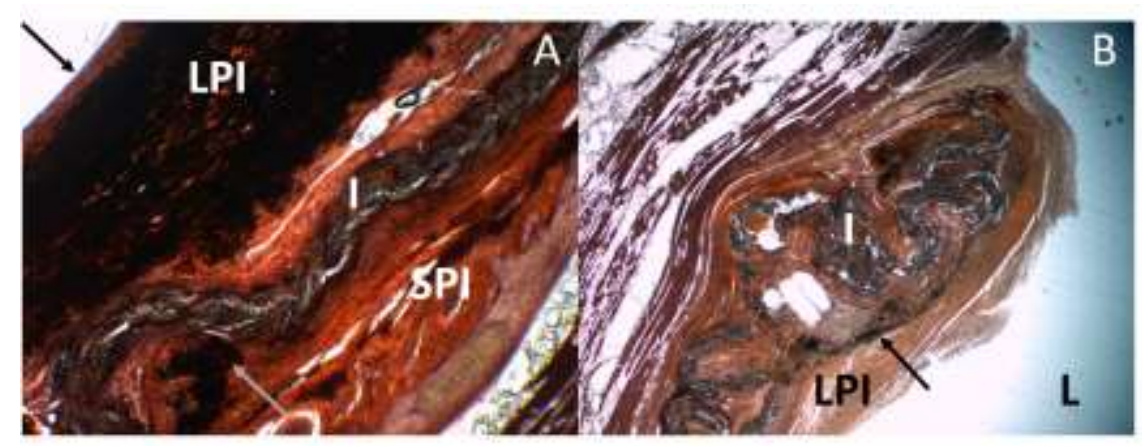

Abbildung 3.46: Von Kossa-Färbungen; Präparat Nr. 44; A stärker verkalkter Okkluderteil, punktförmige Kalkeinschlüsse und großer, konfluierender Kalkherd (schwarzer Pfeil) in Lumenzugewandter Pseudointima (LPI), punktförmige Kalkeinschlüsse (grauer Pfeil) in Septumzugewandter Pseudointima (SPI), Implantat (I); Vergrößerung 40fach; B weniger verkalkter Okkluderteil, punktförmige Kalkeinschlüsse (Pfeil) in Lumen-zugewandter Pseudointima, Lumen (L); Vergrößerung 16 fach 


\subsection{PVA-Okkluder}

Es wurden 2 PVA-Okkluder untersucht.

\section{Endothelialisierung der Pseudointima}

Bei beiden Okkludern war eine Pseudointima ausgebildet. Präparat Nr. 52 wurde auf Endothelialisierung untersucht: Die oberste, lumenseitige Zellschicht der Pseudointima färbte positiv für CD 31 (s. Abbildung 3.47).

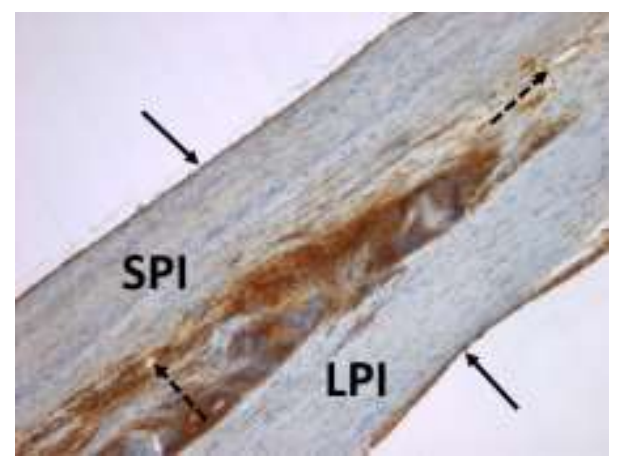

Abbildung 3.47: CD 31-Färbung; Endothelialisierung (Pfeile) der Lumen- (LPI) und Septum-zugewandten Pseudointima (SPI) sowie von kleinen Hohlräumen (gestrichelte Pfeile) in der Pseudointima; Vergößerung 100fach; Präparat Nr. 52

\section{Neovaskularisierung}

In Präparat Nr. 52 färbte die Zellauskleidung verschieden geformter Hohlräume unterschiedlichen Kalibers positiv für CD 31 (s. Abbildung 3.47), die in der Pseudointima, an der Implantatoberfläche und am häufigsten und großkalibrigsten im Okkluder-Steg zu finden waren.

\section{Entzündungszellen}

In beiden Okkludern färbten Histiozyten und FKR positiv für CD 68. In Präparat Nr. 51 färbten in beiden Lumen-zugewandten Pseudointimae und in der Septum-zugewandten Pseudointima einer Okkluderseite sehr viele Histiozyten an der Implantatoberfläche sowie in Implantatnähe positiv für CD 68. In der restlichen Pseudointima sowie der Septumzugewandten Pseudointima der anderen Okkluderseite waren relativ dazu wenige Histiozyten zu sehen. Der Okkluder-Steg war nicht auswertbar. Direkt im Implantatgewebe färbten viele Histiozyten. Sowohl in Buchten und Hohlräumen des Implantatgewebes als auch an dessen Oberfläche waren stellenweise wenige, stellenweise viele FKR zu erkennen (s. Abbildung 3.48 A). Ähnlich war es in Präparat Nr. 52: In den Lumen- und Septum-zugewandten Pseudointimae waren an Implantatoberfläche und in 
Implantatnähe sehr viele Histiozyten vorhanden. In den restlichen Pseudointimae färbten weniger Histiozyten positiv für CD 68. Über den Okkluder-Steg verteilt sowie an der Implantatoberfläche und in Implantatnähe waren sehr viele Histiozyten zu erkennen. In Buchten und Hohlräumen des Implantatgewebes und an dessen Oberfläche färbten sehr viele Histiozyten und FKR (s. Abbildung 3.48 B), deutlich zahlreicher als in Präparat Nr. 51. Direkt im Implantatgewebe waren nur vereinzelt Histiozyten und FKR zu sehen.

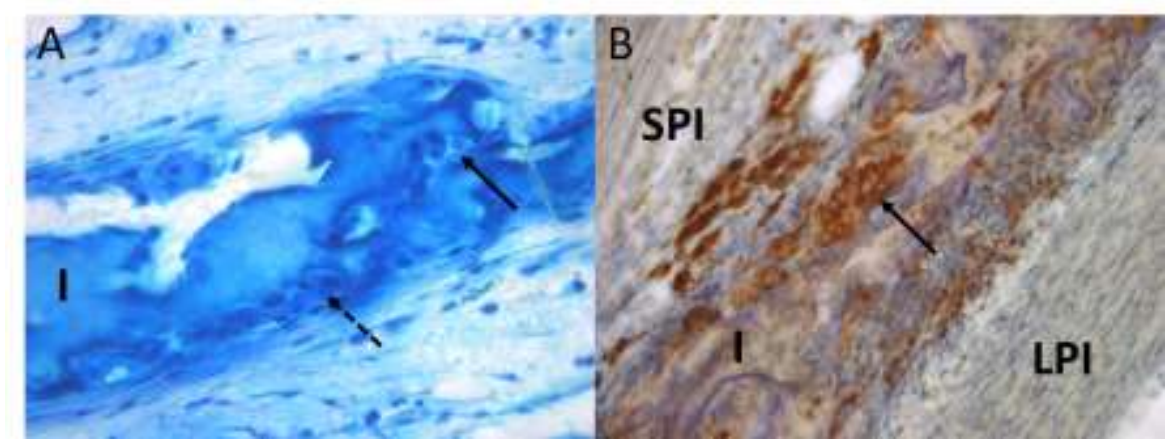

Abbildung 3.48: A Richardson-Färbung; Histiozyten (Pfeil) und FKR (gestrichelter Pfeil) in Buchten und Hohlräumen des PVA-Implantatgewebes (I); Vergrößerung 400fach; Präparat Nr. 51; B CD 68-Färbung; Histiozyten und FKR (Pfeil) in Buchten des PVA-Implantatgewebes (I) sowie Histiozyten in Septum- (SPI) und Lumen-zugewandter (LPI) Pseudointima an der Implantatoberfläche; Vergrößerung 200fach; Präparat Nr. 52

In Präparat Nr. 52 färbten im Okkluder-Steg und in Implantatnähe beziehungsweise an dessen Oberfläche sehr vereinzelt Granulozyten positiv für CD 15.

Positiv für CD 3 färbten in Präparat Nr. 52 einige T-Lymphozyten in den Lumenzugewandten Pseudointimae, vor allem in Implantatnähe und an dessen Oberfläche. Wenige T-Lymphozyten waren in den Septum-zugewandten Pseudointimae, ebenfalls in Implantatnähe und an dessen Oberfläche, vorhanden. Über den Okkluder-Steg verteilt sowie in Implantatnähe und an dessen Oberfläche waren viele T-Lymphozyten zu sehen. Im Implantatgewebe direkt lagen sie nur vereinzelt vor, während an dessen Oberfläche stellenweise viele, stellenweise weniger Zellen für CD 3 positiv färbten (s. Abbildung 3.49). 


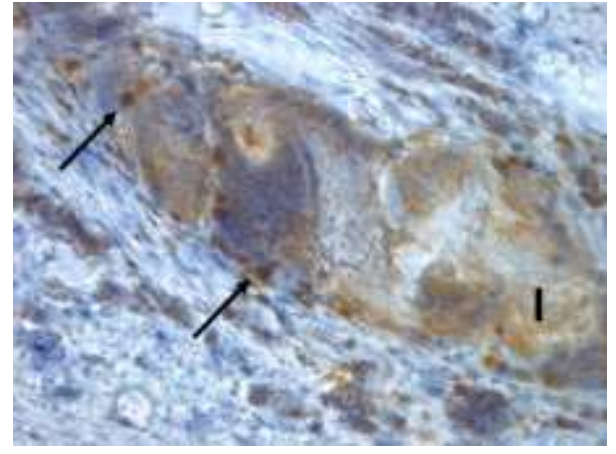

Abbildung 3.49: CD 3-Färbung; T-Lymphozyten am und im (Pfeile) Implantatgewebe (I); Vergrößerung 400fach; Präparat Nr. 52

CD 79 $\alpha$-positive B-Lymphozyten lagen in Form von 2 kleinen Infiltraten in der Lumenzugewandten Pseudointima und im Okkluder-Steg, jeweils in Implantatnähe, vor. Im Implantatgewebe und in der Septum-zugewandten Pseudointima, die allerdings nicht vollständig erhalten war, färbten keine Zellen positiv für CD $79 \alpha$.

\section{Verkalkung}

In beiden Okkludern färbten weder im Pseudointima- noch Implantatgewebe oder dem Okkluder-Steg Verkalkungen für von Kossa. 


\section{4 Übersicht: Verkalkung der verschiedenen Implantatmaterialien in Abhängigkeit von der Implantationszeit}

Die folgende Tabelle soll einen zusammenfassenden Überblick über Verkalkung der verschiedenen Implantatmaterialien in Abhängigkeit von der Implantationszeit geben:

\begin{tabular}{|c|c|c|c|c|c|c|}
\hline \multicolumn{2}{|l|}{ IM } & $\#$ & IZ & PI & I & $\mathbf{P A}$ \\
\hline \multirow{30}{*}{ PTFE } & \multirow{21}{*}{$\mathbf{S}$} & 13 & $6 \mathrm{~d}$ & - & - & - \\
\hline & & 16 & $2 \mathrm{M}$ & - & - & - \\
\hline & & 10 & $3 \mathrm{M}$ & - & - & - \\
\hline & & 18 & $3 \mathrm{M}$ & - & - & - \\
\hline & & 2 & $4 \mathrm{M}$ & - & - & - \\
\hline & & 14 & $4 \mathrm{M}$ & - & - & - \\
\hline & & 21 & $4 \mathrm{M}$ & - & - & - \\
\hline & & 11 & $5 \mathrm{M}$ & - & - & - \\
\hline & & 15 & $6 \mathrm{M}$ & - & - & - \\
\hline & & 3 & $8 \mathrm{M}$ & - & - & - \\
\hline & & 12 & $8 \mathrm{M}$ & - & - & - \\
\hline & & 7 & $9 \mathrm{M}$ & - & - & - \\
\hline & & 17 & $9 \mathrm{M}$ & - & - & - \\
\hline & & 1 & $11 \mathrm{M}$ & - & - & - \\
\hline & & 6 & 1 a $1 \mathrm{M}$ & - & - & - \\
\hline & & 9 & 1 a $1 \mathrm{M}$ & - & - & - \\
\hline & & 8 & 1 a $2 \mathrm{M}$ & - & - & - \\
\hline & & 20 & $2 \mathrm{a}$ & - & - & - \\
\hline & & 19 & 5 a $2 \mathrm{M}$ & - & - & - \\
\hline & & 4 & 5 a $9 \mathrm{M}$ & - & - & - \\
\hline & & 5 & 9 a $5 \mathrm{M}$ & ++ & $++/+++$ & - \\
\hline & \multirow{2}{*}{$\mathbf{O}$} & 39 & 5 a $10 \mathrm{M}$ & + & $+/++/+++$ & \\
\hline & & 40 & 6 a $3 \mathrm{M}$ & $+/++$ & - & \\
\hline & \multirow{7}{*}{$\mathbf{P}$} & 26 & 8 a $3 \mathrm{M}$ & + & + & + \\
\hline & & 22 & 11 a $7 \mathrm{M}$ & $+/+++$ & $+/++/+++$ & $+/++/+++$ \\
\hline & & 27 & $12 \mathrm{a}$ & + & ++ & + \\
\hline & & 25 & 13 a $8 \mathrm{M}$ & $+/+++$ & $+/+++$ & $+/++/+++$ \\
\hline & & 33 & 19 a $4 \mathrm{M}$ & $+/+++$ & $+/+++$ & + \\
\hline & & 28 & 20 a $9 \mathrm{M}$ & + & + & + \\
\hline & & 34 & 21 a $3 \mathrm{M}$ & $+/+++$ & $+/++/+++$ & + \\
\hline
\end{tabular}




\begin{tabular}{|c|c|c|c|c|c|c|}
\hline \multicolumn{2}{|l|}{ IM } & $\#$ & IZ & PI & I & PA \\
\hline & & 23 & 25 a $11 \mathrm{M}$ & $+/+++$ & $+/+++$ & + \\
\hline & & 30 & 28 a $1 \mathrm{M}$ & + & $+/++$ & + \\
\hline & & 29 & 28 a $6 \mathrm{M}$ & $+/++/+++$ & $+/+++$ & $+/++$ \\
\hline & & 31 & 30 a $4 \mathrm{M}$ & $+/+++$ & + & + \\
\hline & & 32 & 32 a $3 \mathrm{M}$ & $+/+++$ & $+/+++$ & + \\
\hline \multirow{12}{*}{ POLYESTER } & \multirow{8}{*}{$\mathbf{O}$} & 47 & $3 \mathrm{M}$ & - & - & \\
\hline & & 50 & $5 \mathrm{M}$ & - & - & \\
\hline & & 49 & 1 a $3 \mathrm{M}$ & - & - & \\
\hline & & 42 & 1 a $8 \mathrm{M}$ & - & - & \\
\hline & & 46 & 2 a $3 \mathrm{M}$ & - & - & \\
\hline & & 45 & 2 a $11 \mathrm{M}$ & - & $\mathrm{NB}$ & \\
\hline & & 48 & 3 a $4 \mathrm{M}$ & + & + & \\
\hline & & 44 & 6 a $9 M$ & $+/+++$ & + & \\
\hline & \multirow{4}{*}{$\mathbf{P}$} & 35 & 18 a $1 \mathrm{M}$ & $+/++$ & + & $+/+++$ \\
\hline & & 36 & 22 a $5 \mathrm{M}$ & $+/+++$ & + & - \\
\hline & & 37 & 31 a $2 \mathrm{M}$ & + & + & + \\
\hline & & 38 & 35 a $2 \mathrm{M}$ & + & + & $++/+++$ \\
\hline \multirow{2}{*}{ PVA } & \multirow{2}{*}{$\mathbf{O}$} & 52 & $7 \mathrm{M}$ & - & - & \\
\hline & & 51 & 3 a $3 \mathrm{M}$ & - & - & \\
\hline
\end{tabular}

Tabelle 3.20: Verkalkung des Pseudointima-, Implantat-, Pseudoadventitiagewebes, Implantate nach aufsteigender Implantationszeit geordnet; (+ punktförmige Kalkeinschlüsse/kleine Kalkaggregate, ++ größere Kalkaggregate $(\leq$ halbe Pseudointima- bzw. Implantatbreite des jeweiligen Präparates), +++ große, konfluierende Kalkherde ( $\geq$ halbe Pseudointima- bzw. Implantatbreite des jeweiligen Präparates), - keine Verkalkung, Beurteilung der Pseudoadventitia anhand jeweiliger Implantatbreite, da unvollständig abgebildet, \# Präparatnummer, I Implantat, PA Pseudoadventitia, PI Pseudointima,)

Anhand dieser Übersichtstabelle wird deutlich, dass insbesondere Implantate mit längeren Implantationszeiten verkalkt waren. In der PTFE-Gruppe (Shunts, Patches, Okkluder) waren alle Präparate ab einer Implantationszeit von 5 Jahren und 10 Monaten (Präparat Nr. 39), in der Polyester-Gruppe (Patches, Okkluder) alle Präparate ab einer Implantationszeit von 3 Jahren und 4 Monaten (Präparat Nr. 48) verkalkt. In den PVAOkkludern fanden sich dagegen keine Verkalkungen. 


\section{Diskussion}

\subsection{Diskussion der Ergebnisse}

In diesem Abschnitt wurden die Ergebnisse dieser Arbeit nach Implantatmaterialien geordnet und somit Implantattyp-übergreifend diskutiert:

- PTFE-Gruppe: Gefäßshunts, Patches und Okkluder mit PTFE-Anteilen

- Polyester-Gruppe: Patches und Okkluder mit Polyester-Anteilen

- PVA-Okkluder-Gruppe

\subsubsection{Endothelialisierung der Pseudointima}

Unabhängig vom Implantatmaterial war mit wenigen Ausnahmen bei allen Präparaten die Ausbildung einer endothelialisierten Pseudointima als neu gebildete Gewebsschicht an der blutzugewandten Seite des Implantats zu erkennen. Bei Präparat Nr. 11 der PTFEGruppe war es zum kompletten Shuntverschluss durch Hyperplasie der Pseudointima gekommen, die daher auch keine Endothelialisierung aufwies. In Präparat Nr. 13 der PTFE-Gruppe mit einer Implantationszeit von 6 Tagen war keine Pseudointima vorhanden, sondern ein auf das lumenzugewandte PTFE-Gewebe aufgelagertes Fibrinnetz mit darin eingeschlossenen Erythrozyten.

Die Ausbildung einer Fibrinschicht als einer der ersten Schritte des Endothelialisierungsprozesses wurde von Bellón et al. 24 bis 48 Stunden nach Implantation auf PTFE-Shunts beobachtet (Bellón et al. 1994), von Lanzetta und Owen bereits 5 Minuten nach Implantation. Bis es durch Endothelzellen ersetzt ist, bleibt das Fibrinnetz erhalten (Lanzetta und Owen 1995). Lanzetta und Owen gingen davon aus, dass die Endothelzellen vom umliegenden Gewebe aus einwandern und das Fibrinnetz als Leitstruktur dient. Des Weiteren postulierten sie, dass es zur Einwanderung von Endothelzellen über transmural (von der Pseudoadventitia in Richtung Lumen) einsprossende Gefäße sowie direkt über das von der Gefäßprothese geführte Blut komme. Die Endothelialisierung der inneren Abschnitte des Implantates beginne ab der 1. postoperativen Woche und halte bis $\mathrm{zu} 3$ Monate post operationem an (Lanzetta und Owen 1995). Entgegen dieser Annahmen zeigten aktuellere Studien, dass Endothelzellen aus zirkulierenden Progenitorzellen des Knochenmarkes hervorgehen: Shi et al. bewiesen 
zunächst in vitro, dass sich CD 34-positive Progenitorzellen des Knochenmarkes bzw. der Blutbahn zu Endothelzellen differenzieren können. Anschließend führten sie allogene Knochenmarkstransplantationen bei Hunden durch, denen 6 bis 8 Wochen später eine Polyester-Gefäßprothese in Aorta thoracica descendens-Position implantiert wurde. Die Gefäßprothese wurde zuvor silikonbeschichtet, um das Einsprossen von Kapillaren zu verhindern. Nach 12 Wochen durchgeführte DNA-Analysen zeigten, dass das neu gebildete Endothel am Implantat nur DNA-Allele des Spenders enthielt, was die Herkunft der Endothelzellen aus zirkulierenden Progenitorzellen des Knochenmark beweist (Shi Q et al. 1998).

Bellón et al. beobachteten eine vollständige Endothelialisierung von PTFE-Shunts in Arteria iliaca communis dextra-Position im Rattenmodell 2 bis 3 Wochen nach Implantation (Bellón et al. 1994).

Bei Sigler und Jux waren Polyester-Okkluder (CardioSEAL/STARflex Septal Occlusion System und Amplatzer Septal Occluder) nach 30 Tagen im Schafmodell und 2 Monate nach Implantation im Menschen mit Ausnahme mancher Metallanteile vollständig endothelialisiert (Sigler und Jux 2007).

Sigler et al beschrieben die frühzeitige Ausbildung einer endothelialisierten Pseudointima auf PVA-plugs zum PDA-Verschluss bei neonatalen Lämmern: Elektronenmikroskopisch wurden erste, über das Fibringeflecht verteilte Endothelzellen nach 10 Tagen und eine geschlossene Endothelzellschicht nach 42 Tagen beschrieben (Sigler et al. 2000).

Die Ergebnisse der genannten Studien sind gut mit denen dieser Arbeit vereinbar: Präparat Nr. 13 mit einer Implantationszeit von 6 Tagen wies noch keine endothelialisierte Pseudointima auf, sondern eine Fibrinschicht als deren Vorläufer. Alle Präparate, die länger als 2 Monate implantiert waren, besaßen bereits eine endothelialisierte Pseudointima.

Diese Befunde haben große klinische Relevanz, da eine vollständig endothelialisierte Implantatoberfläche der Thrombusentstehung vorbeugt (Anzai et al. 2004; Lanzetta und Owen 1995), auf deren Boden es zum Gefäßverschluss, Embolien und Organschäden kommen kann. Daher wird empfohlen, Patienten z. B. nach interventionellem ASDVerschluss über 6 Monate mit Thrombozytenaggregationshemmern zu behandeln (Jux et al. 2010). 


\subsubsection{Neovaskularisierung}

Unabhängig vom Implantatmaterial färbte regelhaft die Zellauskleidung unterschiedlich geformter Hohlräume verschiedenen Kalibers positiv für die Endothel-Marker vWF und CD 31. Diese Hohlräume kamen auch in immunhistochemischen Färbungen zur Identifizierung von Kollagen Typ IV der Lamina densa der Basallamina und Vimentin als Intermediärfilament mesenchymaler Zellen, zu denen auch Endothelzellen zählen, zur Darstellung. Häufig waren sie von Zellen umgeben, die positiv für Antigene glatter Muskelzellen (SMA, SMM) färbten. Die Hohlräume waren zumeist ubiquitär im Präparat vorhanden. Auch im Implantatgewebe - mit Ausnahme der PTFE-Okkluder-Gruppe waren sie zu finden. Sie traten besonders gehäuft in Implantatnähe (vor allem in der implantatnahen Pseudointima) und in den Okkluder-Präparaten im Steg zwischen rechtsund linksatrialen Okkluderanteilen auf. An beiden letztgenannten Lokalisationen waren sie auffallend großkalibrig. Im Implantatgewebe dagegen waren sie kleinkalibriger. Aufgrund des Färbeverhaltens und der Morphologie dieser Hohlräume handelte es sich hierbei am ehesten um Blutgefäße: Es konnte durch o. g. Färbungen eine Endothelauskleidung mit umliegenden glatten Muskelzellen nachgewiesen werden - dem morphologischen Aufbau von Arteriolen und Venolen entsprechend (Welsch 2010).

Auch Foth et al. beschrieben das Vorkommen von Kapillaren und kleinen Blutgefäßen in der Pseudointima sowie im Inneren von Okkludern mit Polyester-Anteilen, die zum ASDoder VSD-Verschluss beim Menschen eingesetzt worden waren. Ähnlich unseren Ergebnissen wurde ein gehäuftes Vorkommen von Neovaskularisierungen im Inneren des Okkluders im Vergleich zur Pseudointima beschrieben (Foth et al. 2009). Ob es auch im Implantatgewebe, die einzelnen Polyesterfäden umgebend, zur Gefäßneubildung kam, beschrieben Foth et al. nicht. Wu et al. untersuchten Polyester-Gefäßprothesen, die für 3 Monate in der infrarenalen Aorta von Hunden implantiert waren und beschrieben transmurale Vaskularisierungen, die von Gefäßen der Adventitia ausgehend durch das Polyestergewebe zur Pseudointima reichten (Wu et al. 1996).

Menger et al. untersuchten den Neovaskularisierungsprozess an 3 verschiedenen PTFEPatches - in der Rückenhautkammer von syrischen Goldhamstern implantiert -, die sich in der Fibrillenlänge voneinander unterschieden: PTFE mit einer Fibrillenlänge von 30 $\mu \mathrm{m}$, welches als Gefäßprothese und kardiovaskulärer Patch eingesetzt wird; PTFE mit einer Fibrillenlänge von $21 \mu \mathrm{m}$, welches als Weichteil-Patch eingesetzt wird; PTFE mit 
einer Fibrillenlänge von $1 \mu \mathrm{m}$, welches als passive biologische Membran beispielsweise als Perikardersatz eingesetzt wird (Menger et al. 1990). Die Arbeitsgruppe beschrieb zwar Gefäßneubildungen im Gewebe, welches die Implantate umgab, jedoch nicht innerhalb des PTFE-Gewebes und nannte als mögliche Ursache die zu geringen Fibrillenlängen (Menger et al. 1990). Im Gegensatz dazu ermöglichen größere PTFE-Fibrillenlängen von 60 und $90 \mu \mathrm{m}$ (Kogel et al. 1989) bzw. größere internodale Abstände von $60 \mu \mathrm{m}$ (Clowes et al. 1986) die transmurale Vaskularisierung ausgehend von der Adventitia durch das PTFE-Gewebe zur Pseudointima. Dies könnte erklären, warum im PTFE-Gewebe der PTFE-Okkluder-Gruppe keine Neovaskularisierungen beobachtet wurden. Möglicherweise besitzt das PTFE-Gewebe des Helex Septal Occluders eine zu geringe Fibrillenlänge, um die Neovaskularisierung des Implantatgewebes zu ermöglichen. (Angaben zur Fibrillenlänge dieses Okkluders werden vom Hersteller nicht gemacht.) Das mechanische Hindernis durch das Implantatmaterial könnte der Grund für das geringere Kaliber der Gefäße des Implantatgewebes gegenüber derer der Pseudointima sein.

Zur Neovaskularisierung von PVA-Implantaten existierten zum Zeitpunkt der Erstellung dieser Arbeit keine vergleichbaren Studien.

Clowes et al. stellten in ihren Untersuchungen fest, dass neu gebildete Gefäße das Implantat mit dem umliegenden Gewebe verbinden (Clowes et al. 1986). Eine solche „feste Integration [des Implantates] in das graftumgebende Gewebe“ (Menger et al. 1990, S.195) beugt Infektionen vor (Menger et al. 1990). Außerdem dienen die im Inneren des Implantates (wie im Okkluder-Steg) und die direkt im Implantatgewebe gelegenen Gefäße der Versorgung des sich darin neu gebildeten Gewebes (Kidd et al. 2002). Ebenso könnte es sich mit den Gefäßen der Pseudointima verhalten, die analog zu Vasa vasorum das Gefäßwandgewebe versorgen. Hierbei ist aber zu erwähnen, dass sich die Vasa vasorum echter Blutgefäße von der Adventitia ausgehend nur in die Media hinein erstrecken, die Intima also nicht erreichen. Diese wird per diffusionem durch das vom Gefäß geführte Blut versorgt (Geiringer 1951; Welsch 2010). Möglicherweise kommt eine unzureichende Versorgung der Pseudointima durch das vom Gefäß geführte Blut als Ursache der Neovaskularisierung der Pseudointima in Betracht, beispielsweise aufgrund einer zu großen Diffusionsstrecke durch Intimaverdickung (Geiringer 1951). Hiermit ist vereinbar, dass sich in unserer Arbeit gerade in der implantatnahen Pseudointima besonders viele, großlumige Gefäße befanden. Zu einer vergrößerten Diffusionsstrecke 
kann es beispielsweise im Rahmen der Atherosklerose kommen, bei der es durch „extraund intrazelluläre Lipidablagerungen“ (Welsch 2010, S. 207) zur Intimaverdickung kommt (Geiringer 1951; Welsch 2010). Diese führt zu lokaler Hypoxie in, vom Lumen aus gesehen, tieferen Intimaabschnitten (Kumamoto et al. 1995; Zemplenyi et al. 1987), wodurch die Neovaskularisierung induziert wird (Kumamoto et al. 1995). Nach Kumamoto et al. treten Neovaskularisierungen der Intima von Koronararterien bereits frühzeitig im Atherosklerose-Prozess auf und sind örtlich mit Zellen der chronischen Entzündung (Lymphozyten und Makrophagen) assoziiert. Es ist möglich, dass über Zytokine dieser Entzündungszellen die Angiogenese zusätzlich stimuliert wird (Kumamoto et al. 1995). Auch nach Subbotin ist die Neovaskularisierung der verdickten Intima eine unbedingte Voraussetzung für die Entstehung der Atherosklerose (Subbotin 2012), in deren Verlauf es auch zur Verkalkung der Gefäßwand kommen kann (Welsch 2010). Auch in dieser Arbeit wurden Verkalkungen des Pseudointima- und Implantatgewebes, insbesondere bei Präparaten mit größeren Implantationszeiten, gefunden (s. Kapitel 4.2.5). Doch auch generell im Rahmen von Entzündungs- und anschließenden Reparaturprozessen spielt die Neovaskularisierung eine Rolle (Sunderkötter et al. 1994): Durch sie werden „Entzündungszellen, Nährstoffe und Sauerstoff“ (Gong und Koh 2010, S. 437) bereitgestellt. So sind insbesondere Makrophagen durch Sezernierung verschiedener Zytokine zur „Initiierung, Aufrechterhaltung und Beendigung“" (Sunderkötter et al. 1994, S. 417) der Angiogenese in der Lage. Auch in dieser Arbeit wurden insbesondere in Implantatnähe große Zahlen von Entzündungszellen dort festgestellt, wo auch die Gefäßdichte besonders hoch war (vor allem in der implantatnahen Pseudointima).

\subsubsection{Zellen und EZM des Pseudointima- und Implantatgewebes}

Unabhängig vom Implantatmaterial war bei allen Präparaten mit wenigen Ausnahmen (s. Kapitel 4.2.1) die Ausbildung einer Pseudointima als neu gebildete Gewebsschicht an der blutzugewandten Seite des Implantats zu erkennen. Die Zellen und die EZM der Pseudointima konnten besonders gut anhand der PTFE-Gruppe untersucht werden, da uns in dieser die meisten Präparate zur Verfügung standen. In der PTFE-Gruppe waren über die gesamte Pseudointima verteilte, spindelförmige Vimentin-positive Zellen zu erkennen. Morphologisch ähnliche Zellen färbten auch für SMA und SMM. Es konnte 
gezeigt werden, dass diese SMA- und SMM-positiven Zellen mit zunehmender Implantationszeit regelhaft eine deutlich größere Konzentration in der lumenseitigen Pseudointima aufwiesen, während sie bei Präparaten mit kürzeren Implantationszeiten entweder dasselbe Verteilungsmuster zeigten oder gleichmäßig über die gesamte Pseudointima verteilt waren. Auch in den untersuchten Polyester-Patches war lumenseitig eine höhere Dichte SMA- und SMM-positiver Zellen zu erkennen. Die EZM der Pseudointima färbte sowohl in der PTFE-Gruppe als auch in den Polyester-Patches netzartig für Kollagen IV. Direkt im Implantatgewebe der PTFE-Gruppe färbten zwar regelhaft Zellen positiv für Vimentin. Deutlich seltener und spärlicher als im Pseudointima-Gewebe waren hier jedoch SMA- und SMM-positive Zellen zu finden. Auch die EZM des PTFE-Implantatgewebes färbte seltener als das Pseudointima-Gewebe positiv für Kollagen IV. In der Polyester-Gruppe fanden sich SMA- und SMM-positive Zellen und Kollagen IV-positive EZM eher an der Implantatoberfläche und weniger im Gewebe um die Polyesterfäden, die aber von Vimentin-positiven Zellen umgeben waren.

Mehrere Studien beschrieben den bindegewebigen Aufbau der Pseudointima kardiovaskulärer Implantate und gehen zum Teil auch auf die Infiltration des Implantatgewebes mit Bindegewebszellen ein, jedoch ohne diese weiter zu klassifizieren: Kreutzer et al. beschrieben die Ausbildung einer dichten, „fibro-elastischen Pseudointima“ (Kreutzer et al. 2001, S. 105) an Okkludern mit Polyester-Komponente, die im Mittel 1,6 Jahre im menschlichen Herz implantiert waren (Kreutzer et al. 2001). Auch Das et al. beschrieben eine Pseudointima aus dichtem Bindegewebe an Okkludern mit Polyester-Komponente im Hundemodell, deren Polyester-Fasern ebenfalls von Bindegewebe umgeben waren (Das et al. 1993). Kuhn et al. beobachteten die Ausbildung einer „fibrösen Kapsel“ (Kuhn et al. 1996, S. 1459) um Okkluder mit PolyesterKomponente im Hundemodell, die sich im Laufe der Implantationszeit immer weiter organisierte (Kuhn et al. 1996).

Andere Studien versuchten dagegen, die Bindegewebszellen weiter zu klassifizieren: Foth et al. untersuchten Okkluder mit Polyester-Komponente, die im menschlichen Herz implantiert waren und beschrieben bei allen Präparaten mit einer Implantationszeit größer als 10 Wochen die Ausbildung einer organisierten Pseudointima, deren Zellen regelhaft positiv für Vimentin, SMA und SMM färbten. Diese Zellen wurden daher als Myofibroblasten-ähnlich beschrieben. Solche Myofibroblasten-ähnliche Zellen befanden 
sich auch im neu gebildeten, lockeren Bindegewebe im Inneren der Okkluder (Foth et al. 2009). Myofibroblasten sind Fibroblasten mit kontraktilen Aktin-Proteinen, die unter bestimmten Bedingungen auch Myosin exprimieren können (Bucher 1997; Desmouliere et al. 2005). Jin et al. konnten zeigen, dass Fibroblasten - von der Pseudoadventitia stammend und durch das PTFE-Gewebe Richtung Lumen wandernd - eine Rolle bei der Ausbildung der mittigen (also Anastomosen-fernen) Pseudointima-Abschnitte von PTFEGefäßprothesen im Hundemodell spielen: Nach 1 Monat Implantationszeit waren zwei Drittel des PTFE-Gewebes von Fibroblasten infiltriert, nach 2 bis 4 Monaten das komplette PTFE-Gewebe. Nach 2 Monaten Implantationszeit zeigte sich in allen untersuchten Präparaten die Ausbildung einer Pseudointima. Das Färbemuster der positiv für Vimentin und SMA färbenden Zellen überschnitt sich größtenteils, weswegen sie als Myofibroblasten identifiziert wurden. Diese bildeten die zelluläre Hauptkomponente der Pseudointima. Um sie von glatten Muskelzellen abzugrenzen, wurden immunhistochemische Färbungen zur Darstellung von Desmin und Smoothelin durchgeführt, die größtenteils negativ ausfielen. Nur wenige Zellen färbten ausschließlich für Vimentin, die damit als Fibroblasten identifiziert wurden. Diese befanden sich hauptsächlich in Implantatnähe und in der lumennahen Pseudointima (Jin et al. 2012). Auch Shi et al. zeigten im Tiermodell, dass Fibroblasten der Adventitia, die sich zu Myofibroblasten weiterentwickeln, an Aufbauprozessen der Neointima nach endoluminaler Verletzung porciner Koronararterien beteiligt sind (Shi Y et al. 1996).

Varcoe et al. postulierten dagegen, dass Fibrozyten am Aufbau von Pseudointima- und Implantatgewebe beteiligt sind (Varcoe et al. 2006). Fibrozyten, die Oberflächenantigene sowohl von Leukozyten als auch von Bindegewebszellen aufweisen, sind im Blut zirkulierende Zellen, die bei Gewebsschäden an Reparaturprozessen beteiligt sind und Eigenschaften glatter Muskelzellen annehmen können (Bucala et al. 1994). Schafen wurde ein Gelatine-versiegelter Polyester-Patch in Arteria carotis communis dextraPosition implantiert und anschließend histologisch ausgewertet: Die Zellen der Pseudointima und des Implantatgewebes färbten positiv für immunhistochemische Marker, die spezifisch für Fibrozyten sind: SMA, Vimentin, CD 34 und CD 45 (Varcoe et al. 2006). Auch Thevenot et al. machten durch Entzündungszellen - insbesondere Mastzellen - stimulierte Fibrozyten für die Ausbildung der Bindegewebskapsel um synthetische Biomaterialien (tissue engineered scaffolds aus Polyglykolsäure) 
verantwortlich (Thevenot et al. 2011). Baker et al. betonten ebenfalls die Rolle der Fibrozyten bei Gewebereaktionen auf subkutan implantiertes Polydimethylsiloxan im Mäusemodell (Baker et al. 2011).

Anhand mehrerer Studien konnte eine Verbindung zwischen o. g. Myofibroblasten und Fibrozyten hergestellt werden: Am Ort der Gewebeverletzung angekommen, differenzieren Fibrozyten weiter zu SMA-exprimierenden Myofibroblasten, die wesentlich an Reparaturprozessen und am Aufbau des Bindegewebes beteiligt sind (Abu El-Asrar et al. 2008; Mori et al. 2005; Quan et al. 2006; Schmidt et al. 2003).

Übertragen auf die Ergebnisse unserer Arbeit kann es sich bei den Zellen der Pseudointima möglicherweise um Myofibroblasten handeln, da sie ebenfalls positiv für SMA, SMM und Vimentin färbten. Einschränkend muss aber darauf hingewiesen werden, dass in unserer Arbeit keine weiterführenden immunhistochemischen Färbungen zur genaueren Klassifizierung dieser Zellen vorgenommen wurde. Das bei Jin et al. beschriebene Verteilungsmuster, bei dem der Großteil der Pseudointima von Myofibroblasten gebildet wird, jedoch aber in der implantatnahen Pseudointima hauptsächlich Fibroblasten zu finden sind, stimmt mit unseren Ergebnissen überein: Häufig waren SMA- und SMM-positive Zellen - insbesondere bei Implantaten mit größeren Implantationszeiten - lumennah konzentriert. Dagegen waren Vimentin-positive Zellen über die gesamte Pseudointima verteilt, also auch in Implantatnähe, wobei es sich folglich um Fibroblasten handeln könnte. Dass die EZM um Myofibroblasten u. a. durch Kollagen IV gebildet wird, konnte in verschiedenen Studien gezeigt werden (Berndt et al. 1994; Yen et al. 2002). Auch in unserer Arbeit färbte die EZM der Pseudointima netzartig für Kollagen IV. Anhand der o. g. Studienergebnisse ergibt sich in Bezug auf den zellulären Aufbau des Implantatgewebes Folgendes: Da die meisten Zellen zwar positiv für Vimentin, aber nur wenige für SMA und SMM färbten, könnte es sich hauptsächlich um Fibroblasten handeln. Positiv für kontraktile Proteine färbende Zellen des Implantatgewebes umgeben möglicherweise als glatte Muskelzellen kleinste Gefäße im Implantatgewebe (s. o.). Hiermit ist auch vereinbar, dass die EZM des Implantatgewebes deutlich seltener als die EZM der Pseudointima für Kollagen IV färbte. Das Kollagen IV des Implantatgewebes könnte als Bestandteil der Basallamina eben genannte glatte Muskelzellen oder Gefäßendothelzellen umgeben. 


\subsubsection{Implantatassoziierte Entzündungsreaktionen}

Die durch Implantate hervorgerufene Entzündungsreaktion wird durch die beim Implantationsprozess verursachte Gewebeverletzung angestoßen. Nach Anderson werden verschiedene Phasen der darauffolgenden lokalen Reaktion des Empfängerorganismus auf das implantierte Fremdmaterial unterschieden: (1) Die akute Entzündungsreaktion, die im Wesentlichen von neutrophilen Granulozyten, die chemotaktisch an den Ort der Gewebeverletzung migrieren, getragen wird und deren Hauptaufgabe die Phagozytose von Krankheitserregern darstellt (Anderson JM 1988). Diese Phase hält meist weniger als 1 Woche an (Anderson JM et al. 2008). (2) Zur darauffolgenden chronischen Entzündungsreaktion kommt es bei fortbestehendem Entzündungsreiz durch das Implantat (Anderson JM 1988). Diese wird zunächst von mononukleären Zellen, insbesondere Monozyten/Makrophagen, Lymphozyten und Plasmazellen, getragen, deren Präsenz „von kurzer Dauer“ (Anderson JM et al. 2008, S. 3) ist. Bei biokompatiblen Materialien hält die aus mononukleären Zellen bestehende Entzündungsreaktion ,gewöhnlich [...] nicht länger als zwei Wochen“ (Anderson JM et al. 2008, S. 3) an (Anderson JM et al. 2008). Lymphozyten und Plasmazellen werden durch Zytokine am Implantat anhaftender Makrophagen aktiviert. Lymphozyten wiederum fördern die Makrophagen-Adhäsion und Fusion zu FKR (Brodbeck et al. 2005; MacEwan et al. 2005), sind also wesentlich an der darauffolgenden Fremdkörperreaktion beteiligt. (3) Die Fremdkörperreaktion als persistierende Komponente der chronischen Entzündungsreaktion stellt die „normale“ (Anderson JM 1988, S. 103) Antwort des Empfängerorganismus auf inerte biokompatible Materialien dar (Anderson JM 1988). Diese Phase ist durch die Anwesenheit von FKR fusionierte Makrophagen - am Implantatmaterial geprägt und geht mit der Bildung von Granulationsgewebe aus Makrophagen, Fibroblasten und Kapillaren einher. Es kommt zur bindegewebigen Einkapselung des Implantats. Laut Anderson persistiert diese Phase, solange das Biomaterial implantiert bleibt. Bereits 4 Tage nach Implantation kann man erste FKR am Implantat beobachten (Anderson JM 1988). Die Ausprägung der Entzündungsreaktion hängt im Wesentlichen von der Implantationslokalisation, der Form und Größe des implantierten Materials (Anderson JM et al. 2008) sowie von dessen Oberflächenstruktur ab (Hunt et al. 1996). Möglicherweise spielt u. a. auch der Vroman-Effekt eine Rolle, der die sequenzielle Adsorption von Proteinen an Oberflächen beschreibt (Leonard und Vroman 1992). So beschrieben Bonfield et al., dass bestimmte Protein- 
Polymer-Verbindungen die Monozytenaktivität und somit die Entzündungsreaktion beeinflussen (Bonfield et al. 1992).

In der PTFE-Gruppe waren implantatassoziiert meist wenige Granulozyten und BLymphozyten zu finden. Die meisten implantatassoziierten T-Lymphozyten waren vor allem in der PTFE-Patch-Gruppe (durchschnittliche Implantationszeit: 247 Monate) und sonst in geringerer Ausprägung vorhanden. In allen Präparaten der Gruppe - mit Ausnahme von Präparat Nr. 5 (s. Kapitel 3.1.1) - waren unabhängig von der Implantationszeit implantatassoziierte Histiozyten im Pseudointima- und Implantatgewebe vorhanden. Im Implantatgewebe der PTFE-Okkluder waren sie jedoch nur sehr vereinzelt zu finden. Während sie in der implantatnahen Pseudoadventitia der PTFE-Shunts in allen Präparaten vorzufinden waren, war dies bei den PTFE-Patches nur in 4 von 11 Präparaten zutreffend. Im Okkluder-Steg kamen sie gehäuft vor. Implantatassoziierte FKR waren in 9 von 16 untersuchten PTFE-Shunts (durchschnittliche Implantationszeit: 18 Monate), in 7 von 11 untersuchten PTFE-Patches und in 2 von 2 PTFE-Okkludern (durchschnittliche Implantationszeit: 74 Monate) vorhanden.

Implantatassoziierte Granulozyten und Lymphozyten waren also auch deutlich länger als von Anderson beschrieben vorhanden (s. o.). Zu ähnlichen Ergebnissen kamen auch Ehler et al:: Das Vorkommen implantatassoziierter neutrophiler Granulozyten und Lymphozyten an PTFE-Patches zum Verschluss rechtsventrikulärer Defekte bei Schweinen wurde noch nach Implantationszeiten zwischen 10 und 14 Monaten beschrieben (Ehler et al. 1990). Fujimoto et al. beobachteten Entzündungsreaktionen bestehend aus Makrophagen an PTFE-Patches im RVOT von Ratten, die über einen Beobachtungszeitraum von 4 bis 12 Wochen post implantationem zwar persistierten, aber deutlich an Intensität verloren, sodass sie nach 12 Wochen nur noch als „leicht“ (Fujimoto et al. 2007, S. 653) beschrieben wurden (Fujimoto et al. 2007). Auch in unserer Arbeit waren implantatassoziierte Makrophagen in der Pseudoadventitia der PTFE-PatchGruppe (mit deutlich größerer durchschnittlicher Implantationszeit) seltener zu finden als in der Pseudoadventitia der PTFE-Shunt-Gruppe oder im Steg der PTFE-Okkluder (je mit kleineren durchschnittlichen Implantationszeiten). Die Fremdkörperreaktion aus Makrophagen und FKR an der Oberfläche von PTFE-Gewebe wurde in der Literatur mehrfach beschrieben (Bellón et al. 1996; Ehler et al. 1990; Kenney et al. 1988), wobei FKR in unserer Arbeit nur in einem Teil der PTFE-Implantate vorhanden waren (s. o.). 
Auch bei Mehta et al. waren ebenfalls nur bei 31 von 40 Gefäßprothesen (mit einer durchschnittlichen Implantationszeit von 64 Monaten im Menschen) FKR vorhanden (Mehta et al. 2011). Dass Histiozyten im Implantatgewebe der PTFE-Okkluder (anders als bei den PTFE-Shunts und -Patches) nur sehr vereinzelt zu finden waren, könnte - wie in Kapitel 4.2.2 besprochen - mit einer geringen Fibrillenlänge des PTFE-Gewebes des Helex Septal Occluders zusammenhängen.

In der Polyester-Gruppe waren Granulozyten vor allem bei Präparaten mit kürzeren Implantationszeiten (wie in der Polyester-Okkluder-Gruppe, durchschnittliche Implantationszeit: 30 Monate) implantatassoziiert regelmäßig vorzufinden, während sie bei Präparaten mit längeren Implantationszeiten (wie in der Polyester-Patch-Gruppe, durchschnittliche Implantationszeit: 321 Monate) meist nicht vorhanden waren. Auch implantatassoziierte T-Lymphozyten kamen häufiger und deutlich zahlreicher als in der PTFE-Gruppe, insbesondere in Präparaten mit kürzeren Implantationszeiten (wie in der Polyester-Okkluder-Gruppe), aber auch etwas schwächer ausgeprägt in Präparaten mit längeren Implantationszeiten (wie in der Polyester-Patch-Gruppe), vor. Wenige BLymphozyten wurden in allen Präparaten meist implantatassoziiert vorgefunden. In allen Präparaten waren implantatassoziierte Histiozyten und FKR unabhängig von der Implantationszeit vorhanden - deutlich zahlreicher als in der PTFE-Gruppe.

Diese Ergebnisse decken sich gut mit anderen Studien an Polyester-Okkludern, nach Implantation im Menschen (Foth et al. 2009) sowie im Schaf und im Menschen (Sigler und Jux 2007), die ebenfalls eine deutliche persistierende Fremdkörper- und lymphozytäre Entzündungsreaktion feststellten. Kreutzer et al beschrieben in fast allen untersuchten Polyester-Okkludern mit Implantationszeiten zwischen 2,7 und 44 Monaten im Menschen Fremdkörperreaktionen (Kreutzer et al. 2001). Salzmann et al. verglichen u. a. den Grad der Fremdkörperreaktion in 5 verschiedenen Polyester- und 2 verschiedenen PTFE-Prothesen im Rattenmodell und kamen zu dem Ergebnis, dass - mit Ausnahme einer Polyester-Prothese - die Fremdkörperreaktion auf die Polyester-Prothesen stärker als auf die PTFE-Prothesen ausgeprägt war (Salzmann et al. 1999). Dass Polyester zu einer stärkeren Monozyten/Makrophagen-Aktivierung als PTFE in vitro führt, konnten Miller und Anderson zeigen (Miller und Anderson 1988). Die mit zunehmender Implantationszeit rückläufige Präsenz von Granulozyten und T-Lymphozyten deckt sich zwar mit dem von Anderson (s. o.) beschriebenen, phasenhaften Verlauf der 
Entzündungsreaktionen auf implantierte Biomaterialien. Trotzdem waren in unserer Arbeit Granulozyten und T- sowie B-Lymphozyten regelhaft in Polyester-Präparaten mit deutlich längeren Implantationszeiten als denen von Anderson veranschlagten Zeiträumen (s. o.) vorhanden.

Bei dem PVA-Okkluder mit 7-monatiger Implantationszeit wurden viele implantatassoziierte T-Lymphozyten gefunden, allerdings weniger als in der PolyesterGruppe, während nur wenige implantatassoziierte B-Lymphozyten und Granulozyten vorkamen. Bei beiden Okkludern der Gruppe (durchschnittliche Implantationszeit: 23 Monate) wurden ähnlich viele CD 68-positive Zellen wie in der Polyester-Gruppe - also deutlich mehr als in der PTFE-Gruppe - gefunden. Histiozyten waren im Pseudointimaund Implantatgewebe und Okkludersteg besonders zahlreich, FKR besonders an der Implantatoberfläche.

Ähnlich der PTFE- und Polyester-Gruppe wurde also auch bei dem PVA-Okkluder eine deutlich über die von Anderson beschriebenen Zeiträume (s. o.) hinaus persistierende implantatassoziierte Infiltration mit Granulozyten und Lymphozyten vorgefunden. Im Gegensatz zu unseren Ergebnissen beschrieben Sigler et al. keinerlei Entzündungsreaktionen an PVA-plugs zum interventionellen PDA-Verschluss bei neonatalen Lämmern, die im Durchschnitt 102 Tage implantiert waren (Sigler et al. 2000), also deutlich kürzer als die von uns untersuchten Okkluder mit Implantationszeiten von 7 Monaten sowie 3 Jahren und 3 Monaten, was als Ursache der unterschiedlichen Ergebnisse angesehen werden kann. Unseres Wissens existierten zum Zeitpunkt der Erstellung dieser Arbeit keine weiteren histologischen Untersuchungen, die PVA als Bestandteil kardiovaskulärer Implantate untersuchten. Daher wurde im Folgenden auf Studien mit andernorts implantiertem PVA zurückgegriffen: Noguchi et al. untersuchten die Tauglichkeit von PVA-Hydrogel als Knorpelersatz im Knie von Kaninchen und beschrieben in einem Beobachtungszeitraum von 2 bis 52 Wochen post implantationem eine milde, initiale Entzündungsreaktion im umliegenden Gewebe, die vermutlich von den operativen Maßnahmen herrührte und später komplett verschwand. Die Art der Entzündungsreaktion wurde allerdings nicht weiter klassifiziert (Noguchi et al. 1991). In unseren Untersuchungen konnte dagegen eine persistierende Entzündungsreaktion beobachtet werden, was am ehesten mit den Ergebnissen von Wang et al. zu vereinbaren ist: Sie implantierten ein Verbundmaterial aus Hydroxyapatit, Gelatine und PVA, das subkutan in 
die Rückenregion von Ratten implantiert wurde. Eine Woche post implantationem wurden viele Entzündungszellen in und um das Implantat beschrieben. Diese Entzündungsreaktion nahm im weiteren Verlauf ab, sodass sie 12 Wochen post implantationem nur noch sehr gering ausgeprägt war (Wang et al. 2008). Auch hier wurde die Art der Entzündungsreaktion nicht näher klassifiziert.

Zusammenfassend kann man aus den Ergebnissen dieser Arbeit bezüglich des Ausprägungsgrades der Entzündungsreaktionen auf die verschiedenen Implantatmaterialien eine materialabhängige Graduierung aufstellen: Die chronische Entzündungsreaktion - sowohl die mononukleäre als auch die Fremdkörperreaktion - war auf Polyester und PVA stärker als auf PTFE ausgeprägt. Der Grad der granulozytären - akuten - Entzündungsreaktion auf die verschiedenen Implantatmaterialien war dagegen ähnlich ausgeprägt. Entgegen der Aussage Andersons bezüglich des zeitlichen Verlaufs der akuten und chronischen, monozytären Entzündungsreaktion (s. o.) waren regelhaft Granulozyten und Lymphozyten deutlich über die von ihm angegebenen Zeiträume hinaus festzustellen.

Die Relevanz dieser Befunde besteht darin, dass implantatassoziierte Entzündungsreaktionen zum Implantatversagen führen können (Anderson JM et al. 2008; Brodbeck et al. 2005; Ehler et al. 1990). Daher sind Implantatmaterialien, die eine stärkere Entzündungsreaktion hervorrufen - wie etwa Polyester oder PVA -, möglicherweise empfindlicher für Mechanismen des Implantatversagens als solche, die eine weniger starke Entzündungsreaktion hervorrufen - wie etwa PTFE. Folgende Mechanismen des Implantatversagens kommen diesbezüglich in Betracht: Beim Versuch, das Implantatmaterial zu phagozytieren, werden u. a. durch Makrophagen und FKR Stoffe freigesetzt, die die Implantatoberfläche angreifen und zersetzen können (Anderson JM et al. 2008; Ziats et al. 1988). Hierzu zählen beispielsweise reaktive Sauerstoffspezies, die zur Oxidation des Implantatmaterials führen können. Des Weiteren ist durch den bei Phagozytose entstehenden oxidativen Burst die Fähigkeit der Phagozyten zur Bakterienabwehr eingeschränkt (Anderson JM et al. 2008). Dass Scherkräfte, denen insbesondere kardiovaskuläre Implantate ausgesetzt sind (Shive et al. 2000), die Apoptose der anhaftenden Leukozyten begünstigen, schränkt die Fähigkeit zur Bakterienabwehr zusätzlich ein, wodurch sich die Infektionsgefahr weiter erhöht. Außerdem regen durch Implantatmaterialien in unterschiedlichem Ausmaß aktivierte Makrophagen Fibroblasten zur Proliferation an, wodurch die Matrixsynthese gesteigert wird (Miller und Anderson 
1988; Miller et al. 1989). Dies kann zum Implantatversagen führen (Miller et al. 1989), z. B. aufgrund einer stenosierenden Intimaverdickung. Ein weiterer durch Entzündungsreaktionen hervorgerufener Mechanismus des Implantatversagens ist die dadurch bedingte Verkalkung des Implantatgewebes und des Implantat-umgebenden Gewebes. Außerdem aktivieren Leukozyten - insbesondere Makrophagen - glatte Gefäßmuskelzellen und Myofibroblasten, die durch verschiedene Mechanismen Kalk bilden (s. Kapitel Kapitel 4.2.5). Chronisch-entzündliche Prozesse bedingen Apoptose und Nekrose, was ebenfalls die Kalkbildung fördert (s. Kapitel 4.2.5). Die Mechanismen des Implantatversagens durch Verkalkung werden in Kapitel 4.2.5 erläutert. Des Weiteren können chronische Entzündungprozesse die neoplastische Entartung des entzündeten Gewebes bedingen. Dieser pathophysiologische Zusammenhang der Tumorgenese ist für verschiedene Neoplasien bekannt und bereits mehrfach in der Literatur beschrieben worden (Mariani et al. 2014; Sakurai et al. 2014; Samraj et al. 2015); jedoch bisher nicht im Zusammenhang mit Entzündungsreaktionen, die durch synthetische Implantatmaterialien hervorgerufen werden.

\subsubsection{Verkalkung}

Insbesondere Implantate mit längeren Implantationszeiten verkalkten (s. Übersichtstabelle in Kapitel 3.4). Meist waren sowohl Pseudointima-, Implantat- als auch Pseudoadventitiagewebe verkalkt. In der Polyester-Gruppe waren alle Präparate ab einer Implantationszeit von 3 Jahren und 4 Monaten, in der PTFE-Gruppe alle Präparate ab einer Implantationszeit von 5 Jahren und 10 Monaten verkalkt. In dieser Gruppe waren jedoch Implantate mit Implantationszeiten größer als 2 Jahre und kleiner als 5 Jahre und 2 Monate nicht vertreten. Es fiel auf, dass die verkalkten Implantate der PTFE-Gruppe in 10 von 15 Fällen (67\%) große, konfluierende Kalkherde ( $\geq$ halbe Pseudointima- bzw. Implantatbreite des jeweiligen Präparates) in Pseudointima und/oder Implantatgewebe aufwiesen, während dies in 2 von 6 (33\%) verkalkten Implantaten der Polyester-Gruppe der Fall war. In dieser traten häufiger punktförmige Verkalkungen bis hin zu kleinen Kalkaggreagten auf. In den PVA-Okkludern (beide mit relativ kurzen Implantationszeiten) fanden sich dagegen keine Verkalkungen.

Anders als bei den von uns untersuchten Implantaten beschrieben mehrere Autoren eine bereits früher einsetzende, histologisch gesicherte Verkalkung kardiovaskulärer PTFE- 
Implantate nach 3 Monaten (Molina et al. 1995) bzw. 6 Monaten im Schafmodell (Kenney et al. 1990) und 10 bis 14 Monaten Implantationszeit im Schweinemodell (Ehler et al. 1990). Mugnai et al. evaluierten die Verkalkung von PTFE-Gefäßprothesen mittels Mikro-Computertomografie (CT) im Rattenmodell, die nach $16 \pm 3,1$ Monaten Implantationszeit festgestellt wurde (Mugnai et al. 2013). Tomizawa et al. berichteten von BT-Shunts aus PTFE und Polyester, die zwischen 11 Monaten und 5 Jahren und 7 Monaten im Menschen implantiert waren. Das Implantatmaterial von 3 von 10 PTFEShunts war - histologisch gesichert - verkalkt. Die kürzeste Implantationszeit dieser verkalkten Shunts lag bei 1 Jahr. Die Implantationszeit der anderen Implantate wurde nicht angegeben (Tomizawa et al. 1998). Us et al. evaluierten PTFE-Patches zum VSDVerschluss beim Menschen. Sie stellten bei „fast allen“ (Us et al. 2004, S. 220) Patienten anhand jährlicher, echokardiografischer Kontrollen, die bis zum 5. postoperativen Jahr durchgeführt wurden, Verkalkungen der Patches fest (Us et al. 2004). Die zeitliche Diskrepanz des Auftretens erster Verkalkungen im Vergleich zu unseren Ergebnissen kann möglicherweise dadurch zu erklären sein, dass uns keine PTFE-Implantate mit Implantationszeiten größer als 2 Jahre und kleiner als 5 Jahre und 2 Monate zur histologischen Auswertung zur Verfügung standen. Jedoch waren auch die PTFE-Shunts Nr. 19 und Nr. 4 mit Implantationszeiten von 5 Jahren und 2 Monaten sowie 5 Jahren und 9 Monaten nicht verkalkt. Somit sahen wir - entgegen den genannten Ergebnissen aus der Literatur - einen später einsetzenden Verkalkungsprozess an PTFE-Implantaten nach einer Implantationszeit von 5 Jahren und 10 Monaten, obwohl in den genannten Studien (Tomizawa et al. und Us et al.) vergleichbare kardiovaskuläre Implantate, die im menschlichen Organismus implantiert waren, untersucht wurden. Es kamen keine sensitiveren Evaluationsmethoden als die von uns angewandte histologische Auswertung zum Einsatz. Bei Molina et al., die u. a. verschiedene klappenlose Polyester- und PTFEConduits in Pulmonalisposition bei 3 bis 4 Wochen alten Ratten untersuchten, zeigte das PTFE-Implantatmaterial den „größten Verkalkungsgrad“ (Molina et al. 1995, S. 431) im Vergleich zum Polyestermaterial. Das PTFE-Implantatmaterial zeigte eine „,ausgedehnte“ (Molina et al. 1995, S. 432), „gleichmäßig generalisierte“ (Molina et al. 1995, S. 431) Verkalkung, während das Polyestermaterial „lückenhaft“ (Molina et al. 1995, S. 432) verkalkt war (Molina et al. 1995). Dies entspricht auch unseren Beobachtungen. 
Bei Wainwright et al. zeigten Polyester-Patches zur RVOT-Rekonstruktion bei Ratten nach einer Implantationszeit von 16 Wochen in der von Kossa-Färbung keine Verkalkungen (Wainwright et al. 2012). Ebenso stellten Randall et al. keine histologisch gesicherte Verkalkung von Polyester-Gefäßprothesen im Hundemodell fest, die bis zu 12 Monaten implantiert waren (Randall et al. 1982). In unserer Arbeit wurden in den Polyester-Implantaten mit vergleichbaren Implantationszeiten ebenfalls keine Verkalkungen gefunden. Bei Molina et al. (s. o.) wiesen die Polyester-Conduits erste histologisch gesicherte Verkalkungen des Implantatgewebes nach einer Implantationszeit von 12 Monaten auf (Molina et al. 1995). Tomizawa et al. untersuchten BT-Shunts aus PTFE und Polyester histologisch (s. o.), die zwischen 11 Monaten und 5 Jahren und 7 Monaten im Menschen implantiert waren. Bei den Polyester-Shunts wurden keine Verkalkungen beschrieben (Tomizawa et al. 1998). Entgegen eben genannter Ergebnisse wurden in unserer Arbeit Verkalkungen von Polyester-Implantaten ab einer Implantationszeit von 3 Jahren und 4 Monaten beobachtet.

Zur Verkalkung kardiovaskulärer PVA-Implantate mit Blutkontakt existierten zum Zeitpunkt dieser Arbeit unseres Wissens keine vergleichbaren Studien. Daher wurde im Folgenden auf Studien mit PVA-Implantaten ohne Blutkontakt und mit anderer Implantationslokalisation zurückgegriffen: De Oliveira et al. untersuchten u. a. den Verkalkungsindex subkutan implantierter PVA-Hydrogel-Membranen bei Ratten mittels Röntgenfluoreszenz. Dieser war nach einer Implantationszeit von 8 Wochen sehr gering $(0,00442 \pm 0,00256 \%$ der Absolutmasse des analysierten Materials) (de Oliveira et al. 2014). Von Schwartz et al. subkutan bei Hunden implantiertes PVA zeigte bereits nach einer Implantationszeit von 1 Monat Kalkspuren, die mittels von Kossa-Färbung dargestellt wurden (Schwartz et al. 1960). In unserer Arbeit wurde ebenfalls die von Kossa-Färbung zur Darstellung von Verkalkungen herangezogen, die für beide PVAOkkluder (Implantationszeit: 7 Monate, 3 Jahre 3 Monate) negativ war. Die unterschiedliche Implantationslokalisation ohne Blutkontakt der PVA-Implantate eben genannter Studien im Vergleich zu unseren Implantaten (subkutan im Gegensatz zu kardiovaskulär) kommt als Ursache der Ergebnisunterschiede infrage. Außerdem kam bei de Oliveira et al. eine sensitivere Methode des Kalknachweises zum Einsatz (Röntgenfluoreszenzanalyse). 
Nach Demer und Tintut kommen u. a. chronisch-entzündliche Prozesse als Ursache der Gefäßverkalkung infrage (Demer und Tintut 2014). Bei der Atherosklerose als chronischentzündlicher Prozess sind im Wesentlichen Makrophagen und glatte Gefäßmuskelzellen mit osteogenetischer Differenzierung am Verkalkungsprozess beteiligt: Aikawa et al. konnten an 20 bis 30 Wochen alten, Apolipoprotein E-defizienten Mäusen fluoreszenzmikroskopisch zeigen, dass in frühen Stadien der Atherosklerose die Makrophageninfiltration atherosklerotischer Herde örtlich mit „osteogenetischer Aktivität“" (Aikawa et al. 2007 b, S. 2842) assoziiert ist und somit die Verkalkung fördert. Die von Kossa-Färbungen zum Verkalkungsnachweis fielen in diesen frühen Stadien der Atherosklerose noch negativ aus (Aikawa et al. 2007 b). Möglicherweise setzten somit die Verkalkungsprozesse bei denen in unserer Arbeit positiv für von Kossa färbenden Implantate früher ein, als es durch die von Kossa-Färbung nachweisbar war. Nicht nur im Tiermodell, auch im Menschen konnte gezeigt werden, dass im Rahmen der Atherosklerose eine Entzündung der Gefäßwand der Plaquebildung vorausgeht: Abdelbaky et al. werteten Fluorodeoxyglucose (FDG)-Positronenemissionstomografieund CT-Daten von 137 Patienten im Alter von $61 \pm 13$ Jahren aus, die sequenziell im Abstand von 1 bis 5 Jahren durchgeführt wurden. Das FDG-uptake der atherosklerotisch bedingt entzündlich veränderten Arterienabschnitte, die später CT-morphologisch verkalkt waren, war höher als das der Arterienabschnitte, die frei von Verkalkung blieben (Abdelbaky et al. 2013). Mehrere Autoren konnten zeigen, dass glatte Gefäßmuskelzellen einen osteogenetischen Phänotyp annehmen können (Aikawa et al. 2007 b; Steitz et al. 2001; Sun et al. 2012): Aikawa et al. zeigten dies an humanen, glatten Gefäßmuskelzellen in vitro, die durch humane Makrophagen stimuliert wurden und signifikant mehr alkalische Phosphatase exprimierten (Aikawa et al. 2007 b). Sun et al. zeigten im Mäusemodell, dass zu osteogenetischen Zellen differenzierte, glatte Gefäßmuskelzellen eine Rolle bei der Gefäßverkalkung in vivo spielen, und dass der osteogenetische Transkriptionsfaktor Runx2 (runt-related transcription factor 2) glatter Gefäßmuskelzellen maßgeblich die Gefäßverkalkung und Makrophageninfiltration verkalkter Herde fördert (Sun et al. 2012). Neben glatten Gefäßmuskelzellen können auch Myofibroblasten, die in dieser Arbeit möglicherweise wesentlich am Aufbau der Pseudointima beteiligt waren, osteogenetische Eigenschaften annehmen: Durch Hochregulierung des Runx2/Cbf 1 pathway werden sie zu Osteoblasten-ähnlichen 
Zellen, was zur Verkalkung führt (Aikawa et al. 2007 a). Auch die verstärkte Expression des Osteoblasten-spezifischen Transkriptionsfaktor Cbf $\alpha 1$ (core binding factor $\alpha 1$ ) (Lee et al. 2006) spielt eine wesentliche Rolle bei der Gefäßverkalkung (Steitz et al. 2001).

Zur Kalkbildung kommt es folgendermaßen: Ähnlich den Osteoblasten oder Chondrozyten bei der Knochenbildung (Demer und Tintut 2014) sind glatte Gefäßmuskelzellen mit osteogenetischen Eigenschaften (s. o.) in der Lage, Matrixvesikel zu bilden, die in den Extrazellulärraum abgegeben werden. Diese enthalten u. a. alkalische Phosphatase und Annexine (Chen et al. 2008; Kapustin et al. 2011), die Kalzium konzentrieren und die Kristallisation von Hydroxyapatit bedingen (Demer und Tintut 2014), was zu deren Verkalkung führt. New et al. zeigten, dass auch Makrophagen entsprechende Matrixvesikel bilden können (New et al. 2013). Laut Anderson spielen Matrixvesikel auch bei der Verkalkung kardiovaskulärer Implantate eine Rolle (Anderson HC 1983). Chronische Entzündung geht mit Nekrose und Apoptose einher (Demer und Tintut 2014). So können - abgesehen von Matrixvesikeln - auch apoptotische Körperchen glatter Gefäßmuskelzellen Kalzium konzentrieren, kristallisieren und somit zum Verkalkungsprozess beitragen (Proudfoot et al. 2000). Nekrose führt zum Kalziumeinstrom in beschädigte Zellen. Das Kalzium reagiert mit der phosphatreichen Zellmembran und führt somit zur Verkalkung, was einen weiteren, möglichen Mechanismus der Verkalkung kardiovaskulärer Implantate darstellt (Anderson HC 1983; Levy et al. 1991).

Die Bedeutung der Ergebnisse dieser Arbeit bezüglich der Verkalkung kardiovaskulärer Implantatmaterialien besteht darin, dass sie zum Implantatversagen führen kann: Mehta et al. zeigten, dass Kalziumablagerungen häufig in PTFE-Gefäßprothesen gefunden wurden, die dem Implantatversagen unterlagen (Mehta et al. 2011). Hierzu kann es zum einen durch mechanische Dysfunktion (Levy et al. 1991) kommen, wenn sich Kalzium im Interstitium des Implantatmaterials ablagert, es dadurch versteift und Rissbildungen ermöglicht (Mehta et al. 2011). Zum anderen ist auch eine Obstruktion des Lumens möglich. So berichteten einige Autoren von obstruierten PTFE-Gefäßprothesen durch Verkalkung (Janssens de Varebeke und Van Osselaer 1994; Nordstrand et al. 1988). Außerdem können Verkalkungen - der Virchow-Trias gemäß - auch die Thrombusbildung begünstigen, da sie eine Endothel-Dysfunktion sowie hämodynamische Veränderungen 
bedingen können (Mehta et al. 2011). Zusätzlich ist eine Embolisation von Kalkablagerungen möglich (Levy et al. 1991).

In dieser Arbeit wurde keine Quantifizierung von Verkalkung vorgenommen (s. Kapitel 4.3). Vielmehr wurde deren Verteilungsmuster insbesondere in Pseudointima- und Implantatgewebe beschrieben. Zusammenfassend konnte hierbei gezeigt werden, dass PTFE-Implantate häufiger gleichmäßige, großflächig-konfluierende Verkalkungsareale des Pseudointima- und/oder Implantatgewebes aufwiesen. Im Gegensatz dazu waren bei den Polyester-Implantaten eher unregelmäßig verteilte, punktförmige Verkalkungen bis hin zu kleinen Kalkaggregaten vorhanden. Dass Polyesterimplantate eine größere Dichte implantatassoziierter Entzündungszellen - u. a. Makrophagen und zu FKR fusionierte Makrophagen - aufwiesen, ist möglicherweise als Ursache des früheren Auftretens von Verkalkungen bei Polyester- im Vergleich zu PTFE-Implantaten anzusehen. Wie oben genannt, können Makrophagen zum Verkalkungsprozess beitragen, indem sie u. a. Myofibroblasten stimulieren, die daraufhin osteogenetische Eigenschaften annehmen. (Wie in Kapitel 4.2.3 diskutiert, wurde die Pseudointima der in dieser Arbeit untersuchten Implantate größtenteils durch Myofibroblasten gebildet.) Durch von Myofibroblasten produzierte Matrixvesikel kann es zur Verkalkung (s. o.) der Implantate gekommen sein. Außerdem sind - wie oben genannt - chronische Entzündungsprozesse mit Apoptose und Nekrose assoziiert, die wiederum zur Verkalkung beigetragen haben können. Bei Implantaten mit Polyester- oder PTFE-Anteilen ist also mittelfristig mit der Entwicklung von lokalen Verkalkungen zu rechnen. Dies sollte bei der Implantatauswahl beachtet werden, da sich hieraus im Langzeitverlauf Komplikationen für die Patientin/den Patienten ergeben können (s. o.). Möglicherweise kann in Zukunft durch die Entwicklung neuartiger Materialien eine Verminderung der Verkalkungstendenz zum Beispiel durch Biodegradierbarkeit des Implantatmaterials erreicht werden. Zur Verkalkung von PVAGewebe sind weiterführende Studien notwendig, denen PVA-Implantate mit längeren Implantationszeiten zur Verfügung stehen. Angesichts der Tatsache, dass es bisher keine vergleichbaren Studien zur Verkalkung kardiovaskulärer PVA-Implantate gab, stellen unsere Ergebnisse eine erste Grundlage dar. 


\subsection{Limitationen}

Limitationen dieser Arbeit ergaben sich zum einen aufgrund der Fragilität histologischer Präparate, insbesondere an der Grenzfläche zwischen Implantat und Gewebe. Trotz mehrerer Färbeversuche war es zum Teil nicht möglich, alle 3 Präparatabschnitte (Pseudointima, Implantatgewebe, Pseudoadventitia) zu erhalten und darstellen zu können. Manche Implantate könnten jedoch bereits bei der operativen Entfernung beschädigt worden sein.

Zum anderen war eine quantitative Auswertung der histologischen Präparate nicht möglich, da bei der Herstellung der Schliffe Präparatscheiben von 200 bis $300 \mu$ m Dicke auf 10 bis $30 \mu \mathrm{m}$ Dicke ausgedünnt werden mussten, um sie lichtmikroskopisch untersuchen zu können. Hierbei ging gezwungenermaßen Implantatmaterial verloren, welches nicht ausgewertet werden konnte. Es wurden daher qualitative Beschreibungen und semiquantitative Auswertungen vorgenommen, die einer gewissen Subjektivität unterliegen.

Zudem stellt diese Arbeit eine retrospektive Studie dar. Die Entnahmezeitpunkte der untersuchten Implantate wurden allein durch die klinische Indikation von Korrekturoperationen bestimmt. Eine zeitlich sequenzielle Beurteilung histologischer Gewebereaktionen war daher nur eingeschränkt möglich.

Außerdem standen uns nur 2 PVA-Okkluder zur Auswertung zur Verfügung, weswegen diese Ergebnisse möglicherweise nicht repräsentativ sind. Somit sind weiterführende Untersuchungen notwendig, die größere Implantatzahlen untersuchen.

Zur Diskussion der Ergebnisse mussten zum Teil tierexperimentelle Studien mit kardiovaskulären Implantaten herangezogen werden, da nicht immer Studien mit kardiovaskulären Implantaten, die im Menschen eingesetzt waren, existierten. Möglicherweise sind diese tierexperimentellen Studienergebnisse nicht vollständig auf den Menschen übertragbar. Des Weiteren musste auf Studien zurückgegriffen werden, die Implantate, die in einem anderen Milieu (z. B. subkutan) als die von uns untersuchten kardiovaskulären Implantate (mit Blutkontakt) eingesetzt waren. Auch hier ist die direkte Vergleichbarkeit infrage zu stellen. 


\section{$5 \quad$ Zusammenfassung}

Bei angeborenen Herzfehlern, die bei 1 bis $1,2 \%$ aller Lebendgeburten auftreten und somit die häufigste behandlungsbedürftige Organfehlbildung darstellen, kommen regelhaft kardiovaskuläre Implantate im Rahmen der chirurgischen bzw. interventionellen Therapie zum Einsatz. Hierzu zählen u. a. Shunts, Patches und Okkluder, die aus verschiedenen Implantatmaterialien hergestellt werden. Das Ziel dieser Arbeit bestand darin - basierend auf histologischen Untersuchungen - Unterschiede bzw. Gemeinsamkeiten bezüglich der Biokompatibilität nicht-metallischer Implantatmaterialien zu prüfen, da eine bewusste Materialauswahl kardiovaskulärer Implantate zur Therapie angeborener Herzfehler zu besseren Langzeitergebnissen der Implantate beitragen kann.

Untersucht wurden Implantate, die im Rahmen von Korrekturoperationen entnommen wurden und anschließend im Forschungslabor für Pädiatrische Kardiologie und Intensivmedizin der Universitätsmedizin Göttingen ausgewertet wurden: Shunts aus PTFE ( $\mathrm{n}=21$, durchschnittliche Implantationszeit: 18 Monate), Patches aus PTFE ( $\mathrm{n}=$ 13, durchschnittliche Implantationszeit: 247 Monate) und Polyester ( $\mathrm{n}=4$, durchschnittliche Implantationszeit: 321 Monate) sowie Okkluder aus PTFE ( $\mathrm{n}=3$, durchschnittliche Implantationszeit: 74 Monate), Polyester ( $\mathrm{n}=9$, durchschnittliche Implantationszeit: 30 Monate) und PVA ( $\mathrm{n}=2$, durchschnittliche Implantationszeit: 23 Monate). Zur Herstellung histologischer Präparate wurden metallhaltige Implantate (Okkluder) sowie solche mit bereits makroskopisch sichtbarer Verkalkung in Methylmethacrylat-Kunstharz eingebettet und anschließend gesägt und geschliffen, sodass sie lichtmikroskopisch ausgewertet werden konnten. Die anderen Implantate wurden in Paraffin eingebettet und geschnitten. Neben konventionellen Färbungen zur Übersicht und Darstellung von Verkalkungen wurden immunhistochemische Färbungen eingesetzt.

Unabhängig vom Implantatmaterial konnte regelhaft eine endothelialisierte und neovaskularisierte Pseudointima, hauptsächlich am ehesten aus Myofibroblasten und Fibroblasten bestehend, dargestellt werden. Das im Implantatmaterial neu gebildete Gewebe bestand hauptsächlich aus Fibroblasten und war neovaskularisiert. Implantatassoziierte, chronische Entzündungsreaktionen - getragen durch Makrophagen und Lymphozyten - sowie Fremdkörperreaktionen - getragen durch FKR - waren bei den 
Polyester- und PVA-Implantaten stärker ausgeprägt als bei den PTFE-Implantaten. Verkalkungen in Pseudointima- und Implantatgewebe wurden bei den PolyesterImplantaten ab einer Implantationszeit von 3 Jahren und 4 Monaten, bei den PTFEImplantaten ab einer Implantationszeit von 5 Jahren und 10 Monaten beobachtet. Die durch Polyester hervorgerufene, stärker ausgeprägte Entzündungsreaktion ist als Ursache der $\mathrm{zu}$ einem früheren Zeitpunkt einsetzenden Verkalkung von Polyester-Implantaten anzusehen. Während bei den Polyester-Implantaten häufig eher ungleichmäßig verteilte und unregelmäßig geformte, punktförmige Verkalkungen bis hin $\mathrm{zu}$ kleinen Kalkaggregaten in Pseudointima- und Implantatgewebe vorhanden waren, wiesen die PTFE-Implantate zumeist gleichmäßige, großflächig-konfluierende Verkalkungen auf.

Es konnte gezeigt werden, dass bei Implantaten, die Polyester- oder PTFE-Anteile enthalten, mittelfristig mit der Entwicklung von lokalen Verkalkungen zu rechnen ist, die im Langzeitverlauf zu Komplikationen führen können. Dies muss bei der Implantatauswahl beachtet werden. Möglicherweise kann in Zukunft durch die Entwicklung neuartiger Materialien eine Verminderung der Verkalkungstendenz, zum Beispiel durch Biodegradierbarkeit des Implantatmaterials, erreicht werden. 


\section{$6 \quad$ Literaturverzeichnis}

Abdelbaky A, Corsini E, Figueroa AL, Fontanez S, Subramanian S, Ferencik M, Brady TJ, Hoffmann U, Tawakol A (2013): Focal Arterial Inflammation Precedes Subsequent Calcification in the Same Location A Longitudinal FDG-PET/CT Study. Circ Cardiovasc Imaging $\underline{6}, 747-754$

Abu El-Asrar AM, Struyf S, Van Damme J, Geboes K (2008): Circulating fibrocytes contribute to the myofibroblast population in proliferative vitreoretinopathy epiretinal membranes. Br J Ophthalmol 92, 699-704

Aikawa E, Nahrendorf M, Sosnovik D, Lok VM, Jaffer FA, Aikawa M, Weissleder R (2007 a): Multimodality molecular imaging identifies proteolytic and osteogenic activities in early aortic valve disease. Circulation $\underline{115}, 377-386$

Aikawa E, Nahrendorf M, Figueiredo J-L, Swirski F, Shtatland T, Kohler R, Jaffer F, Aikawa M, Weissleder R (2007 b): Osteogenesis associates with inflammation in earlystage atherosclerosis evaluated by molecular imaging in vivo. Circulation $\underline{116}, 2841-50$

Anderson HC (1983): Calcific diseases. A concept. Arch Pathol Lab Med 107, 341-348

Anderson JM (1988): Inflammatory response to implants. ASAIO Trans $\underline{34}$, 101-107

Anderson JM, Rodriguez A, Chang DT (2008): Foreign body reaction to biomaterials. Semin Immunol 20, 86-100

Anzai H, Child J, Natterson B, Krivokapich J, Fishbein MC, Chan VK, Tobis JM (2004): Incidence of thrombus formation on the CardioSEAL and the Amplatzer interatrial closure devices. Am J Cardiol 93, 426-431

Baker D, Liu X, Weng H, Luo C, Tang L (2011): Fibroblast/Fibrocyte: Surface Interaction Dictates Tissue Reactions to Micropillar Implants. Biomacromolecules $\underline{12}$, 997-1005

Bellón JM, Bujan J, Hernando A, Honduvilla NG, Jurado F (1994): Arterial autografts and PTFE vascular microprostheses: similarities in the healing process. Eur J Vasc Surg $\underline{8}, 694-702$

Bellón JM, Bujan J, Contreras LA, Hernando A, Jurado F (1996): Similarity in behavior of polytetrafluoroethylene (ePTFE) prostheses implanted into different interfaces. J Biomed Mater Res $\underline{31}, 1-9$

Berndt A, Kosmehl H, Katenkamp D, Tauchmann V (1994): Appearance of the Myofibroblastic Phenotype in Dupuytren's Disease Is Associated with a Fibronectin, Laminin, Collagen Type IV and Tenascin Extracellular Matrix. Pathobiology 62, 55-58

Black MM (1995): Cardiovascular applications of biomaterials and implants--an overview. J Med Eng Technol 19, 151-157 
Bonfield TL, Colton E, Anderson JM (1992): Protein adsorption of biomedical polymers influences activated monocytes to produce fibroblast stimulating factors. J Biomed Mater Res $\underline{26}, 457-465$

Brodbeck WG, Macewan M, Colton E, Meyerson H, Anderson JM (2005): Lymphocytes and the foreign body response: lymphocyte enhancement of macrophage adhesion and fusion. J Biomed Mater Res 74, 222-229

Bucala R, Spiegel LA, Chesney J, Hogan M, Cerami A (1994): Circulating fibrocytes define a new leukocyte subpopulation that mediates tissue repair. Mol Med $\underline{1}, 71-81$

Bucher O: Zytologie, Histologie und mikroskopische Anatomie des Menschen. Unter Mitarbeit von, Wartenberg H, 12. Auflage; Hans Huber Verlag, Bern 1997

Chen NX, O'Neill KD, Chen X, Moe SM (2008): Annexin-Mediated Matrix Vesicle Calcification in Vascular Smooth Muscle Cells. J Bone Miner Res 23, 1798-1805

Clowes A, Kirkman TR, Reidy M (1986): Mechanisms of arterial graft healing. Rapid transmural capillary ingrowth provides a source of intimal endothelium and smooth muscle in porous PTFE prostheses. Am J Pathol $\underline{123}, 220$

Das GS, Voss G, Jarvis G, Wyche K, Gunther R, Wilson RF (1993): Experimental atrial septal defect closure with a new, transcatheter, self-centering device. Circulation $\underline{88}$, $1754-1764$

de Mol BA (1996): Retrieval analysis of cardiovascular implants. Int J Risk Saf Med $\underline{8}$, $119-23$

de Oliveira PP, Bavaresco VP, Silveira-Filho LM, Schenka AA, Vilarinho KA, Barbosa de Oliveira Severino ES, Petrucci O (2014): Use of a novel polyvinyl alcohol membrane as a pericardial substitute reduces adhesion formation and inflammatory response after cardiac reoperation. J Thorac Cardiovasc Surg 147, 1405-10

Demer L, Tintut Y (2014): Inflammatory, metabolic, and genetic mechanisms of vascular calcification. Arterioscler Thromb Vasc Biol $\underline{34}$, 715-23

Desmouliere A, Chaponnier C, Gabbiani G (2005): Tissue repair, contraction, and the myofibroblast. Wound Repair Regen $\underline{13}$, 7-12

Doble M, Makadia N, Pavithran S, Kumar RS (2008): Analysis of explanted ePTFE cardiovascular grafts (modified BT shunt). Biomed Mater $\underline{3}, 034118$

Edmunds LH, Stephenson LW, Gadzik JP (1980): The Blalock-Taussig anastomosis in infants younger than 1 week of age. Circulation $\underline{62}, 597-603$

Ehler WJ, Cissik JH, Smith VC, Hubbard GB (1990): Evaluation of Gore-Tex graft material in the repair of right ventricular outflow tract defect. J Invest Surg $\underline{3}, 119-27$

Ewert P (2008): Interventional closure of atrial septal defects (ASD) and persistent foramen ovale (PFO). Der Kardiologe 2, 39-48 
Foth R, Quentin T, Michel-Behnke I, Vogt MO, Kriebel T, Kreischer A, Ruschewski W, Paul T, Sigler M (2009): Immunohistochemical characterization of neotissues and tissue reactions to septal defect-occlusion devices. Circ Cardiovasc Interv $\underline{2}$, 90-96

Fujimoto K, Guan J, Oshima H, Sakai T, Wagner W (2007): In Vivo Evaluation of a Porous, Elastic, Biodegradable Patch for Reconstructive Cardiac Procedures. Ann Thorac Surg $\underline{83}, 648-654$

Geiringer E (1951): Intimal vascularisation and atherosclerosis. J Pathol Bacteriol $\underline{63}$, 201-211

Geißler HJ, Schlensak C, Südkamp M, Beyersdorf F (2009): Herzklappenchirurgie heute: Indikationsstellung, OP-Technik und ausgewählte Aspekte der Nachsorge bei erworbenen Herzklappenvitien. Deutsches Ärzteblatt $\underline{13}$, 224-234

Gong Y, Koh DR (2010): Neutrophils promote inflammatory angiogenesis via release of preformed VEGF in an in vivo corneal model. Cell Tissue Res $\underline{339}, 437-48$

Hench L (1998): Biomaterials: a forecast for the future. Biomaterials $\underline{19}$, 1419-1423

Hunt JA, Flanagan BF, McLaughlin PJ, Strickland I, Williams DF (1996): Effect of biomaterial surface charge on the inflammatory reponse: Evaluation of cellular infiltration and TNF $\alpha$ production. J Biomed Mater Res $\underline{31}$, 139-144

Izutani H (2000): Right ventricular outflow tract reconstruction using a Goretex membrane monocusp valve in infant animals. ASAIO J $\underline{46}, 553$

Janssens de Varebeke B, Van Osselaer G (1994): Late occlusion of a polytetrafluoroethylene femoropopliteal graft due to implant calcification and heterotopic ossification. Acta Chir Belg 94, 288-90

Jin D, Takai S, Li Z, Sakonjo H, Otsuki Y, Shibayama Y, Miyazaki M (2012): Outside fibroblasts play a key role in the development of inner neointima after the implantation of polytetrafluoroethylene grafts. J Pharmacol Sci 119, 139-49

Jux C, Vogel M, Scheewe J: S2k Leitlinie Pädiatrische Kardiologie: Vorhofseptumdefekt (ASD) im Kindes- und Jugendalter. [http://www.awmf.org/uploads/tx_szleitlinien/0230111_S2k_Vorhofseptumdefekt_Kinder_Jugendliche_2014-06.pdf, Zugriff am 17.06.2015] AWMF online 2010

Kalra N, Klewer SE, Raasch H, Sorrell VL (2010): Update on tetralogy of Fallot for the adult cardiologist including a brief historical and surgical perspective. Congenit Heart Dis $\underline{5}, 208-19$

Kapustin AN, Davies JD, Reynolds JL, McNair R, Jones GT, Sidibe A, Schurgers LJ, Skepper JN, Proudfoot D, Mayr M (2011): Calcium regulates key components of vascular smooth muscle cell-derived matrix vesicles to enhance mineralization. Circ Res $\underline{109}, 1-12$

Kay PH, Capuani A, Franks R, Lincoln C (1983): Experience with the modified BlalockTaussig operation using polytetrafluoroethylene (Impra) grafts. Br Heart J $\underline{49}$, 359-63 
Kececioglu D: Herz-Kreislaufsystem: Erkrankungen des Herzens und der Gefäße, Herzrhythmusstörungen, kardiologische Intensivmedizin. In: Speer CP, Gahr M (Hrsg.): Pädiatrie. Springer Verlag, Heidelberg 2009, 515-542

Kenney DA, Tu R, Peterson RC (1988): Evaluation of compliant and noncompliant PTFE vascular prostheses. ASAIO J $\underline{34}, 661-663$

Kenney DA, Tu R, Peterson RC, Lu CL (1990): Performance of a longitudinally compliant PTFE vascular prosthesis in an ovine A-V fistula model. ASAIO Trans $\underline{36}$, 761-763

Kidd KR, Dal Ponte DB, Kellar RS, Williams SK (2002): A comparative evaluation of the tissue responses associated with polymeric implants in the rat and mouse. J Biomed Mater Res 59, 682-9

Kogel H, Kogel W, Amselgruber D, Frösch W, Mohr S, Cyba A (1989): New techniques of analyzing the healing process of artificial vascular grafts, transmural vascularization, and endothelialization. Res Exp Med (Berl) 189, 61-68

Kreutzer J, Ryan CA, Gauvreau K, Van Praagh R, Anderson JM, Jenkins KJ (2001): Healing response to the Clamshell device for closure of intracardiac defects in humans. Catheter Cardiovasc Interv 54, 101-111

Kuhn MA, Latson LA, Cheatham JP, McManus B, Anderson JM, Kilzer KL, Furst J (1996): Biological response to Bard Clamshell Septal Occluders in the canine heart. Circulation $\underline{93}, 1459-1463$

Kumamoto M, Nakashima Y, Sueishi K (1995): Intimal neovascularization in human coronary atherosclerosis: Its origin and pathophysiological significance. Hum Pathol 26 , $450-456$

Lanzetta M, Owen ER (1995): Neo-endothelialisation of PTFE microvascular grafts: a five-year experience. Microsurgery $\underline{16}, 404-11$

Lee JS, Basalyga DM, Simionescu A, Isenburg JC, Simionescu DT, Vyavahare NR (2006): Elastin calcification in the rat subdermal model is accompanied by up-regulation of degradative and osteogenic cellular responses. Am J Pathol 168, 490-498

Leonard EF, Vroman L (1992): Is the Vroman effect of importance in the interaction of blood with artificial materials? J Biomater Sci Polym Ed $\underline{3}, 95-107$

Levy RJ, Schoen FJ, Anderson HC, Harasaki H, Koch TH, Brown W, Lian JB, Cumming R, Gavin JB (1991): Cardiovascular implant calcification: a survey and update. Biomaterials $\underline{12}, 707-14$

Limbach HG, Lindinger A, Hoffmann W: Herz-Kreislauf-Erkrankungen. In: Gortner L, Meyer S, Sitzmann FC (Hrsg.): Pädiatrie. Thieme Verlag, Stuttgart 2012, 331-355

MacEwan M, Brodbeck W, Matsuda T, Anderson J (2005): Monocyte/lymphocyte interactions and the foreign body response:In vitro effects of biomaterial surface chemistry. J Biomed Mater Res 74, 285-293 
Mariani F, Sena P, Roncucci L (2014): Inflammatory pathways in the early steps of colorectal cancer development. World J Gastroenterol 20, 9716

Mehta RI, Mukherjee AK, Patterson TD, Fishbein MC (2011): Pathology of explanted polytetrafluoroethylene vascular grafts. Cardiovasc Pathol 20, 213-221

Menger MD, Walter P, Hammersen F, Messmer K (1990): Quantitative analysis of neovascularization of different PTFE-implants. Eur J Cardiothorac Surg 4, 191-6

Miller KM, Anderson JM (1988): Human monocyte/macrophage activation and interleukin 1 generation by biomedical polymers. J Biomed Mater Res $\underline{22}$, 713-731

Miller KM, Rose Caprara V, Anderson JM (1989): Generation of IL1-like activity in response to biomedical polymer implants: A comparison of in vitro and in vivo models. $\mathbf{J}$ Biomed Mater Res 23, 1007-1026

Miyazaki T, Yamagishi M, Maeda Y, Yamamoto Y, Taniguchi S, Sasaki Y, Yaku H (2011): Expanded polytetrafluoroethylene conduits and patches with bulging sinuses and fan-shaped valves in right ventricular outflow tract reconstruction: Multicenter study in Japan. J Thorac Cardiovasc Surg 142, 1122-1129

Molina JE, Edwards JE, Bianco RW, Clack RW, Lang G, Molina JR (1995): Composite and plain tubular synthetic graft conduits in right ventricle-pulmonary artery position: fate in growing lambs. J Thorac Cardiovasc Surg $\underline{110}$, 427-35

Mori L, Bellini A, Stacey MA, Schmidt M, Mattoli S (2005): Fibrocytes contribute to the myofibroblast population in wounded skin and originate from the bone marrow. Exp Cell Res $\underline{304}, 81-90$

Mugnai D, Tille JC, Mrowczynski W, de Valence S, Montet X, Moller M, Walpoth BH (2013): Experimental noninferiority trial of synthetic small-caliber biodegradable versus stable vascular grafts. J Thorac Cardiovasc Surg 146, 400-7

New SEP, Goettsch C, Aikawa M, Marchini J, Shibasaki M, Yabusaki K, Libby P, Shanahan C, Croce K, Aikawa E (2013): Macrophage-derived matrix vesicles: an alternative novel mechanism for microcalcification in atherosclerotic plaques. Circ Res $\underline{113}, 72-7$

Noguchi T, Yamamuro M, Oka P, Kumar Y, Kotoura S-H, Hyonyt Y, Ikadat (1991): Poly(vinyl alcohol) hydrogel as an artificial articular cartilage: Evaluation of biocompatibility. J Appl Biomater 2, 101-107

Nordstrand K, Eide TJ, Sorlie DG (1988): Late occlusion of expanded Teflon femoropopliteal graft due to calcification and fracture of implant. Case report. Acta Chir Scand $\underline{154}, 473-4$

Oda T, Hoashi T, Kagisaki K, Shiraishi I, Yagihara T, Ichikawa H (2012): Alternative to pulmonary allograft for reconstruction of right ventricular outflow tract in small patients undergoing the Ross procedure. Eur J Cardiothorac Surg 42, 226-32 
Pok S, Jacot JG (2011): Biomaterials advances in patches for congenital heart defect repair. J Cardiovasc Transl Res $\underline{4}, 646-54$

Proudfoot D, Skepper JN, Hegyi L, Bennett MR, Shanahan CM, Weissberg PL (2000): Apoptosis regulates human vascular calcification in vitro: evidence for initiation of vascular calcification by apoptotic bodies. Circ Res $\underline{87}$, 1055-62

Quan T, Cowper S, Bucala R (2006): The role of circulating fibrocytes in fibrosis. Curr Rheumatol Rep $\underline{8}, 145-150$

Randall RD, Jr., Walley BD, Meredith JH (1982): Comparison of polytetrafluoroethylene (PTFE) and dacron as long, small-diameter arterial grafts in dogs. Am Surg $\underline{48}, 622-7$

Reddy VM, Meyrick B, Wong J, Khoor A, Liddicoat JR, Hanley FL, Fineman JR (1995): In Utero Placement of Aortopulmonary Shunts: A Model of Postnatal Pulmonary Hypertension With Increased Pulmonary Blood Flow in Lambs. Circulation 92, 606-613

Sakurai T, Kashida H, Watanabe T, Hagiwara S, Mizushima T, Iijima H, Nishida N, Higashitsuji H, Fujita J, Kudo M (2014): Stress response protein Cirp links inflammation and tumorigenesis in colitis-associated cancer. Cancer Res $\underline{74}$, 6119-6128

Salzmann DL, Kleinert LB, Berman SS, Williams SK (1999): Inflammation and neovascularization associated with clinically used vascular prosthetic materials. Cardiovasc Pathol $\underline{8}, 63-71$

Samraj AN, Pearce OM, Läubli H, Crittenden AN, Bergfeld AK, Banda K, Gregg CJ, Bingman AE, Secrest P, Diaz SL (2015): A red meat-derived glycan promotes inflammation and cancer progression. Proc Natl Acad Sci U S A $\underline{112}, 542-547$

Sano S, Ishino K, Kawada M, Arai S, Kasahara S, Asai T, Masuda Z-i, Takeuchi M, Ohtsuki S-i (2003): Right ventricle-pulmonary artery shunt in first-stage palliation of hypoplastic left heart syndrome. J Thorac Cardiovasc Surg 126, 504-509

Schmidt M, Sun G, Stacey MA, Mori L, Mattoli S (2003): Identification of circulating fibrocytes as precursors of bronchial myofibroblasts in asthma. J Immunol 171, 380-9

Schwartz A, Dockerty M, Grindlay J (1960): Calcification of polyvinylformal (Ivalon) sponge. Plast Reconstr Surg $\underline{26}, 110-111$

Shi Q, Rafii S, Wu MH, Wijelath ES, Yu C, Ishida A, Fujita Y, Kothari S, Mohle R, Sauvage LR, et al. (1998): Evidence for circulating bone marrow-derived endothelial cells. Blood $\underline{92}, 362-367$

Shi Y, O'Brien JE, Fard A, Mannion JD, Wang D, Zalewski A (1996): Adventitial myofibroblasts contribute to neointimal formation in injured porcine coronary arteries. Circulation $\underline{94}$, 1655-64

Shive MS, Salloum ML, Anderson JM (2000): Shear stress-induced apoptosis of adherent neutrophils: a mechanism for persistence of cardiovascular device infections. Proc Natl Acad Sci U S A 97, 6710-6715 
Sigler M, Handt S, Seghaye MC, von Bernuth G, Grabitz, RG (2000): Evaluation of in vivo biocompatibility of different devices for interventional closure of the patent ductus arteriosus in an animal model. Heart $\underline{83}, 570-573$

Sigler M, Paul T, Grabitz RG (2005): Biocompatibility screening in cardiovascular implants. Z Kardiol 94, 383-391

Sigler M, Jux C (2007): Biocompatibility of septal defect closure devices. Heart $\underline{93}$, 444449

Starr JP (2010): Tetralogy of fallot: yesterday and today. World J Surg $\underline{34}$, 658-68

Steitz SA, Speer MY, Curinga G, Yang H-Y, Haynes P, Aebersold R, Schinke T, Karsenty G, Giachelli CM (2001): Smooth muscle cell phenotypic transition associated with calcification upregulation of cbfa1 and downregulation of smooth muscle lineage markers. Circ Res $\underline{89}, 1147-1154$

Subbotin VM (2012): Neovascularization of coronary tunica intima (DIT) is the cause of coronary atherosclerosis. Lipoproteins invade coronary intima via neovascularization from adventitial vasa vasorum, but not from the arterial lumen: a hypothesis. Theor Biol Med Model $\underline{9}, 11$

Sun Y, Byon C, Yuan K, Chen J, Mao X, Heath J, Javed A, Zhang K, Anderson P, Chen Y (2012): Smooth muscle cell-specific runx2 deficiency inhibits vascular calcification. Circ Res $\underline{111}, 543-52$

Sunderkötter C, Steinbrink K, Goebeler M, Bhardwaj R, Sorg C (1994): Macrophages and angiogenesis. J Leukoc Biol 55, 410-422

Thevenot PT, Baker DW, Weng H, Sun MW, Tang L (2011): The pivotal role of fibrocytes and mast cells in mediating fibrotic reactions to biomaterials. Biomaterials $\underline{32}$, 8394-403

Tomizawa Y, Takanashi Y, Noishiki Y, Nishida H, Endo M, Koyanagi H (1998): Evaluation of small caliber vascular prostheses implanted in small children: activated angiogenesis and accelerated calcification. ASAIO J $\underline{44}$, M496-500

Us MH, Sungun M, Sanioglu S, Pocan S, Cebeci BS, Ogus T, Ucak A, Guler A (2004): A retrospective comparison of bovine pericardium and polytetrafluoroethylene patch for closure of ventricular septal defects. J Int Med Res $\underline{32}$, 218-21

Vahanian A, Alfieri O: ESC Pocket Guidelines: Herzklappenerkrankung. [http://leitlinien.dgk.org/files/2014_PLL_Herzklappenerkrankung_Internet.pdf, Zugriff am 07.07.2015] Deutsche Gesellschaft für Kardiologie 2012

Vander Sloten J, Hobatho MC, Verdonck P (1998): Applications of computer modelling for the design of orthopaedic, dental and cardiovascular biomaterials. Proc Inst Mech Eng $\mathrm{H} \underline{212}, 489-500$ 
Varcoe RL, Mikhail M, Guiffre AK, Pennings G, Vicaretti M, Hawthorne WJ, Fletcher JP, Medbury HJ (2006): The role of the fibrocyte in intimal hyperplasia. J Thromb Haemost $\underline{4}, 1125-1133$

Wainwright JM, Hashizume R, Fujimoto KL, Remlinger NT, Pesyna C, Wagner WR, Tobita K, Gilbert TW, Badylak SF (2012): Right ventricular outflow tract repair with a cardiac biologic scaffold. Cells Tissues Organs 195, 159-70

Wang M, Li Y, Wu J, Xu F, Zuo Y, Jansen JA (2008): In vitro andin vivo study to the biocompatibility and biodegradation of hydroxyapatite/poly(vinyl alcohol)/gelatin composite. J Biomed Mater Res $\underline{85}$, 418-426

Welsch U: Lehrbuch Histologie. Unter Mitarbeit von, Deller T, 3. Auflage; Urban \& Fischer Verlag, München 2010

Wintermantel E, Shah-Derler B, Bruinink A, Petitmermet M, Blum J, Ha S-W: Biokompatibilität. In: Wintermantel E, Ha S-W (Hrsg.): Medizintechnik Life Science Engineering. Springer Verlag, Heidelberg 2008, 59-60

Witt R, Raff G, Van Gundy J, Rodgers Ohlau M, Si M-S (2013): Short-term experience of porcine small intestinal submucosa patches in paediatric cardiovascular surgery. Eur $\mathbf{J}$ Cardiothorac Surg $\underline{44}, 72-6$

Wu MH, Shi Q, Onuki Y, Kouchi Y, Sauvage LR (1996): Histologic observation of continuity of transmural microvessels between the perigraft vessels and flow surface microostia in a porous vascular prosthesis. Ann Vasc Surg 10, 11-5

Yen TW, Aardal NP, Bronner MP, Thorning DR, Savard CE, Lee SP, Bell RH, Jr. (2002): Myofibroblasts are responsible for the desmoplastic reaction surrounding human pancreatic carcinomas. Surgery $\underline{131}, 129-34$

Zemplenyi T, Crawford D, Tidwell D, Cole M: The effect of balloon deendothelialization on arterial enzymes and metabolic intermediates in rabbits. In: Schlierf G, Mörl H (Hrsg.): Expanding Horizons in Atherosclerosis Research. Springer Verlag, Heidelberg 1987, 82-86

Ziats N, Miller K, Anderson J (1988): In vitro and in vivo interactions of cells with biomaterials. Biomaterials $\underline{9}, 5-13$ 


\section{$7 \quad$ Abkürzungsverzeichnis}

\section{Abkürzungsverzeichnis}

a

AI

AKE

AoV

AP

AS

ASD

BTA

CD

CT

d

DHZ

DILV

DKS

DORV

EKG

EZM

FDG

FKR

HE

HLHS

IAS

ISTA

IVS

IZ

INZ
$\operatorname{Jahr}(\mathrm{e})$

Aortenklappeninsuffizienz

Aortenklappenersatz

Aortenklappe

aortopulmonal

Aortenstenose

Atriumseptumdefekt

Blalock-Taussig-Anastomose

cluster of differentiation

Computertomografie

$\operatorname{Tag}(\mathrm{e})$

Deutsches Herzzentrum

double inlet left ventricle

Damus-Kaye-Stansel

double outlet right ventricle

Elektrokardiogramm

Extrazellulärmatrix

Fluorodeoxyglucose

Fremdkörperriesenzellen

Hämatoxylin-Eosin

hypoplastisches Linksherzsyndrom

interatriales Septum

Aortenisthmusstenose

intaktes Ventrikelseptum

Implantationszeit

Inkubationszeit 
LA linkes Atrium

LV linker Ventrikel

LVOTO left ventricular outflow tract obstruction

M Monat(e)

MAPCA major aortopulmonary collateral artery

PA Pulmonalatresie

PAB Pulmonalarterienbanding

PDA persistierender Ductus arteriosus Botalli

PFO persistierendes Foramen ovale

PKE Pulmonalklappenersatz

PS Pulmonalstenose

PTFE Polytetrafluorethylen

PV Pulmonalklappe

PVA Polyvinylalkohol

RA rechtes Atrium

RV rechter Ventrikel

RVOT rechtsventrikulärer Ausflusstrakt

RT Raumtemperatur

SMA smooth muscle actin

SMM smooth muscle myosin

TA Trikuspidalatresie

TAP transanulärer Patch

TCPA totale cavo-pulmonale Anastomose

TGA Transposition der großen Arterien

TIA transitorisch-ischämische Attacke

TV Trikuspidalklappe

ToF Fallot'sche Tetralogie

VSD Ventrikelseptumdefekt

vWF von-Willebrand-Faktor

Z. n. Zustand nach 


\section{Danksagung}

Recht herzlich möchte ich mich bei Herrn Prof. Dr. med. Matthias Sigler, leitender Oberarzt der Klinik für Pädiatrische Kardiologie und Intensivmedizin, für die Vergabe des Dissertationsthemas sowie die intensive und außergewöhnlich engagierte Betreuung bedanken. Ein großes Dankeschön auch an das Laborteam, insbesondere an die medizinisch-labortechnischen Assistentinnen Sabrina Goldmann sowie Andrea Poppe und Karin Bär, die wesentlich an der Herstellung histologischer Präparate und deren Färbung beteiligt waren und mir darüber hinaus mit Rat und Tat zur Seite standen. Meiner Mutter, Frau Dagmar Schuster-Hüll, sowie meiner Großtante, Frau Ingrid Klement, möchte ich für das entgegengebrachte Interesse und die Unterstützung während meines Studiums der Humanmedizin, der Erstellung dieser Arbeit und darüber hinaus danken. 


\section{Lebenslauf}

Als Älteste von drei Geschwistern wurde ich, Stephanie Hüll, am 9. Dezember 1985 im baden-württembergischen Sigmaringen geboren. Dort besuchte ich von 1992 bis 1996 die Geschwister-Scholl-Grundschule und von 1996 bis 2006 das Gymnasium der Liebfrauenschule. Das zwölfte Schuljahr verbrachte ich an der Manor High School in Austin, Texas, USA. Nach dem Abitur im Jahre 2006, welches ich mit der Gesamtnote 1,2 absolvierte, verbrachte ich ein Freiwilliges Soziales Jahr in Lima, Perú. Während diesem war ich in einem städtischen Krankenhaus, einer kirchlichen Poliklinik sowie einer Schule für geistig und körperlich behinderte Kinder tätig. Vor Aufnahme des Studiums der Humanmedizin an der Georg-August-Universität Göttingen im Sommersemester 2008 absolvierte ich eine Ausbildung zur Rettungssanitäterin und war bis Studienende ehrenamtlich beim Malteser Hilfsdienst e. V. in Sigmaringen beschäftigt. Das Physikum legte ich im Jahre 2010 mit der Gesamtnote 2,0 ab. Im selben Jahr absolvierte ich eine Famulatur am Hospital Universitário Virgen de la Victoria in Málaga, Spanien. 2012 begann ich unter Betreuung von Herr Prof. Dr. med. Matthias Sigler mit den Arbeiten für diese Dissertation. An der Medizinischen Fakultät der Universidade de Lisboa studierte ich im Sommersemester 2013 im Rahmen des ErasmusAustauschprogramms. Nach dem Praktischen Jahr von August 2013 bis Juli 2014 legte ich das zweite Staatsexamen im Dezember 2014 mit der Gesamtnote 1,5 ab. Seit dem 1. September 2015 arbeite ich als Assistenzärztin in der Abteilung für Innere Medizin des Kreiskrankenhauses Dormagen. 